\title{
Empirical Tests of Asset Pricing Models with Individual Assets: \\ Resolving the Errors-in-Variables Bias in Risk Premium Estimation
}

\author{
by \\ Narasimhan Jegadeesh, Joonki Noh, \\ Kuntara Pukthuanthong, Richard Roll, and Junbo Wang
}

May, 2018

\begin{abstract}
To attenuate an inherent errors-in-variables bias, portfolios are widely employed to test asset pricing models; but portfolios might mask relevant risk- or return-related features of individual stocks. We propose an instrumental variables approach that allows the use of individual stocks as test assets, yet delivers consistent estimates of ex-post risk premiums. This estimator also yields well-specified tests in small samples. The market risk premium under the CAPM and the liquidityadjusted CAPM, premiums on risk factors under the Fama-French three- and five-factor models and the Hou, Xue, and Zhang (2015) four-factor model are all insignificant after controlling for asset characteristics.
\end{abstract}

\begin{tabular}{|c|c|c|c|}
\hline Co-Author & Affiliation & Voice & E-Mail \\
\hline Jegadeesh & $\begin{array}{c}\text { Emory University } \\
\text { Atlanta GA 30322 }\end{array}$ & 404-727-4821 & $\begin{array}{c}\text { Jegadeesh@ } \\
\text { Emory.Edu }\end{array}$ \\
\hline Noh & $\begin{array}{c}\text { Case Western Reserve } \\
\text { University } \\
\text { Cleveland OH 44106 }\end{array}$ & $216-368-3737$ & $\begin{array}{c}\text { Joonki.Noh@ } \\
\text { Case.Edu }\end{array}$ \\
\hline Pukthuanthong & $\begin{array}{c}\text { University of Missouri } \\
\text { Columbia MO 65211 }\end{array}$ & $619-807-6124$ & $\begin{array}{c}\text { PukthuanthongK@ } \\
\text { Missouri.Edu }\end{array}$ \\
\hline Roll & $\begin{array}{c}\text { California Institute of } \\
\text { Technology } \\
\text { Pasadena CA 91125 }\end{array}$ & $626-395-3890$ & RRoll@ Caltech.Edu \\
\hline Wang & $\begin{array}{c}\text { Louisiana State University } \\
\text { Baton Rouge LA 70808 }\end{array}$ & $781-258-8806$ & junbowang@1su.edu \\
\hline
\end{tabular}

For insightful and constructive comments, we thank the referee, Bill Schwert (the editor), Yakov Amihud, Francisco Barillas, Hank Bessembinder, Michael Brennan, Tarun Chordia, John Cochrane, Wayne Ferson, Chris Jones, Raymond Kan, Cheng-Few Lee, Jay Shanken, Georgios Skoulakis, Avanidhar Subrahmanyam, Guofu Zhou, and seminar participants at Caltech, Case Western Reserve University, Emory University, KAIST, UCLA, University of Melbourne, University of Missouri, University of New South Wales, University of South Florida, University of Technology at Sydney, Yonsei University, York University, Financial Management Association Meetings 2014, Northern Finance Association Meetings 2017, and American Finance Association Meetings 2018. Corresponding author: Joonki Noh, Joonki.Noh@Case.Edu. 


\title{
Empirical Tests of Asset Pricing Models with Individual Assets: \\ Resolving the Errors-in-Variables Bias in Risk Premium Estimation
}

\begin{abstract}
To attenuate an inherent errors-in-variables bias, portfolios are widely employed to test asset pricing models; but portfolios might mask relevant risk- or return-related features of individual stocks. We propose an instrumental variables approach that allows the use of individual stocks as test assets yet delivers consistent estimates of ex-post risk premiums. This estimator also yields well-specified tests in small samples. The market risk premium under the CAPM and the liquidityadjusted CAPM, premiums on risk factors under the Fama-French three- and five-factor models and the Hou, Xue, and Zhang (2015) four-factor model are all insignificant after controlling for asset characteristics.
\end{abstract}

Key Words: Risk Premium Estimation, Errors-in-Variables Bias, Instrumental Variables, Individual Stocks, Asset Pricing Models 


\section{Introduction}

A fundamental precept of financial economics is that investors earn higher average returns by bearing systematic risks. While this idea is well accepted, there is little agreement about the identities of systematic risks or the magnitudes of the supposed compensations. This is not due to a lack of efforts along two lines of enquiry. First, numerous candidates have been proposed as underlying risk factors. Second, empirical efforts to estimate risk premiums have a long and varied history.

Starting with the single-factor CAPM (Sharpe, 1964; Lintner, 1965) and the multi-factor APT (Ross, 1976), the first line of enquiry has brought forth an abundance of risk factor candidates. Among others, these include the Fama and French size and book-to-market factors, human capital risk (Jagannathan and Wang, 1996), productivity and capital investment risks (Cochrane, 1996; Eisfeldt and Papanikolaou, 2013; Hou, Xue and Zhang, 2015), different components of consumption risk (Lettau and Ludvigson, 2001; Ait-Sahalia, Parker, and Yogo, 2004; Li, Vassalou, and Xing, 2006), cash flow and discount rate risks (Campbell and Vuolteenaho, 2004) and illiquidity risks (Pastor and Stambaugh, 2003; Acharya and Pedersen, 2005).

The papers that propose the new risk factors also typically present evidence suggesting that the factors command risk premiums. Their empircal tests mostly follow the methodology originally introduced by Black, Jensen and Scholes (1972), (BJS), and refined by Fama and MacBeth (1973), (FM). A prominent feature of this methodolgy is that it uses portfolios rather than individual stocks as test assets.

The BJS and FM methods involve two-pass regressions: the first pass is a time-series regression of individual asset returns on the proposed factors to estimate factor loadings, or "betas." 1 The second pass regresses the cross-section of asset returns on betas obtained from the first-pass regression. The explanatory variables in the second pass regressions are beta estimates from the first pass, which estimate true betas with error and therefore has an errors-in-varaibles (EIV) problem. As a result, the risk premium estimates from the second pass regressions are biased and inconsistent; and the directions of the biases are unknown when there are multiple factors involved in the two-pass regressions.

With a large number of individual stocks, the EIV bias can be reduced by using portfolios rather than individual stocks as test assets. This process begins by forming diversified portfolios

\footnotetext{
${ }^{1}$ Hereafter, we will adopt the shorthand nomenclature "Beta" to mean "factor sensitivity" or "factor loading".
} 
classified by some individual asset characteristics, such as a beta estimated over a preliminary sample period. It then estimates portfolio betas using data for a second period. Finally. it runs the cross-sectional regressions on estimated portfolio betas using data for a third period. BJS, Blume and Friend (1973), and FM note that portfolios betas are estimated more precisely than individual stock betas; so the EIV bias is reduced with portfolios as test assets, which can be entirely eliminated as the number of stocks in the sample grows indefinitely.

But using portfolios as test assets has its own shortcomings. There is an immediate issue of test power since the dimensioniality is reduced; i.e., average returns vary with fewer explantory variables across portfolios than across individual stocks. Perhaps more troubling is that diversification into portfolios can mask cross-sectional phenomena in individual stocks that are unrelated to the portfolio grouping procedure. For example, advocates of fundamental indexation (Arnott, Hsu and Moore, 2005) argue that assets with high market values are overpriced and vice versa, but any portfolio grouping by an attribute other than market value itself could diversify away such potential mispricing, rendering any mispricing undetectable.

Another disquieting result of portfolio masking involves the cross-sectional relation between average returns and betas. Take the single-factor CAPM as an illustration, though the same effect is also at work for any linear factor models. The linear relation between expected returns and betas holds exactly, if and only if, the market index used for computing betas is on the mean/variance frontier of the individual asset universe. Rejection of this linear relation would imply that the index is not on the frontier. But if the individual assets are grouped into portfolios sorted by beta, any asset pricing errors across individual assets not related to beta are unlikely to be detected. Therefore, this procedure could lead to a mistaken inference if the index is on the efficient frontier constructed with beta-sorted portfolios.

Test portfolios are typically organized by firm characteristics related to average returns, such as size and book-to-market. Sorting on characteristics that are known to predict returns helps generate a reasonable variation in average returns across test assets. But Lewellen, Nagel, and Shanken (2010) point out sorting on characteristics also imparts a strong factor structure in test portfolio returns. Lewellen et al. (2010) show that as a result even factors weakly correlated with the sorting characteristics could explain the differences in average returns across test portfolios, regardless of the economic merits of the theories that underlie the factors. 
Finally, the statistical significance and economic magnitudes of risk premiums are likely to depend critically on the choice of test portfolios. For example, the Fama and French size and bookto-market risk factors are significantly priced when test portfolios are sorted based on the corresponding characteristics. However, they do not command significant risk premiums when test portfolios are sorted only on momentum.

We develop a new procedure to estimate risk premiums and to test their statistical significance using individual stocks that avoids the EIV bias. Our method adopts the instrumental variables technique, a standard econometric solution to the EIV problem. We refer to our approach as the IV method, which first estimates betas for individual stocks from a subset of the observations in the data sample. These betas are the "independent" variables for the second-stage cross-sectional regressions. Then, we estimate betas again using a disjoint data sample, and these betas are the "instrumental" variables in the second-stage regressions. Since we estimate the independent and instrumental variables from disjoint data samples, their measurement errors are uncorrelated. ${ }^{2}$ For some of our empirical tests, we modify our IV method and employ stock characteristics as additional instruments for betas.

We show that the IV estimator consistently estimates the ex-post risk premiums as the number of stocks in the sample $(\mathrm{N})$ increases indefinitely. We refer to this property of the estimator as $\mathrm{N}$ consistency, following Shanken (1992). Since consistency is a large sample property, it is important to examine the estimator's small sample properties as well. We do so using a number of simulation experiments. We match the simulation parameters to those in the actual data. We find that the IV estimates in the simulation are not different from the true parameters even when betas are estimated using a relatively short time-series of data. In contrast, the standard approach that fits the the second-stage regressions using OLS (hereafter we will refer to this standard approach as the OLS method) suffers from severe EIV biases. For example, in simulations with a single factor model, we find that the OLS estimates with individual stocks are significantly biased towards zero, even when betas are estimated with about ten years of daily data. In contrast, the IV estimates are not different from the true parameters when we use only about one year of daily data to estimate betas.

\footnotetext{
${ }^{2}$ For example, the efficient market hypothesis implies that the unexpected returns are serially uncorrelated and, hence, the measurement errors in betas estimated with returns from disjoint sample periods are uncorrelated crosssectionally as well.
} 
In terms of test size (i.e., type I error) and power (i.e., type II error), we find that the conventional $t$-tests based on the IV estimator are well specified, and they are reasonably powerful even in small samples for the CAPM and for the Fama-French three-factor model. We also show analytically that our IV estimator is consistent, even if betas of individual stocks vary over time, as long as they follow covariance stationary processes. The simulation evidence with time-varying betas is similar to that with constant betas.

We apply the IV method to empirically test whether the risks proposed by the CAPM, the three-factor and five-factor models of Fama and French (1993 and 2014), the q-factor asset pricing model of Hou, Xue, and Zhang (2015), and the liquidity-adjusted capital asset pricing model (LCAPM) of Acharya and Pedersen (2005) command risk premiums that are different from zero. All these papers find significant premiums for the risks they propose. However, they all use portfolios as test assets and, hence, these tests potentially suffer from low dimensionality problems. In contrast to the original papers, we find that none of these risks are associated with a significant risk premium in the cross-section of individual stock returns after controlling for corresponding stock characteristics.

This failure to find significant risk premiums is not due to the lack of test power of the IV method. Our simulation evidence indicates the t-tests based on the IV method provide reasonably high power under the alternative hypotheses that the true risk premiums equal the sample means of factor realizations observed in the data. For example, when the true HML risk premium equals the sample risk premium ( $4.36 \%$ per year), the IV-test rejects the null hypothesis that the risk premium is zero with $91.5 \%$ probability.

Several papers in the literature, including Berk et al. (1999), Carlson et al. (2004 and 2006), Zhang (2005), and Novy-Marx (2013) argue that firm characteristics may appear to be priced because they may serve as proxies for betas. For example, consider firms A and B that are identical except for their risk. If firm A were riskier than firm B, then firm A would have a bigger book-tomarket ratio than firm B because the market would discount its expected cash flows at a bigger discount rate. If error-ridden betas were used along with book-to-market ratios, it may appear that difference in returns is related to book-to-market ratios even when betas are the true measures of risk.

We modify our tests to investigate this alternative explanation. Specifically, we allow for timevarying betas and characteristics, and we let the characteristics anticipate future changes in betas. 
In the second-stage cross-sectional regression, we use average returns over a long sample period as the dependent variable. We use both betas and characteristics as instruments. We show that this modified IV estimator is consistent, and we find that it is well-specified in small samples. We find that the factor risk premiums are not statistically significant with this modified IV approach as well.

Litzenberger and Ramaswamy (1979) is an early paper that uses individual stocks to test asset pricing models. That paper assumes that stock returns follow a single factor model. A contemporaneous paper by Chordia et al. (2015) generalizes that approach to multifactor settings. These papers derive the asymptotic bias due to the EIV problem and analytically undo the bias. Kim (1995) corrects the EIV bias using lagged betas to derive a closed-form solution for the MLE estimator of market risk premium. The solution proposed by Kim is based on the adjustment by Theil (1971). In contrast, we use the well-known IV approach to address the EIV problem. We show that our approach is consistent even with time-varying betas. We also modify our approach to address the concerns in Berk et al. (1999), Novy-Marx (2013), and others that betas may be proxies for true betas. The other papers do not address such concerns.

\section{Risk-Return Models and IV Estimation}

A number of asset pricing models predict that expected returns on risky assets are linearly related to their covariances with certain risk factors. A general specification of a $K$-factor asset pricing model can be written as:

$$
E\left(\mathrm{r}_{\mathrm{i}}\right)=\gamma_{0}+\sum_{\mathrm{k}=1}^{\mathrm{K}} \beta_{\mathrm{i}, \mathrm{k}} \gamma_{\mathrm{k}}
$$

where $\mathrm{E}\left(\mathrm{r}_{\mathrm{i}}\right)$ is the expected excess return on stock $\mathrm{i}, \beta_{\mathrm{i}, \mathrm{k}}$ is the sensitivity of stock $\mathrm{i}$ to factor $\mathrm{k}$, and $\gamma_{\mathrm{k}}$ is the risk premium on factor k. $\gamma_{0}$ is the excess return on the zero-beta asset. If riskless borrowing and lending are allowed, then the zero-beta asset earns the risk-free rate and its excess return is zero, i.e. $\gamma_{0}=0$.

The CAPM predicts that only the market risk is priced in the cross-section of stock returns. Several recent papers propose multifactor models based on empirical evidence of deviations from the CAPM. For example, Fama and French (1993) propose a three-factor model with additional factors that capture risks related to size and book-to-market. 
Many empirical tests of asset pricing models employ the Fama-MacBeth (FM) two-stage regression procedure to evaluate whether the betas of risk factors are priced in the cross-section. The first-stage estimates betas using the following time-series regressions:

$$
r_{i, t}=a_{i}+\sum_{k=1}^{K} \beta_{i, k} f_{k, t}+\varepsilon_{i, t},
$$

where $f_{k, t}$ is the realization of factor $k$ in time $t$. The time-series estimates of factor sensitivities, say $\widehat{\beta}_{\mathrm{i}, \mathrm{k}}$ for factor $\mathrm{k}$, are the independent variables in the following second-stage cross-sectional regressions to estimate factor risk premiums: For given time t,

$$
r_{i, t}=\gamma_{0, t}+\sum_{k=1}^{K} \hat{\beta}_{i, k} \gamma_{k, t}+\xi_{i, t},
$$

where realized excess return $r_{i, t}$ is the dependent variable. The standard FM approach fits OLS regression to estimate the parameters of Eq. (3). These OLS estimates are biased due to the EIV problem, since $\widehat{\beta}_{\mathrm{i}, \mathrm{k}} \mathrm{s}$ are estimated with errors. To mitigate such bias, portfolios are typically used as test assets rather than individual stocks because portfolio betas are estimated more precisely than individual stock betas.

Our empirical tests use individual stocks as test assets to avoid the shortcomings of using portfolios as test assets that we discussed earlier. We propose an instrumental variable estimator to avoid EIV-induced biases. To describe our estimator, rewrite Eq. (3) as

$$
\mathbf{r}_{\mathrm{t}}=\hat{\gamma} \widehat{\mathbf{B}}+\xi_{\mathrm{t}}
$$

where $r_{t}$ is a $1 \times N$ row vector of realized excess returns in month $t, \widehat{B}$ is the $(K+1) \times N$ matrix containing the unit vector and $\mathrm{K}$ factor betas, and $\hat{\boldsymbol{\gamma}}$ is a $1 \times(\mathrm{K}+1)$ vector of factor risk premiums (including the excess return of zero-beta asset). We propose the following instrumental variables (IV) estimator:

$$
\widehat{\boldsymbol{\gamma}}_{\mathrm{IV}, \mathrm{t}}{ }^{\prime}=\left(\widehat{\mathbf{B}}_{\mathrm{IV}} \widehat{\mathbf{B}}_{\mathrm{EV}}{ }^{\prime}\right)^{-1}\left(\widehat{\mathbf{B}}_{\mathrm{IV}} \mathbf{r}_{\mathrm{t}}{ }^{\prime}\right)
$$

where $\widehat{\mathbf{B}}_{\mathrm{IV}}$ and $\widehat{\mathbf{B}}_{\mathrm{EV}}$ are the matrices of instrumental and explanatory variables, respectively. We estimate betas within odd months and even months separately. Then we use odd-month betas as instrumental variables and even-month betas as explanatory variables when month $t$ is even and 
vice versa when month $\mathrm{t}$ is odd. ${ }^{3}$ We use daily data within odd and even months to estimate betas so that the measurement errors in the instrumental variables and explanatory variables are not correlated cross-sectionally. We fit the cross-sectional regression each month using the IV estimator.

The IV estimator has been widely used in the literature to address the EIV problem, and it is well known that the estimator is consistent under mild regularity conditions. In our context, the IV estimator converges to the ex-post risk premium even for finite $\mathrm{T}$ when the number of stocks in the cross-section is sufficiently large, which Shanken (1992) refers to as N-consistency. The proposition below formally states the N-consistency of the IV estimator:

Proposition 1: Suppose stock returns follow an approximate factor structure with $\mathrm{K}$ common factors. Under mild regularity conditions, the IV estimator given by Eq. (4) is N-consistent when the number of stocks in the cross-section increases without bound.

\section{Proof: See Appendix E in Online Appendix.}

We can explain the underlying intuition behind why the IV estimator is unbiased by framing it as a two-stage least square (2SLS) cross-sectional regression. The first-stage of the 2SLS regresses the explanatory variables against the instrumental variables. The slope coefficients from the first-stage regression are:

$$
\hat{\boldsymbol{\lambda}}=\left(\widehat{\mathbf{B}}_{\mathrm{IV}} \widehat{\mathbf{B}}_{\mathrm{IV}}^{\prime}\right)^{-1}\left(\widehat{\mathbf{B}}_{\mathrm{IV}} \widehat{\mathbf{B}}_{\mathrm{EV}}^{\prime}\right) .
$$

The second-stage regression uses the fitted values from the first-stage regression as explanatory variables and the OLS estimator of this second-stage regression is the IV estimator. After substituting the relation in Eq. (5) and rearranging the terms, the second-stage regression estimator can be written as:

$$
\widehat{\boldsymbol{\gamma}}_{\mathrm{IV}, \mathrm{t}}{ }^{\prime}=\hat{\boldsymbol{\lambda}}^{-1}\left\{\left(\widehat{\mathbf{B}}_{\mathrm{IV}} \widehat{\mathbf{B}}_{\mathrm{IV}}^{\prime}\right)^{-1}\left(\widehat{\mathbf{B}}_{\mathrm{IV}} \mathbf{r}_{\mathrm{t}}{ }^{\prime}\right)\right\}
$$

\footnotetext{
3 The EV and IV betas are computed using half the number of observations that one would use to compute OLS betas and, hence, they are noisier. However, this does not affect the consistency of the IV estimator. Our simulation results indicate that the IV estimates are on average equal to the simulation parameters even when we use only one year of daily data to estimate betas.
} 
The expression within braces in Eq. (6) is the OLS estimates of the risk premiums if returns were regressed against IV betas. These estimates are subject to the EIV bias. The premultiplication by the inverse of matrix $\hat{\lambda}$ corrects for the EIV bias and yields consistent estimates.

In the case of a single factor model, the element in the second row and column of $\hat{\lambda}$ is the slope coefficient obtained from regressing the explanatory variable on the instrumental variable. Both these variables measure true betas with errors, but the errors are mutually uncorrelated. Therefore, we can show that this element of the matrix $\hat{\lambda}$ equals the ratio of the variance of true beta divided by the sum of the variance of true betas and variance of measurement error in estimated betas, which is smaller than one. The IV slope coefficient equals the OLS slope coefficient divided by this factor, and this division effectively scales up the OLS estimate and exactly offsets the EIV bias and yields consistent estimates. Scaling up the OLS estimate to get the IV estimate also scales up the standard error by the same factor. Therefore, these effects cancel each other when we compute the t-statistics, and asymptotically the t-statistics computed with the OLS and IV estimators are the same.

In addition, note that the regression in the first stage of the 2SLS shrinks the beta used as the explanatory variable towards the cross-sectional means of their instruments. Such shrinkage in a single factor model is reminiscent of Vasicek (1973) estimators for betas that shrink estimated betas towards the market beta of 1 .

\section{Small Sample Properties of the IV Method - Simulation Evidence}

To evaluate the small sample properties of the IV method, we conduct a battery of simulations using the parameters matched to real data. We first investigate the bias and the rootmean-squared error (RMSE) of the IV estimator and then we examine the size and power of the associated $t$-test, which we refer to as the IV test.

\subsection{Bias and RMSE of IV Estimator}

We set the simulation parameters to equal the corresponding parameters in the actual data during the January 1956 through December 2012 sample period. We use the Center for Research in Security Prices (CRSP) value-weighted index as the market index and the one-month T-bill rate as the risk-free rate. For each stock, we fit market model regressions to estimate betas and residual return standard deviations. We match the simulation parameters to the distribution of these 
parameters in the data. Table 1 reports the simulation parameters.

We conduct simulations with the cross-sectional size of $\mathrm{N}=2000$ stocks. We randomly generate daily returns using the following procedure:

1) For each stock, we randomly generate a beta and a standard deviation of return residuals $\sigma_{\mathrm{i}, \varepsilon}$ from normal distributions with means and standard deviations equal to the corresponding sample means and standard deviations from the real data. ${ }^{4}$ We generate betas and $\sigma_{i, \varepsilon} \mathrm{s}$ in the beginning of each simulation and keep them constant across 1000 repetitions.

2) For each day, we randomly draw market excess return from a normal distribution with mean and standard deviation equal to the sample mean and standard deviation from the data.

3) For each stock, we then randomly generate daily residual return $\varepsilon_{i, \tau}$ from a normal distribution with mean zero and standard deviation equal to the value generated in step (1).

For stock $i$, we compute the excess return on day $\tau$ as

$$
r_{i, \tau}=\beta_{i} r_{M K T, \tau}+\varepsilon_{i, \tau}
$$

where $r_{M K T, t}$ is the market excess returns.

For the first-stage regression in the simulation, we estimate betas using the following market model regression with daily excess returns for each stock: ${ }^{5}$

$$
r_{i, \tau}=a_{i}+\beta_{i} r_{M K T, \tau}+\varepsilon_{i, \tau}
$$

Each "month" in the simulation has 21 trading days and we use three years of daily returns (756 days) to fit the time-series regression in Eq. (8). For the IV method, we use daily returns from odd and even months during a rolling three-year estimation period to compute independent and instrumental variables.

We fit the second-stage regression with monthly returns, following the common practice in the literature. We could have fit the second-stage regression with daily returns as well, but this would not improve the precision of the second-stage estimates. To see this intuitively, we compare fitting one cross-sectional regression for month $\mathrm{t}$ with fitting 21 separate daily regressions for the month and averaging the daily regression slope coefficients over the month. With the same set of stocks in both regressions and same betas for the month, the slope coefficient of the monthly

\footnotetext{
${ }^{4}$ If the random draw of $\sigma_{i, \varepsilon}$ is negative, we replace it with its absolute value.

${ }^{5}$ We employ daily returns rather than monthly returns to obtain more precise beta estimates in the first-stage regression. We also experiment with monthly data to estimate betas. In untabulated results, when $\mathrm{T}=120,180$, and 240 months, we find that the IV estimator with monthly data has similar small sample properties to that with daily data, which are reported in Tables 2 and 3 .
} 
regression would be exactly 21 times the average slope coefficient of the daily regressions and the standard error of the monthly regression would also be 21 times the standard error of average daily regression coefficient. As a result, both specifications would yield the same t-statistic for the slope coefficient. There would be some differences between the two specifications if daily returns are compounded to compute monthly returns but such differences are likely small.

We compound daily stock and factor returns to compute corresponding monthly returns. We fit the cross-sectional IV regression in Eq. (4) for each month t to estimate $\gamma_{0, t}$ and $\gamma_{1, t}$. We then roll the three-year estimation window forward by one month and repeat the IV estimation procedure over 684 months (57 years). Finally, the time-series averages of $\gamma_{0, t}$ and $\gamma_{1, t}$ are the parameter estimates.

We conduct the three-factor model simulations analogously, but in addition to market returns and market betas we randomly generate the SMB and HML factors and corresponding betas as well. We match the means and standard deviations of the simulation parameters to those of actual data. We draw SMB and HML betas independently and, hence, the cross-sectional correlations among betas are zero in the simulation. Table 1 presents the simulation parameters.

One of the issues that often arises with IV estimators is that for any finite $\mathrm{N}$, there is a very small chance that the cross-products of $\widehat{\mathbf{B}}_{\mathrm{IV}}$ and $\widehat{\mathbf{B}}_{\mathrm{EV}}$ might be close to non-invertible; this could result in an unreasonably large value of parameter estimates (see Kinal, 1980). To avoid this potential problem in finite samples, we treat monthly risk premium estimates that deviate six or more standard deviations of the corresponding factor realizations from their sample average as missing values. ${ }^{6}$

The average differences between the risk premium estimates and the corersponding true simulation parameters over the 1000 replications are the ex-ante biases relative to the true risk premiums. Since all risk premium estimates within a sample are conditional on a particular set of factor realizations, we also report the ex-post biases relative to the average realized risk premiums in that particular sample.

Panel A of Table 2 presents the ex-ante and ex-post biases, as percentages of the true market premium. $^{7}$ The OLS estimate is biased towards zero by $20 \%$ relative to the ex-ante risk premium

${ }^{6}$ We could also use the ratio of IV estimator to OLS estimator to identify outliers among IV risk premium estimates. Exclusions based on this ratio yield qualitatively similar results in our simulations.

${ }^{7}$ We know the ex-ante or the "true" risk premiums in simulations, but we only observe ex-post realizations in practice. Ex-post biases measure the biases conditional on particular factor realizations and would likely be more relevant in 
and by $21 \%$ relative to the ex-post risk premium, respectively, which are statistically significantly different from zero. In contrast, the average differences between IV estimates and the ex-ante and ex-post risk premiums are about $1 \%$, which is statistically insignificant. ${ }^{8}$

The next two columns in Panel A present the ex-ante and ex-post RMSEs, which measure the combined effects of standard errors and bias. We find that the ex-ante RMSE for the IV estimator is slightly smaller than that for the OLS estimator. The ex-post RMSE is .125 for the OLS estimator, compared with .080 for the IV estimator. These results indicate that overall the IV estimator is more accurate than the OLS estimator (as assessed by RMSEs) for the parameters used in our simulations. ${ }^{9}$

Figure 1 plots the ex-ante and ex-post biases of the IV and OLS estimators as a function of the number of days (T) in the rolling window to estimate the market betas with 2000 stocks under the single-factor CAPM. The bias of the OLS estimator is $-44 \%$ of the simulation parameters when we use a sample period of 252 days to estimate betas. ${ }^{10}$ The magnitude of the bias is greater than $5 \%$ even when we estimate betas over 2520 days, or 10 years. In contrast, the bias is fairly close to zero for the IV estimator even for $\mathrm{T}=252$ days, or 1 year.

Panel B of Table 2 presents the results for the Fama-French three-factor model. The EIV problem always biases OLS risk premium estimates towards zero in univariate regressions, but in theory the bias could be in any direction in multivariate regressions. The results in Panel B indicate that the OLS risk premium estimates for the Fama-French three-factor model are all biased towards zero in the simulation. For example, the ex-ante biases of the OLS estimates are $-54.4 \%$ and $-50.6 \%$ for SMB and HML, respectively. We find that all ex-ante and ex-post biases in the OLS estimates are significantly different from zero. In contrast, the magnitudes of the biases in the IV estimates are all less than $2.1 \%$, and these biases are statistically indistinguishable from zero. $^{11}$

practice, although both ex-ante and ex-post measures are conceptually interesting.

8 Based on the standard errors across the 1,000 repetitions, the t-statistics of the ex-ante and ex-post biases of OLS estimate are -31.30 and -58.14 , respectively. Therefore, OLS estimates are significantly biased at any conventional significance level. In contrast, the t-statistics of ex-ante and ex-post biases of IV estimate are insignificant at -0.46 and -0.22 , respectively.

9 The magnitude of the EIV bias in the OLS estimator is proportional to the true risk premium, and therefore the RMSE of the OLS estimator decreases with the magnitude of the risk premium. In untabulated results, we find that the ex-post RMSE for the OLS estimator would be smaller than that for the IV estimator if the true market risk premium were smaller than about $2 \%$ per annum. For comparison, the sample risk premium is $5.8 \%$.

${ }^{10}$ Since our simulation assumes 21 days per month, $\mathrm{T}=252$ days corresponds to one year.

${ }^{11}$ Based on the standard errors across the 1,000 repetitions, the t-statistics of the ex-ante and ex-post biases of OLS 


\subsection{Size and Power of IV Test}

We follow the Fama-MacBeth approach to test whether the risk premiums associated with various common factors are reliably different from zero. For example, in the case of a single factor model, the test statistic is defined as:

$$
\mathrm{t}_{\gamma}=\frac{\widehat{\gamma}}{\widehat{\sigma}_{\gamma}}
$$

where $\hat{\gamma}$ is the time-series average of monthly IV risk premium estimates and $\widehat{\sigma}_{\gamma}$ is the corresponding Fama-MacBeth standard error (FMSE). ${ }^{12}$

To examine the small sample properties of the t-statistic in Eq. (9) under the null hypotheses, we follow the same steps as above to generate simulated data, but we set all true risk premiums equal to zero. We then examine the percentage of repetitions (out of 1000 total repetitions) when the t-statistics are positively significant at the various levels (one-sided) using critical values based on the standard normal distribution.

Panel A of Table 3 presents the sizes of the IV tests under the CAPM and the Fama-French three-factor model for 2000 stocks, respectively. The results indicate that the IV tests are well specified when returns over 756 days (three years of daily data) are used to estimate betas. For example, the test sizes for all risk premiums at the 5\% significance level are between $4.8 \%$ and $5.2 \%$ and those at the $10 \%$ significance level are between $9.8 \%$ and $10.5 \%$. In untabulated results, we find that the distribution of the test statistic becomes closer to the theoretical distribution as we increase T. We also find similar results in simulations with a sample of 1500 stocks.

The next set of tests investigates the power of the IV tests to reject the null hypotheses when the alternative hypotheses are true. To evaluate the power, we generate factor realizations from a normal distribution with mean equal to the average risk premiums for the corresponding factors in the real data. All the other simulation parameters are the same as in the simulations under the null hypotheses. We evaluate the frequency of rejection of the null hypothesis at the $5 \%$ significance level.

estimates for the three Fama-French factors are smaller than -45 , and, hence, highly significant. In contrast, the tstatistics of ex-ante and ex-post biases of IV estimates for the three Fama-French factors range from -1 to 0 , and they are all statistically insignificant.

${ }^{12}$ An earlier version of our paper analytically derived the asymptotic distribution of the IV estimator, which could also be employed in our empirical tests. However, we use the Fama-MacBeth standard errors because they are fairly straightforward to compute and more commonly used in the literature. Since the monthly IV estimates are serially uncorrelated, the usual intuition behind the FM approach applies. 
Panel B of Table 3 shows that the power of the IV test to reject the null hypothesis under the single-factor CAPM is $85.6 \%$. Under the Fama-French three-factor model, we find that the frequency of rejection of the null of zero market risk premium is $83.8 \%$ and that of zero HML risk premium is $91.5 \%$. The test power is somewhat weaker for the positive SMB risk premium, but it is still $51.8 \%$. We also find that in $99.6 \%$ of the simulations, at least one of the risk premiums for the Fama-French three factors is significantly different from zero.

For comparison, Table 3 also presents the power of OLS tests. Under the CAPM, we reject the null hypothesis that the market risk premium equals zero in $84.2 \%$ of the simulations with OLS tests, compared with $85.6 \%$ with the IV tests. Although, the OLS estimates are biased towards zero, the OLS tests are almost as powerful as the IV tests because of smaller standard errors. We find similar power results for the Fama-French three-factor model as well, although the OLS tests are generally less powerful than the IV tests.

We also examine the power of the IV and OLS tests to reject the CAPM for different levels of true market risk premium. Figure 2 presents these results. If the market risk premium equals $2.9 \%$ per annum, which is $50 \%$ of the ex-post risk premium observed from real data, then the power of the IV tests is about $40 \%$ and the power of the OLS test is slightly smaller.

\subsection{Time-varying betas}

Our analyses so far assume that betas and risk premiums are constant over time. We show that the IV estimator is $\mathrm{N}$-consistent even with time-varying betas and risk premiums in Appendix A. We also conduct simulations to investigate the small sample properties allowing for such time variation. When betas follow AR(1) processes, we find that the small sample properties of the IV estimator and the size and power of the IV tests are similar to what we report with constant betas in Tables 2 and 3. Appendix A presents the results for simulation with time-varying betas.

\section{IV Risk Premium Estimates for Selected Asset Pricing Models}

This section employs the IV method to estimate the premiums for risk factors proposed by prominent asset pricing models.

\subsection{Data}

We obtain stock return, trading volume, and market capitalization data from CRSP and 
financial statement data from COMPUSTAT for the sample period from January 1956 through December 2012. We include all common stocks (CRSP share codes of 10 or 11). ${ }^{13}$ The sample for month $\mathrm{t}$ excludes all stocks priced below $\$ 1$ or stocks with market capitalizations less than $\$ 1,000,000$ at the end of month $\mathrm{t}-1$. Since daily returns are used to estimate betas, we restrict the sample to stocks with returns in month $\mathrm{t}$, with at least 200 days of return data during each of the three years prior to month $\mathrm{t}^{14}$

The sample period for testing the CAPM and the Fama-French three-factor model starts in 1956. Table 4 presents the summary statistics for this sample. A total of 14,056 distinct stocks enter the sample at different points in time during this sample period and the sample is comprised of 2,425 stocks per month on average. The factors data for the q-factor model and Fama-French five-factor model are available from 1972 and 1964, respectively. We use the first three years of data to estimate betas and hence the sample periods for fitting the cross-sectional regressions for these models start three years after the first date of data availability. The sample period for the liquidity-adjusted CAPM starts in 1959. The sample for each table includes only firms with all necessary data to compute characteristics available on COMPUSTAT for all regressions in the corresponding table.

\subsection{The CAPM and the Fama-French Three-factor Model}

This section first tests whether the risk premiums under the CAPM and the Fama-French threefactor models are significantly different from zero using the IV method with individual stocks. The first stage regressions estimate individual stock betas with daily returns. We use Dimson (1979) betas to account for non-synchronous trading effects. For CAPM tests, we augment the market model with one-day lead and lagged market returns and the sum of the slope coefficients is the Dimson beta. Specifically, we obtain the Dimson beta for stock i as follows:

$$
\begin{gathered}
\mathrm{r}_{\mathrm{i}, \tau}=\mathrm{a}_{\mathrm{i}}+\sum_{\mathrm{k}=-1}^{1} \beta_{\mathrm{i}, \mathrm{MKT}, \mathrm{k}} \mathrm{r}_{\mathrm{MKT}, \tau-\mathrm{k}}+\varepsilon_{\mathrm{i}, \tau} \\
\widehat{\beta}_{\mathrm{i}, \mathrm{MKT}}=\widehat{\beta}_{\mathrm{i}, \mathrm{MKT},-1}+\widehat{\beta}_{\mathrm{i}, \mathrm{MKT}, 0}+\widehat{\beta}_{\mathrm{i}, \mathrm{MKT}, 1} .
\end{gathered}
$$

\footnotetext{
${ }^{13}$ We exclude American depository receipts (ADRs), shares of beneficial interest, American Trust components, closed-end funds, preferred stocks, and real estate investment trusts (REITs).

${ }^{14}$ We find similar results of asset pricing tests when the sample includes all stocks with at least 100 or 150 return observations per year, instead of 200 observations.
} 
For the OLS tests, we fit the regression with daily return data from month $\tau-36$ to month $\tau-1$ to estimate beta for month t. For the IV tests we estimate odd- and even-month betas separately using returns on days belonging to odd and even months within this rolling window, respectively. ${ }^{15}$ Because of the non-synchronous trading adjustment in Eq. (10), we exclude the first and the last days of each month to avoid any potential biases due to data overlap. ${ }^{16}$ We use an analogous multivariate regression to estimate the three betas under the Fama-French three-factor model.

Table 5 presents the correlations between betas and firm size (SIZE) and book-to-market ratios (BM). For each stock and month, SIZE is the natural logarithm of market capitalization at the end of the previous month. BM is the book value divided by the market value where book value is the sum of book equity value plus deferred taxes and credits minus the book value of preferred stock. We compute cross-sectional pairwise cross-sectional correlations each month, and Table 5 reports their time-series averages. The CAPM beta estimated using the market model exhibits negative correlation with both SIZE and BM. For the Fama-French three-factor model, the correlations between market beta and the SMB and HML betas are positive. The correlation between SIZE and SMB betas is negative, and the correlation between BM and HML betas is positive.

For comparison, Table 5 also presents the average cross-sectional correlations for 25 FamaFrench SIZE and BM sorted portfolios that the literature typically uses as tests assets. For each portfolio and each month, we compute SIZE and BM as the value-weighted averages across all stocks that belong to the portfolio. The magnitudes of correlations among portfolio betas and characteristics are much larger; between the SMB beta and SIZE it is -.97 and between the HML beta and BM it is .88 .

Table 6 presents risk premium estimates using the IV method and individual stocks as test assets. We first test the CAPM using betas estimated from the univariate regression. The market risk premium estimate in Column (1) is $-.246 \%$, which is not reliably different from zero. Therefore, there is no empirical support for the CAPM with individual stocks.

For the Fama-French three-factor model, the betas come from multivariate time-series regressions with all three factors. In Column (2), the market risk premium estimate is $-.288 \%$ and

\footnotetext{
${ }^{15}$ Our results are qualitatively similar when we use 12-, 24- or 60-month rolling windows to estimate betas.

16 We find almost identical results while including the first and last days of each month. Also, the results are qualitatively similar when no adjustment is used for non-synchronous trading.
} 
the SMB and HML risk premiums are $.301 \%$ and $.344 \%$, respectively. The risk premiums of SMB and HML betas are statistically significant at the 5\% level, but the market risk premium is insignificant.

The significance of SMB and HML risk premium estimates suggests that these factor risks may be priced in the cross-section of stock returns, but it is also possible that these significant estimates might be due to an omitted variable bias because the second-stage cross-sectional regressions in Column (2) do not control for SIZE and BM. Our next test includes SIZE and BM as additional independent variables in the second-stage cross-sectional regressions. When we add these variables to market beta, the slope coefficients on SIZE and BM are $-.120 \%$ and $.196 \%$, respectively, and both are statistically significant at the $1 \%$ level. The market risk premium estimate is $-.090 \%$, which is still not significantly different from zero.

Under the Fama-French three-factor model in Column (4), none of the risk premiums is significant at the 5\% level in the presence of SIZE and BM, including the previously significant SMB and HML risk premiums. In contrast, the slope coefficients of SIZE and BM remain highly significant. We also find similar results when we use the logarithm of BM instead of BM in Column (5).

Table 6 also presents the test results using OLS regression estimates for comparison. As in the IV tests, we find that the SMB and HML risk premiums are statistically significant when we do not use SIZE and BM as control variables. However, they become insignificant when SIZE and $\mathrm{BM}$ are included in the model. The OLS test results are similar to what we find with the risk premium estimates using the IV method, and they also indicate that the factor risks under the CAPM or Fama-French three-factor model are not priced in the cross-section of individual stock returns.

Table 6 also reports the results for two roughly equal subperiods. The factor risk premium estimates are insignificant in both subperiods when SIZE and BM characteristics are included. The slope coefficients of SIZE and BM are significant in both subperiods at conventional levels. ${ }^{17}$

\subsection{The Fama-French Five-factor Model}

Novy-Marx (2013). Aharoni, Grundy, and Zeng (2013), and others find that stock returns are

\footnotetext{
${ }^{17}$ In this table, we drop slightly less than $3 \%$ of monthly IV estimates of risk premium. The results remain qualitatively similar when we exclude $1 \%$ or $2 \%$ of the extreme observations. We do not drop any observations for OLS estimates.
} 
significantly related to profitability and investment after controlling for Fama and French's three factors. To capture these effects Fama and French (2014) add profitability and investment factors to their three-factor model and propose the following five-factor model:

$$
\mathrm{E}\left(\mathrm{r}_{\mathrm{i}, \mathrm{t}}\right)=\beta_{\mathrm{i}, \mathrm{MKT}} \gamma_{\mathrm{MKT}}+\beta_{\mathrm{i}, \mathrm{SMB}} \gamma_{\mathrm{SMB}}+\beta_{\mathrm{i}, \mathrm{HML}} \gamma_{\mathrm{HML}}+\beta_{\mathrm{i}, \mathrm{RMW}} \gamma_{\mathrm{RMW}}+\beta_{\mathrm{i}, \mathrm{CMA}} \gamma_{\mathrm{CMA}}
$$

where $\beta_{\mathrm{i}, \mathrm{MKT}}, \beta_{\mathrm{i}, \mathrm{SMB}}, \beta_{\mathrm{i}, \mathrm{HML}}, \beta_{\mathrm{i}, \mathrm{RMW}}$, and $\beta_{\mathrm{i}, \mathrm{CMA}}$ are the betas with respect to market, size, bookto-market, profitability, and investment factors, and $\gamma_{\mathrm{MKT}}, \gamma_{\mathrm{SMB}}, \gamma_{\mathrm{HML}}, \gamma_{\mathrm{RMW}}$, and $\gamma_{\mathrm{CMA}}$ are the corresponding risk premiums. The RMW factor is based on the difference between the returns on diversified portfolios of stocks with robust and weak operating profitability and the CMA factor is based on the difference between the returns on diversified portfolios of the stocks with conservative and aggressive investment. We obtain the daily data for the five factors from Ken French's website. As in Fama and French (2014), the sample period for the asset pricing tests in this subsection is from January, 1967 through December, 2012.

Panel A of Table 7 presents the estimates for the Fama-French five-factor model. For the entire sample period, we find that none of the risk premiums for the five factors are significant at the 5\% level, even without adding controls for characteristics. We also fit the cross-sectional regressions with the characteristics related to each of the factors: SIZE, BM, operating profitability (OP), and investment (INV). Column (6) reports the results. None of the factor risks are priced in this regression as well, but the slope coefficients on all characteristics are significant. ${ }^{18} \mathrm{We}$ find qualitatively similar results within two roughly equal subperiods.

\subsection{The q-factor Asset Pricing Model}

Cochrane (1991) and Liu, Whited, and Zhang (2009) present production-based asset pricing models in which productivity shocks are tied to the changes in the investment opportunity set, which is consistent with Merton's (1973) ICAPM framework. Since the shocks to productivity are difficult to measure accurately, Hou, Xue, and Zhang (2015) (henceforth HXZ) propose an

\footnotetext{
${ }^{18}$ We follow Fama and French (2014) to construct OP and INV. As described in French's data library: “OP for June of year $t$ is annual revenues minus cost of goods sold, interest expense, and selling, general, and administrative expenses divided by book equity for the last fiscal year end in $\mathrm{t}-1$." The slope coefficient in a univariate regression of stock returns against this measure of OP is insignificant, as in Column (4) of Table 7. Novy-Marx (2013) defines gross profit as revenue minus cost of goods, scaled by current period total assets. In untabulated results, we find a significantly positive slope coefficient in the univariate regression with Novy-Marx's definition of OP. Apparently, the definition of OP affects the univariate relation. Because we use Fama-French factors, we follow their definition.
} 
empirical q-factor model where an investment factor and a ROE factor capture productivity shocks. Their asset pricing model is specified as:

$$
E\left(\mathrm{r}_{\mathrm{i}, \mathrm{t}}\right)=\beta_{\mathrm{i}, \mathrm{MKT}} \gamma_{\mathrm{MKT}}+\beta_{\mathrm{i}, \mathrm{ME}} \gamma_{\mathrm{ME}}+\beta_{\mathrm{i}, \mathrm{I} / \mathrm{A}} \gamma_{\mathrm{I} / \mathrm{A}}+\beta_{\mathrm{i}, \mathrm{ROE}} \gamma_{\mathrm{ROE}}
$$

where $\beta_{\mathrm{i}, \mathrm{MKT}}, \beta_{\mathrm{i}, \mathrm{ME}}, \beta_{\mathrm{i}, \mathrm{I} / \mathrm{A}}$ and $\beta_{\mathrm{i}, \mathrm{ROE}}$ are the betas with respect to market, size, investment, and ROE factors, respectively, and $\gamma_{\mathrm{MKT}}, \gamma_{\mathrm{ME}}, \gamma_{\mathrm{I} / \mathrm{A}}$ and $\gamma_{\mathrm{ROE}}$ are the corresponding risk premiums.

The investment factor captures new investments, and the ROE factor captures the return on investments, i.e., profitability. The investment factor is constructed as the return difference between firms with low and high levels of new investments, and the ROE factor is constructed as the return difference between firms with high and low levels of profitability. Intuitively, the new investments and rates of return on investments are likely to reflect the sensitivity to unanticipated productivity shocks, and these factors are intended to capture the price impact of such shocks. HXZ argue that their factors explain the cross-sectional return differences across portfolios based on various anomalies such as BM, SIZE, momentum, and earnings surprise better than the FamaFrench three-factor model and the Carhart four-factor model.

HXZ use a variety of different test portfolios for their asset pricing tests. For instance, their test of SIZE and BM uses the 25 Fama-French SIZE and BM sorted portfolios, their test of momentum uses 10 portfolios based on momentum, and their test of the standardized earnings surprises (SUE) uses 10 SUE sorted portfolios. Since all the tests employ selected sets of test portfolios, they are also subject to the low dimensionality problems. We examine whether the HXZ factors are priced in the cross-section of individual stock returns. We obtain daily $\mathrm{HXZ}$ factors from HXZ.

Table 8 presents the test results of the q-factor asset pricing model using the IV method. To facilitate comparison, this table uses the sample period of January 1975 through December 2012, which HXZ use in their empirical tests. Columns (1) to (4) report the risk premium estimates for each of the four betas under the $\mathrm{HXZ}$ model in univariate regressions. None of the risk premiums are statistically significant at conventional levels.

Column (5) presents the risk premium estimates for all four betas under the HXZ model together, none of which are reliably different from zero. Column (8) presents the regression estimates when we add SIZE, OP, and INV to the HXZ model. The slope coefficients on all three characteristics are statistically significant with usual signs, but none of the factor risk premiums 
are reliably different from zero. Therefore, we find no empirical support for the HXZ model when using individual stocks as test assets. We find similar results within two equal subperiods as well.

\subsection{Liquidity-Adjusted CAPM}

Next, we examine the liquidity-adjusted capital asset pricing model (LCAPM) proposed by Acharya and Pedersen (2005), which accounts for the impact of illiquidity-based trading frictions on asset pricing. ${ }^{19}$ According to the LCAPM, the level of illiquidity and the covariances of return and illiquidity innovation with the market-wide return and illiquidity innovation affect expected returns. The unconditional expected return in excess of the risk-free rate under the LCAPM is defined as:

$$
E\left(\mathrm{r}_{\mathrm{i}, \mathrm{t}}\right)=E\left(\mathrm{c}_{\mathrm{i}, \mathrm{t}}\right)+\lambda\left(\beta_{\mathrm{i}, 1}+\beta_{\mathrm{i}, 2}-\beta_{\mathrm{i}, 3}-\beta_{\mathrm{i}, 4}\right),
$$

where $c_{i, t}$ is the illiquidity cost, the price of risk is the market excess return minus aggregate illiquidity cost (i.e., $\left.\lambda=\mathrm{E}\left(\mathrm{r}_{\mathrm{MKT}, \mathrm{t}}-\mathrm{c}_{\mathrm{MKT}, \mathrm{t}}\right)\right)$, and the betas are

$$
\begin{aligned}
& \beta_{\mathrm{i}, 1}=\frac{\operatorname{cov}\left(\mathrm{r}_{\mathrm{i}, \mathrm{t}}, \mathrm{r}_{\mathrm{MKT}, \mathrm{t}}-E_{\mathrm{t}-1}\left(\mathrm{r}_{\mathrm{MKT}, \mathrm{t}}\right)\right)}{\operatorname{var}\left(\mathrm{r}_{\mathrm{MKT}, \mathrm{t}}-E_{\mathrm{t}-1}\left(\mathrm{r}_{\mathrm{MKT}, \mathrm{t}}\right)-\left[\mathrm{c}_{\mathrm{MKT}, \mathrm{t}}-E_{\mathrm{t}-1}\left(\mathrm{c}_{\mathrm{MKT}, \mathrm{t}}\right)\right]\right)}, \\
& \beta_{\mathrm{i}, 2}=\frac{\operatorname{cov}\left(\mathrm{c}_{\mathrm{i}, \mathrm{t}}-E_{\mathrm{t}-1}\left(\mathrm{c}_{\mathrm{i}, \mathrm{t}}\right) \mathrm{c}_{\mathrm{MKT}, \mathrm{t}}-E_{\mathrm{t}-1}\left(\mathrm{c}_{\mathrm{MKT}, \mathrm{t}}\right)\right)}{\operatorname{var}\left(\mathrm{r}_{\mathrm{MKT}, \mathrm{t}}-E_{\mathrm{t}-1}\left(\mathrm{r}_{\mathrm{MKT}, \mathrm{t}}\right)-\left[\mathrm{c}_{\mathrm{MKT}, \mathrm{t}}-E_{\mathrm{t}-1}\left(\mathrm{c}_{\mathrm{MKT}, \mathrm{t}}\right)\right]\right)}, \\
& \beta_{\mathrm{i}, 3}=\frac{\operatorname{cov}\left(\mathrm{r}_{\mathrm{i}, \mathrm{t}}, \mathrm{c}_{\mathrm{MKT}, \mathrm{t}}-E_{\mathrm{t}-1}\left(\mathrm{c}_{\mathrm{MKT}, \mathrm{t}}\right)\right)}{\operatorname{var}\left(\mathrm{r}_{\mathrm{MKT}, \mathrm{t}}-E_{\mathrm{t}-1}\left(\mathrm{r}_{\mathrm{MKT}, \mathrm{t}}\right)-\left[\mathrm{c}_{\mathrm{MKT}, \mathrm{t}}-E_{\mathrm{t}-1}\left(\mathrm{c}_{\mathrm{MKT}, \mathrm{t}}\right)\right]\right)}, \\
& \beta_{\mathrm{i}, 4}=\frac{\operatorname{cov}\left(\mathrm{c}_{\mathrm{i}, \mathrm{t}}, \mathrm{r}_{\mathrm{MKTT}}-E_{\mathrm{t}-1}\left(\mathrm{r}_{\mathrm{MKT}, \mathrm{t}}\right)\right)}{\operatorname{var}\left(\mathrm{r}_{\mathrm{MKT}, \mathrm{t}}-E_{\mathrm{t}-1}\left(\mathrm{r}_{\mathrm{MKT}, \mathrm{t}}\right)-\left[\mathrm{c}_{\mathrm{MKT}, \mathrm{t}}-E_{\mathrm{t}-1}\left(\mathrm{c}_{\mathrm{MKT}, \mathrm{t}}\right)\right]\right)} .
\end{aligned}
$$

The term $E\left(\mathrm{c}_{\mathrm{i}, \mathrm{t}}\right)$ is the reward for firm-specific illiquidity level, which is the compensation for holding an illiquid asset, as in Amihud and Mendelson (1986). Acharya and Pedersen define illiquidity-adjusted net beta as:

$$
\beta_{\mathrm{i}, \mathrm{LMKT}}=\beta_{\mathrm{i}, 1}+\beta_{\mathrm{i}, 2}-\beta_{\mathrm{i}, 3}-\beta_{\mathrm{i}, 4} .
$$

The LCAPM implies that the linear relation between risk and return applies for the liquidityadjusted market beta, but not for the standard market beta under the CAPM. The LCAPM also implies that the linearity between risk and return applies to excess returns net of firm-specific illiquidity $\operatorname{cost}\left(\mathrm{c}_{\mathrm{i}, \mathrm{t}}\right)$.

\footnotetext{
${ }^{19}$ Several other papers, e.g., Pastor and Stambaugh (2003), also propose models where a stock's return sensitivity to market-wide (il)liquidity is priced in the cross-section. Since we do not have daily Pastor and Stambaugh's liquidity factor, we do not examine their model here.
} 
Acharya and Pedersen test the LCAPM using two sets of test portfolios sorted on the average and standard deviation of illiquidity. They sort stocks based on Amihud (2002) illiquidity measures during each year and form 25 value-weighted illiquidity portfolios for the subsequent year. They also form 25 value-weighted $\sigma$ (illiquidity) portfolios similarly by sorting based on the standard deviation of illiquidity.

We examine the correlations between $\beta_{\mathrm{i}, \mathrm{LMKT}}$ and the value-weighted averages of SIZE and $\mathrm{BM}$ for those portfolios used by Acharya and Pedersen. The average cross-sectional correlations of $\beta_{\mathrm{i}, \mathrm{LMKT}}$ with SIZE for illiquidity and $\sigma$ (illiquidity) portfolios are -.96 and -.97 , respectively, and those with BM are .71 and .74, respectively. Such high correlations between liquidity-adjusted market beta, i.e., $\beta_{\mathrm{i}, \mathrm{LMKT}}$, and SIZE suggest that it would be hard to determine empirically whether average returns differ across test portfolios due to SIZE or illiquidity-adjusted market betas. This situation parallels that in Chan and Chen (1988) who use 20 size-sorted portfolios as test assets and find strong support for the standard CAPM. The correlations between the standard market beta and SIZE across Chan and Chen's test portfolios range from -.988 to -.909 over different sample periods, and the corresponding correlations in the cases of illiquidity and $\sigma$ (illiquidity) portfolios are within this range. Jegadeesh (1992) shows that when test portfolios are constructed so that SIZE and standard market beta have low correlation (in absolute value), market beta is not priced and that the significant market risk premium found across size-sorted portfolios is due to the high correlation (in absolute value) between SIZE and market beta.

To avoid such confounding effects, we employ the IV method with individual stocks to investigate whether $\beta_{\mathrm{i}, \mathrm{LMKT}}$ under the LCAPM is priced in the cross-section. To facilitate comparison, we follow the same procedure as in Acharya and Pedersen (2005) in all other respects. Because of the differences in the market structures of the NYSE/AMEX and NASDAQ, the trading volumes reported in these two markets are not comparable and, hence, NASDAQ stocks are excluded for this test.

Acharya and Pedersen define the illiquidity cost as follows: ${ }^{20}$

$$
\begin{gathered}
\operatorname{ILLIQ}_{\mathrm{i}, \tau}=\frac{\left|\mathrm{r}_{\mathrm{i}, \tau}\right|}{\mathrm{v}_{\mathrm{i}, \tau}}, \\
\mathrm{c}_{\mathrm{i}, \tau}=\min \left(0.25+0.3 \operatorname{ILLIQ}_{\mathrm{i}, \tau} \mathrm{P}_{\mathrm{MKT}, \mathrm{t}-1}, 30\right),
\end{gathered}
$$

\footnotetext{
${ }^{20}$ Acharya and Pedersen use illiquidity costs at monthly frequency, but we use them at daily frequency.
} 
where $r_{i, \tau}$ is the return on day $\tau$ in month $t, v_{i, \tau}$ is the dollar volume (in millions) and $P_{M K T, t-1}$ is the month $t-1$ value of $\$ 1$ invested in the market portfolio as of the end of July 1962. Eq. (16) is based on Amihud's (2002) illiquidity measure. Acharya and Pedersen use Eq. (17) as a measure of illiquidity cost where $\mathrm{P}_{\mathrm{MKT}, \mathrm{t}-1}$ is used to adjust for inflation and the illiquidity cost is capped at $30 \%$ to avoid an obviously unreasonable value for it. The market-wide illiquidity cost $\mathrm{c}_{\mathrm{MKT}, \tau}$ is the value-weighted average of individual illiquidity costs using market capitalization in month t1.

As in Acharya and Pedersen (2005), we estimate the innovations in illiquidity costs using AR models and then estimate each individual component of betas in Eq. (15) using a time-series GMM approach and Dimson-type corrections. ${ }^{21}$ We then fit the following cross-sectional regression each month t:

$$
r_{i, t}=\alpha_{t}+\gamma_{\text {ILLIQ }, \mathrm{t}} c_{i, t}+\gamma_{\text {LMKT }, t} \widehat{\beta}_{\mathrm{i}, \mathrm{LMKT}}+\varepsilon_{\mathrm{i}, \mathrm{t}},
$$

where $c_{i, t}$ is the average illiquidity for stock $i$ in month $\tau .{ }^{22}$

The IV estimator in month $t$ is:

$$
\widehat{\boldsymbol{\gamma}}_{\mathrm{t}}^{\prime}=\left(\widehat{\mathbf{\Psi}}_{\mathrm{IV}, \mathrm{t}} \widehat{\Psi}_{\mathrm{EV}, \mathrm{t}}^{\prime}\right)^{-1} \widehat{\boldsymbol{\Psi}}_{\mathrm{IV}, \mathrm{t}} \mathbf{r}_{\mathrm{t}}^{\prime}
$$

where $\widehat{\mathbf{\Psi}}_{\mathrm{IV}, \mathrm{t}}$ is $\widehat{\boldsymbol{\Psi}}_{\text {even,t }}$ when month $\mathrm{t}$ is odd and it is $\widehat{\boldsymbol{\Psi}}_{\text {odd }, \mathrm{t}}$ when month $\mathrm{t}$ is even, and

$$
\begin{aligned}
\widehat{\Psi}_{\text {even,t }} \equiv & 3 \times \mathrm{N} \text { matrix with unit vector as the first row, } c_{\mathrm{i}, \mathrm{t}} \text {, and estimated even-month } \\
& \text { LMKT betas for } \mathrm{N} \text { stocks as the second and third rows, respectively. We estimate } \\
& \text { the even-month LMKT betas using daily data in even months in the rolling } \\
& \text { estimation window from month t-36 to month t- } 1 \text {. } \\
\widehat{\Psi}_{\text {odd, } \mathrm{t}} \equiv & \text { Analogous to } \widehat{\Psi}_{\text {even,t }} \text { estimated using all daily data in odd months. }
\end{aligned}
$$

For the IV estimator in month $\mathrm{t}+1$, we move the three-year rolling estimation window forward by one month. We repeat this estimation procedure until all available observations are exhausted.

Table 9 presents the risk premium estimates for the LMKT betas when using individual stocks as test assets. The slope coefficient on the Amihud illiquidity measure is $.220 \%$, which is positive and highly significant. However, the risk premium estimates for $\beta_{\mathrm{i}, \mathrm{LMKT}}$ are $.150 \%$ and $.085 \%$,

\footnotetext{
${ }^{21}$ Appendix B presents the AR models that we use to estimate expected and unexpected components of illiquidity.
}

${ }^{22}$ As in Acharya and Pedersen (2005), 30\% capping is applied after taking monthly average. 
respectively, without and with controlling for Amihud illiquidity. These premiums are not reliably different from zero. These test results indicate that firm-specific illiquidity, which is a firm characteristic, is positively related to average returns, but liquidity-adjusted market beta, which is the systematic risk under the LCAPM, does not command a significant risk premium. We find similar results in two subperiods as well.

In comparison, Acharya and Pedersen (2005) report a liquidity-adjusted market risk premium estimate of about $2.5 \%$ per month using the value-weighted index (see Panel B of Table 5 in Acharya and Pedersen, 2005), which is about $30 \%$ per year. ${ }^{23}$ The equity risk premium puzzle literature argues that even an annual risk premium of about $6 \%$ observed in the data is hard to justify with realistic levels of risk aversion, and larger risk premiums would be harder to justify. The large risk premium estimate obtained with test portfolios seems likely to be the result of high correlations between $\beta_{\mathrm{i}, \mathrm{LMKT}}$ and portfolios characteristics rather than a true depiction of the compensation for a systematic risk.

\section{Additional Tests}

This section examines the robustness of our findings to a number of variations in the test specifications and also evaluates the strength of the instruments.

\subsection{Do Characteristics Proxy for True Betas?}

Our results provide no evidence that many of the systematic risk factors proposed in the literature command significant premiums after controlling for stock characteristics. However, it is possible that because beta estimates contain measurement errors, characteristics may serve as better proxies for true betas and the slope coefficients on characteristics may actually reflect the risk premiums of underlying systematic risk factors. In other words, it is possible that the characteristics measure the "true" future betas better than the betas estimated from past data, which we refer to as the past betas. Several papers in the literature, including Berk et al. (1999), Carlson et al. (2004 and 2006), Zhang (2005), and Novy-Marx (2013), present variations of such an interpretation.

\footnotetext{
${ }^{23}$ The liquidity-adjusted market risk premium equals the market risk premium minus expected market-wide illiquidity
} cost and, hence, it is smaller than the unadjusted market risk premium. 
The fact that true betas are unobservable makes it difficult to evaluate the tenability of this interpretation directly. However, there are several empirical implications of this "risk-proxy" hypothesis that we can test. One implication of this hypothesis is that characteristics should be more highly correlated with the betas estimated from future data, which we refer to as the future betas, than past betas. However, under the CAPM and Fama-French three-factor model, we find that the average cross-sectional correlations between past betas and future betas are slightly larger than those between characteristics and future betas.

The average cross-sectional correlation between past betas and future betas increases as we increase the sample periods over which we estimate them. For example, under the Fama-French three-factor model, the average correlation between past SMB betas and future SMB betas increases from 0.395 to 0.497 and the average correlation between past HML betas and future HML betas increases from 0.233 to 0.276 as we increase the length of rolling estimation window from 1.5 years to 2.5 years.

We repeat our asset pricing tests by employing the past SMB and HML betas as instrumental variables and their future betas as independent variables. The results provide no evidence of significant risk premiums for SMB and HML betas in the second-stage regressions, while the slope coefficients on SIZE and BM remain significant, similar to the results in Table 6. We also apply the same past and future betas specification to the other asset pricing models tested in Section 4 and find that our conclusions stay the same as before.

Finally, we develop and implement tests that directly examine whether characteristics are priced because they contain forward-looking information about future betas that is not contained in the corresponding past betas. Formally, suppose that the dynamics of beta for stock $\mathrm{i}$ is described by the following AR(1) process:

$$
\beta_{i, t}=\theta+\rho \beta_{i, t-1}+u_{i, t} .
$$

Suppose that the market is aware of $u_{i, t}$ at the end of time $t-1$. Then, under the CAPM expected return is:

$$
E_{\mathrm{t}-1}\left(\mathrm{r}_{\mathrm{i}, \mathrm{t}}\right)=\gamma_{0}+\gamma \beta_{\mathrm{i}, \mathrm{t}}
$$

Let the corresponding characteristic also follow an AR(1) process given by:

$$
\mathrm{C}_{\mathrm{i}, \mathrm{t}}=\mathrm{a}+\mathrm{bC}_{\mathrm{i}, \mathrm{t}-1}+\mathrm{e}_{\mathrm{i}, \mathrm{t}},
$$

where, to capture the idea that the characteristic anticipates the innovation in beta, we assume that $\mathrm{e}_{\mathrm{i}, \mathrm{t}}=\mathrm{u}_{\mathrm{i}, \mathrm{t}+1}+\delta_{\mathrm{i}, \mathrm{t}}$. 
We can obtain an unbiased estimate of $\beta_{\mathrm{i}, \mathrm{t}-1}$ using the past returns available up to time $\mathrm{t}$ 1 , but these data do not contain the information about $\mathrm{u}_{\mathrm{i}, \mathrm{t}}$. In contrast, $\mathrm{C}_{\mathrm{i}, \mathrm{t}-1}$ contains the information about $\mathrm{u}_{\mathrm{i}, \mathrm{t}}$. Therefore, the expected return under the CAPM can be written as a function of $\beta_{\mathrm{i}, \mathrm{t}-1}$ and $\mathrm{C}_{\mathrm{i}, \mathrm{t}-1}$ as follows: ${ }^{24}$

$$
E_{\mathrm{t}-1}\left(\mathrm{r}_{\mathrm{i}, \mathrm{t}}\right)=\gamma_{\alpha}+\gamma_{\beta} \beta_{\mathrm{i}, \mathrm{t}-1}+\gamma_{\mathrm{c}} \mathrm{C}_{\mathrm{i}, \mathrm{t}-1} \text {. }
$$

When we use the estimate of $\beta_{i, t-1}$ and $C_{i, t-1}$ as independent variables in the second-stage regression, the slope coefficient on characteristic, i.e. $\gamma_{c}$, would be significant because the characteristic anticipates the innovation in the future beta and because the measurement error in $\beta_{\mathrm{i}, \mathrm{t}-1}$ estimate would allow the characteristic $\mathrm{C}_{\mathrm{i}, \mathrm{t}-1}$ to capture a part of the true risk premium as well.

We modify our IV method to address this issue. The proposition below presents the modified approach and shows that it yields consistent risk premium estimates:

Proposition 2: Suppose that the CAPM is true as in Eq. (20). Let the time-series dynamics of beta and characteristic be given by Eqs. (19) and (21), respectively. The risk premium estimate computed using estimator in Eq. (23) converges to $\left[\gamma_{0}, \frac{1}{T_{m}} \sum_{\tau=0}^{T_{m}-1}\left(\gamma+f_{t+\tau}-E\left(f_{t+\tau} \mid \beta_{i, t+\tau}\right)\right), 0\right]^{\prime}$, when $\mathrm{N}, \mathrm{T}$, and $\mathrm{T}_{\mathrm{m}}$ approach to infinity, under some mild regularity assumptions:

$$
\hat{\gamma}_{t}^{\prime}=\left(\frac{1}{N} X_{I V, t-1}\left(X_{E V, t-1}\right)^{\prime}\right)^{-1}\left(\frac{1}{N} X_{I V, t-1} \dot{\bar{r}}_{t}^{\prime}\right)
$$

where $\mathrm{X}_{\mathrm{IV}, \mathrm{t}-1}=\left(\begin{array}{ccc}1 & \ldots & 1 \\ \widehat{\beta}_{\mathrm{IV}, \mathrm{i}, \mathrm{t}-1} & \ldots & \widehat{\beta}_{\mathrm{IV}, \mathrm{N}, \mathrm{t}-1} \\ \overline{\mathrm{C}}_{1, \mathrm{t}-1} & \ldots & \overline{\mathrm{C}}_{\mathrm{N}, \mathrm{t}-1}\end{array}\right), \mathrm{X}_{\mathrm{EV}, \mathrm{t}-1}=\left(\begin{array}{ccc}1 & \ldots & 1 \\ \widehat{\beta}_{\mathrm{EV}, \mathrm{i}, \mathrm{t}-1} & \ldots & \widehat{\beta}_{\mathrm{EV}, \mathrm{N}, \mathrm{t}-1} \\ \overline{\mathrm{C}}_{1, \mathrm{t}-1} & \ldots & \overline{\mathrm{C}}_{\mathrm{N}, \mathrm{t}-1}\end{array}\right)$

$\overline{\mathrm{r}}_{\mathrm{t}}=\left[\overline{\mathrm{r}}_{1, \mathrm{t}}, \cdots, \overline{\mathrm{r}}_{\mathrm{N}, \mathrm{t}}\right], \overline{\mathrm{r}}_{\mathrm{i}, \mathrm{t}}=\frac{1}{\mathrm{~T}_{\mathrm{m}}} \sum_{\tau=0}^{\mathrm{T}_{\mathrm{m}}-1} \mathrm{r}_{\mathrm{i}, \mathrm{t}+\tau}$, and $\overline{\mathrm{C}}_{\mathrm{i}, \mathrm{t}}=\frac{1}{\mathrm{~T}_{\mathrm{m}}} \sum_{\tau=1}^{\mathrm{T}_{\mathrm{m}}} \mathrm{C}_{\mathrm{i}, \mathrm{t}-\tau}$. The betas for both explanatory variable $\left(\widehat{\beta}_{\mathrm{EV}, \mathrm{i}, \mathrm{t}-1}\right)$ and instrumental variable $\left(\widehat{\beta}_{\mathrm{IV}, \mathrm{i}, \mathrm{t}-1}\right)$ are estimated from past data. We refer to

${ }^{24}$ The parameters in Eq. (22) are determined as $\gamma_{\alpha}=\left(\gamma_{0}+\gamma \theta\right)-\gamma\left(\mathrm{a}+\mathrm{bC}_{\mathrm{i}, \mathrm{t}-2}+\delta_{\mathrm{i}, \mathrm{t}-1}\right), \gamma_{\beta}=\gamma \rho$ and $\gamma_{\mathrm{C}}=\gamma$. 
the risk premium estimator based on the time-series average of Eq. (23) as the IV mean-estimator. Proof: See Appendix $C$.

For ease of exposition, we present Proposition 2 only for the CAPM, assuming that both beta and characteristic follow AR(1) processes. The proposition also holds for multifactor models when we allow for time-varying risk premiums, and for betas and characteristics to follow any stationary and ergodic processes. We present the proposition and proof for the general case in Appendix G of Online Appendix.

The IV mean-estimator in Proposition 2 differs from the previous IV estimator in Eq. (4) in two important ways. First, the IV mean-estimator uses characteristics as well as $\widehat{\beta}_{\mathrm{IV}, \mathrm{i}, \mathrm{t}-1}$ as instruments for $\widehat{\beta}_{\mathrm{EV}, \mathrm{i}, \mathrm{t}-1}$. In contrast, our previous IV estimator uses characteristics only as control variables. Second, the IV mean-estimator uses the time-series averages of current (in month t) and future returns as the dependent variable, and past betas and time-series averages of characteristics as independent variables, while our previous IV estimator uses returns in month $t$ as the dependent variable and past betas and one-month lagged characteristics as independent variables.

Intuitively, the IV mean-estimator increases the time lag between the observations of the characteristics and those of future returns. For example, if we employ a characteristic averaged over the past 12 months as an independent variable and the average return over the next 12 months as dependent variable, the time lag between the two variables is on average 12 months. As we increase the time lag between independent and dependent variables, under the null hypothesis that expected returns are associated with characteristics indirectly through betas, the informational advantage of the characteristics over beta estimates diminishes and disappears in the limit.

In the additional simulations that we report in Appendix $\mathrm{C}$, we examine the small sample properties of the IV mean-estimator in Proposition 2. For the IV mean-estimator, we find that the ex-ante biases of the slope coefficients on betas range from $-6.5 \%$ to $-4.5 \%$ and the biases of the slope coefficients on characteristics are virtually zero under the CAPM and Fama-French threefactor model. In contrast, for the OLS estimator, the biases of the slope coefficients on betas range from $-67.6 \%$ to $-29.1 \%$ and those on characteristics range from $4.1 \%$ to $18.1 \%$, which indicates that the IV mean-estimates of the slope coefficients on betas and characteristics are substantially less biased than their corresponding OLS estimates. We also investigate the size and power of the asset pricing tests based on the IV mean-estimator. The size of this IV test is close to its theoretical 
percentile. Under the CAPM, the power of the IV test to detect a positive market risk premium is virtually $100 \%$. Under the Fama-French three-factor model, the power of the IV test to detect positive market, SMB, or HML risk premium is also close to $100 \%$.

We fit the following cross-sectional regression in month $t$ to obtain the IV mean-estimates of risk premiums for all the models that we examined above:

$$
\overline{\mathrm{r}}_{\mathrm{i}, \mathrm{t}}=\gamma_{0, \mathrm{t}}+\sum_{\mathrm{k}=1}^{\mathrm{K}} \gamma_{\mathrm{k}, \mathrm{t}} \widehat{\beta}_{\mathrm{i}, \mathrm{k}, \mathrm{t}-1}+\sum_{\mathrm{j}=1}^{\mathrm{J}} \delta_{\mathrm{j}, \mathrm{t}} \overline{\mathrm{C}}_{\mathrm{i}, \mathrm{j}, \mathrm{t}-1}+\xi_{\mathrm{i}, \mathrm{t}}
$$

where $\bar{r}_{i, t}$ is the average return over the period from month to month $t+11$ and the betas used as independent and instrumental are estimated over the past 36 months as we did earlier. $\overline{\mathrm{C}}_{\mathrm{j}, \mathrm{i}, \mathrm{t}-1}$ denotes the average on characteristic $\mathrm{j}$ over the past 12 months. Table 10 reports the time-series averages of monthly slope coefficients of betas and characteristics. Because the dependent variable in Eq. (25) is the average return over the current and future twelve months (columns labelled as $\mathrm{T}_{\mathrm{m}}=12$ ), we use the Hansen and Hodrick standard errors with 12 lags. For comparison, Table 10 also reports the results of asset pricing tests when we use one-month returns as the dependent variable and the characteristics in month t-1 as control variables. Unlike the earlier tests, we now use characteristics as instruments as well.

The results in Table 10 are similar to those in the corresponding tables that use characteristics only as control variables. Specifically, we find that none of the factor risk premiums is significant when we use one- or 12-month average returns as dependent variables. Most of the characteristics remain statistically significant, although the effects of some characteristics become weaker than before because we also use them as instruments now. We also find similar results when we use average returns over 24 or 26 months as dependent variables. Therefore, the test results based on the IV mean-estimator do not support the hypothesis that the slope coefficients of characteristics are significant because they are better proxies for true future betas than past betas.

\subsection{Robustness with Respect to Changes in Beta Estimation Procedure}

We carry out a number of tests to examine the robustness of our asset pricing results to changes in how we estimate betas. For the IV estimator, the test results that we report so far employ 36-month estimation windows to obtain betas (i.e., 18 months each for independent and instrumental betas). We also experiment with increasing this estimation interval to 48 and 60 months. In addition, we employ alternate quarters instead of alternate months to estimate betas 
used as independent and instrumental variables. In all these experiments, we find qualitatively similar results to those we report earlier.

We also carry out the following additional experiments to examine whether our test results are sensitive to the changes in the Dimson-type corrections for betas: (i) increase the number of daily lags up to five days and (ii) use weekly returns to estimate independent and instrumental betas and allow for up to five weeks of lagged returns. ${ }^{25} \mathrm{With}$ all of these experiments, we find qualitatively similar test results.

\subsection{On the Strength of Instrumental Variables}

An important issue to consider in IV regressions is the strength of the relation between the instruments and the corresponding independent variables. The cross-product matrix of instrumental variables and independent variables could be close to being singular if the correlations between independent and instrumental variables are too small, i.e., if the instruments are too weak. Nelson and Startz (1990) show that if the instruments are sufficiently weak, then the expected value of the IV estimator may not exist. A univariate regression with a weak instrument can provide the intuition behind this result. If the covariance between the independent and instrumental variables is close to zero, then the sample covariance could be small and be either negative or positive, resulting in large variations in both the sign and magnitude of the slope coefficients of IV regressions in finite samples. However, if the covariance and the number of samples are sufficiently large, then the probability that the sample covariance is close to zero becomes negligibly small, and the IV estimator is well behaved.

Nelson and Startz (1990) show that weak instruments would be a concern if

$$
\frac{1}{\hat{\rho}_{\mathrm{xz}}^{2}} \gg \mathrm{N},
$$

where $\hat{\rho}_{\mathrm{xz}}$ is the correlation between the independent variable (x) and the corresponding instrument (z), and $\mathrm{N}$ is the number of individual stocks. Our sample in Section 4.2 is comprised of 2,425 stocks per month on average and the minimum number of stocks in any month is 309 . Inequality (26) indicates that with 309 stocks, weak instrument problem would be a concern for $\hat{\rho}_{\mathrm{xz}}<.057$ in absolute value.

Table 11 presents the average cross-sectional correlations between the odd- and even-month

\footnotetext{
${ }^{25}$ We use rolling windows of past 260 weeks (about five years) to estimate these betas.
} 
beta estimates for all asset pricing models that we test. The correlation for market beta under the CAPM is .72. The market beta of the Fama-French three-factor (five-factor) model is less precisely estimated, and its average correlation is smaller at .59 (.43). The market beta in the q-factor asset pricing model by HXZ and the net beta under the LCAPM also exhibit similar levels of average cross-sectional correlation to that of the market beta under the Fama-French three-factor model. The average correlations for SMB, HML, RMW, CMA, I/A, and ROE betas range from .13 to .49. Although these correlations are smaller than those for market betas, they are all bigger than the critical value suggested by Nelson and Startz (1990).

To provide further insights into the strength of the instruments in our IV method, we also estimate the cross-sectional correlations between the instruments and the corresponding true but unobservable betas. Although the true betas are unobservable, we can estimate these correlations based on the correlations between odd- and even-month betas as we show in the following proposition:

Proposition 3: Let $\beta_{\mathrm{i}, \mathrm{k}}$ be stock i's true but unobservable sensitivity to factor $\mathrm{k}$ and let $\widehat{\beta}_{\mathrm{odd}, \mathrm{i}, \mathrm{k}}$ and $\widehat{\beta}_{\text {even,i,k }}$ be the odd-and even-month estimates of the true beta, respectively. Then we can show that

$$
\begin{aligned}
& \operatorname{correlation}\left(\beta_{\mathrm{i}, \mathrm{k}}, \hat{\beta}_{\text {even, }, \mathrm{i}, \mathrm{k}}\right)=\operatorname{correlation}\left(\beta_{\mathrm{i}, \mathrm{k}}, \hat{\beta}_{\text {odd }, \mathrm{i}, \mathrm{k}}\right) \\
& =\sqrt{\operatorname{correlation}\left(\hat{\beta}_{\text {odd }, \mathrm{i}, \mathrm{k}}, \hat{\beta}_{\text {even }, \mathrm{i}, \mathrm{k}}\right)}
\end{aligned}
$$

\section{Proof: See Appendix D.}

Table 11 also presents the average cross-sectional correlations between estimated betas and true but unobservable betas. ${ }^{26}$ Under the CAPM, the average correlation between estimated market betas and unobserved true market betas is .85. Under the Fama-French three- and five-factor models, we find smaller correlations for SMB, HML, RMW, and CMA betas, but even for CMA, the average correlation between estimated CMA betas and unobservable true CMA betas is .36. Under the q-factor asset pricing model, the correlations for the investment and ROE betas are about the same as that for the HML beta under the Fama-French five-factor model.

\footnotetext{
${ }^{26}$ To compute the average correlation between estimated betas and true betas, we first compute the square root of the correlation between odd- and even-month betas each month and then compute the average across months. Because the variability of correlation between odd- and even-month betas is relatively small, the square root of average correlation is about the same as the average of the square root of the monthly correlations.
} 


\section{Conclusion}

We propose a method for estimating risk premiums using individual stocks as test assets. It overcomes concerns about risk premiums estimated with test portfolios, which have been employed in almost all previous researches to mitigate an inherent errors-in-variables problem in testing asset pricing models. Estimated betas from one sample period can serve as effective instruments for estimated betas from a disjoint sample period that serve as the explanatory variables in cross-sectional regressions. We prove the consistency of the proposed IV risk premium estimator when the number of individual stocks grows without bounds under various specifications for betas and characteristics. In simulations, our IV method yields risk premium estimates close to true parameters even for relatively short time-series and also provides valid tests for statistical inference.

We use this IV method to test whether the premiums for risk factors proposed by several popular asset pricing models are reliably different from zero. The asset pricing models we test are the standard CAPM, the Fama-French three- and five-factor models, the q-factor asset pricing model proposed by Hou, Xue, and Zhang (2015), and the liquidity-adjusted CAPM proposed by Acharya and Pedersen (2005). Previous empirical research use portfolios as tests assets and find strong empirical support for these asset pricing models. But Lewellen, Nagel, and Shanken (2010) suggest caution in interpreting those results because of the low dimensionality issue with portfolios as test assets. We find that when we use individual stocks as test assets, none of the factors from those asset pricing models is associated with a significant risk premium after controlling for corresponding firm characteristics. The evidence in simulations and empirical analyses indicates that this empirical failure is unlikely to be due to the lack of test power, so it represents a puzzle that calls for further research. 
Figure 1

\section{Biases versus Number of Days Used to Estimate Betas}

This figure presents the ex-ante and ex-post biases using the ordinary least squares (OLS) and instrumental variables (IV) estimators of the market risk premium under the CAPM, as a function of the number of days in the rolling window to estimate the market betas. The simulations use the market risk premium of $5.80 \%$ per annum and 2000 individual stocks in the cross-section. The sample period for the simulations is 684 months. The y-axis is bias as a percentage of the true market risk premium, and the $\mathrm{x}$-axis is the number of days in the rolling window to estimate the market betas. These results are based on 1,000 repetitions for each estimation window.

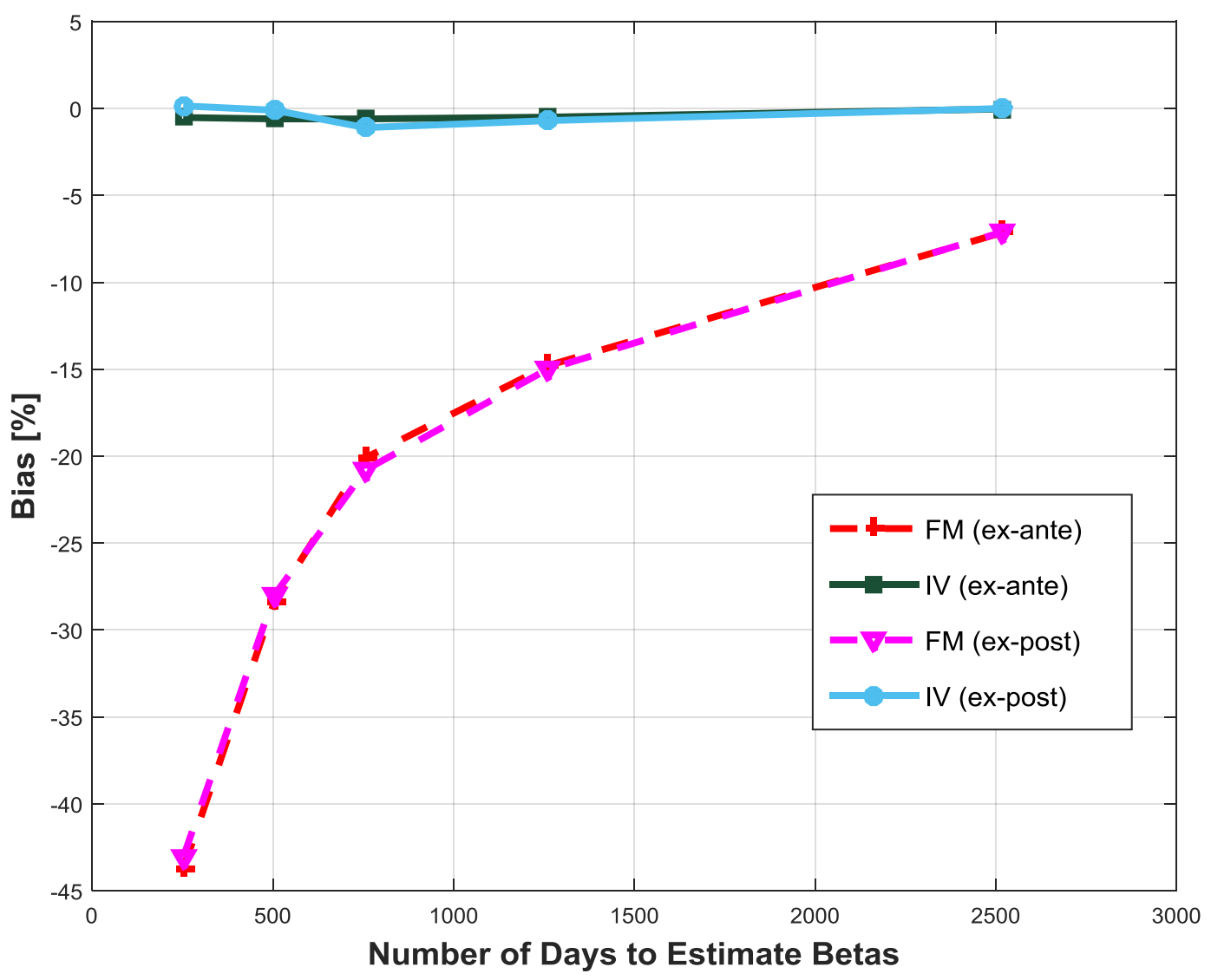


Figure 2

\section{Power of IV and OLS Tests for Varying Levels of Market Risk Premium}

This figure presents the power of tests using the ordinary least squares (OLS) and instrumental variables (IV) estimators as a function of the market risk premium. The simulations use 2000 individual stocks in the cross-section and the sample period is 684 months. For each month, rolling betas are estimated using daily return data over the previous 36 months, with data over 18 months to estimate the independent variables (betas) and data over the other separate sample of 18 months to estimate the corresponding instrumental variables. The power of a test denotes the rejection frequency of the null hypothesis based on 1,000 repetitions. The market risk premiums are in percent per annum.

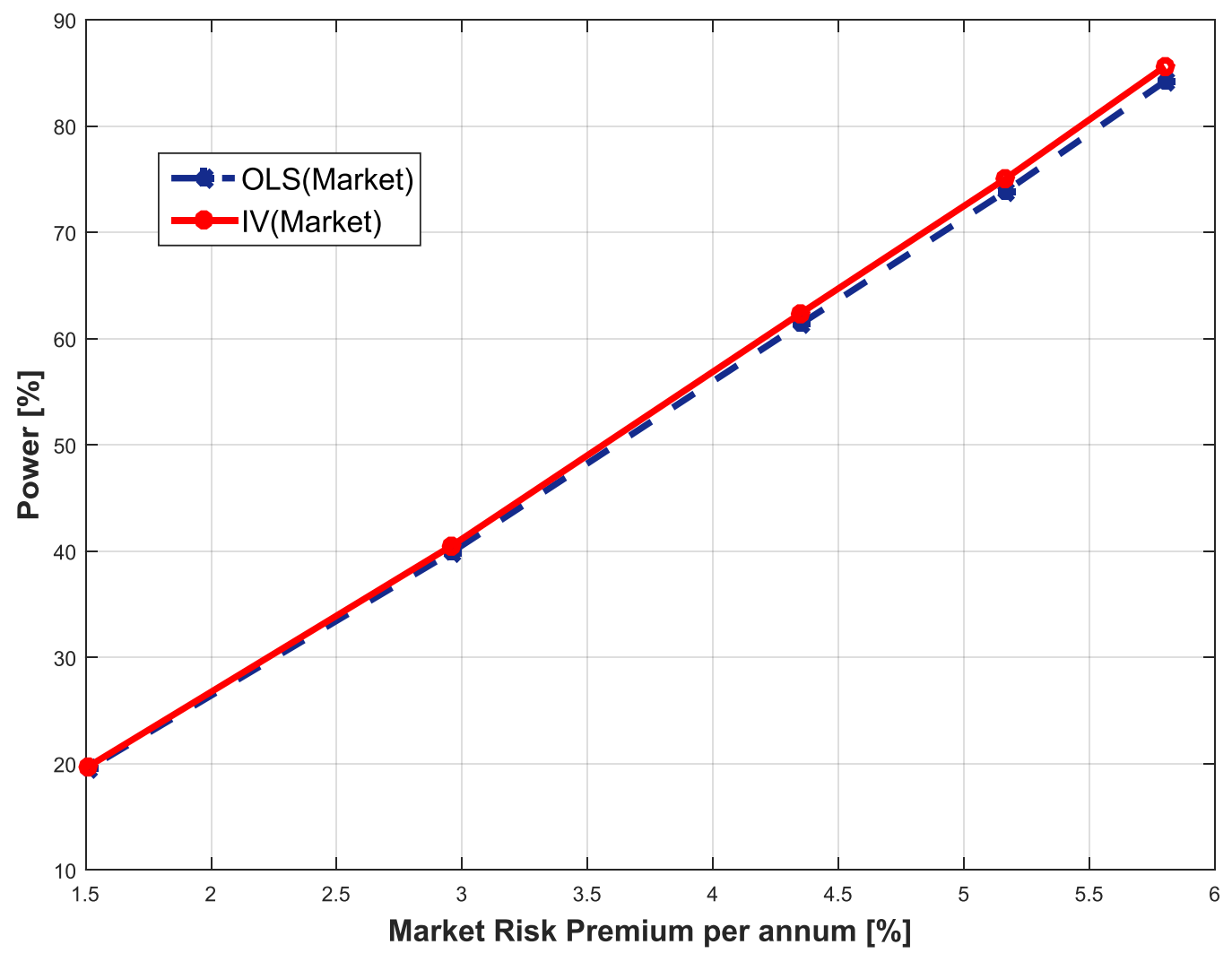




\section{Table 1}

\section{Simulation Parameters}

This table presents the parameters that are used in the simulations. We set the risk premiums of the common factors and their covariance structure in the simulations equal to the corresponding sample values during the sample period of January, 1956 through December, 2012. We maintain the historical covariances among the common factors under the Fama-French three-factor model. The means and standard deviations of the common factors and idiosyncratic volatility are annualized and reported in percentages.

Panel A: Common Factors

\begin{tabular}{|c|c|c|c|c|c|}
\hline & & \multicolumn{2}{|c|}{ Single-factor CAPM } & \multicolumn{2}{|c|}{$\begin{array}{c}\text { Fama-French } \\
\text { Three-factor Model }\end{array}$} \\
\hline & & Mean & Std. Dev. & Mean & Std. Dev. \\
\hline \multirow[t]{3}{*}{ Factors } & MKT & 5.80 & 15.33 & 5.80 & 15.33 \\
\hline & SMB & & & 2.64 & 7.89 \\
\hline & HML & & & 4.36 & 7.56 \\
\hline
\end{tabular}

Panel B: Betas and Idiosyncratic Volatility

\begin{tabular}{|c|c|c|c|c|c|}
\hline & & \multicolumn{2}{|c|}{ Single-factor CAPM } & \multicolumn{2}{|c|}{$\begin{array}{c}\text { Fama-French } \\
\text { Three-factor Model }\end{array}$} \\
\hline & & Mean & Std. Dev. & Mean & Std. Dev \\
\hline \multirow[t]{3}{*}{ Betas } & MKT & 0.95 & 0.42 & 0.95 & 0.42 \\
\hline & SMB & & & 0.80 & 0.50 \\
\hline & HML & & & 0.19 & 0.51 \\
\hline $\begin{array}{l}\text { Idiosyncratic } \\
\text { Volatility }\end{array}$ & & 58.73 & 23.81 & 58.73 & 23.81 \\
\hline
\end{tabular}




\section{Table 2 \\ Small Sample Properties of IV Risk Premium Estimates}

Panel A presents the biases and root-mean-squared errors (RMSEs) of risk premium estimates when the second-stage regressions are fitted using the OLS and Instrumental Variable (IV) methods under the single-factor CAPM. Panel B presents those results under the Fama-French three-factor model. The simulation uses 2000 stocks in the cross-section, and the results are based on 1,000 repetitions. The sample period for the simulations is 684 months. For each month, rolling betas are estimated using daily return data over the previous 36 months. Betas used as independent and instrumental variables are estimated over two disjoint 18-month periods within each 36-month rolling window. Ex-ante bias is the difference between the mean risk premium estimate and the corresponding true risk premium. Ex-post bias is the difference between the mean risk premium estimate and the sample mean of the corresponding risk factor realizations in that particular simulation. Ex-ante and ex-post biases are expressed as percentages of the true risk premiums.

Panel A: Single-factor CAPM

\begin{tabular}{cccccc}
\hline Risk & \multirow{2}{*}{ Estimator } & Ex-ante & Ex-post & Ex-ante & Ex-post \\
Factor & Bias (\%) & Bias (\%) & RMSE & RMSE \\
\hline \multirow{2}{*}{ MKT } & OLS & -20.1 & -20.8 & 0.184 & 0.125 \\
& IV & -0.6 & -1.1 & 0.174 & 0.080 \\
\hline
\end{tabular}

Panel B: Fama-French Three-factor Model

\begin{tabular}{cccccc}
\hline $\begin{array}{c}\text { Risk } \\
\text { Factor }\end{array}$ & \multirow{2}{*}{ Estimator } & $\begin{array}{c}\text { Ex-ante } \\
\text { Bias (\%) }\end{array}$ & $\begin{array}{c}\text { Ex-post } \\
\text { Bias (\%) }\end{array}$ & $\begin{array}{c}\text { Ex-ante } \\
\text { RMSE }\end{array}$ & $\begin{array}{c}\text { Ex-post } \\
\text { RMSE }\end{array}$ \\
\hline \multirow{2}{*}{ MKT } & OLS & -28.7 & -29.4 & 0.199 & 0.158 \\
& IV & 1.2 & 0.5 & 0.189 & 0.084 \\
\hline \multirow{2}{*}{ SMB } & OLS & -54.4 & -55.2 & 0.136 & 0.135 \\
& IV & -1.4 & -2.1 & 0.126 & 0.096 \\
\hline HML & OLS & -50.6 & -51.2 & 0.194 & 0.193 \\
& IV & 1.6 & 1.0 & 0.124 & 0.092 \\
\hline
\end{tabular}




\section{Table 3 \\ Size and Power of the IV Test}

Panel A presents the sizes of the OLS and IV tests under the null hypotheses that the risk premiums equal zero for the CAPM and the Fama-French three-factor model. The t-statistics are computed using Fama-MacBeth standard errors. The simulation uses 2000 stocks and length of the sample period is 684 months. For each month, rolling betas are estimated using daily return data over the previous 36 months. Betas used as independent and instrumental variables are estimated over two disjoint 18-month periods within each 36-month rolling window. The results are based on 1,000 repetitions. Panel B presents the power of the OLS and IV tests to reject the null hypothesis when we set the market (MKT) risk premium equal to $5.80 \%$ per annum for the single-factor CAPM and when we set the MKT, SMB and HML risk premiums equal to $5.80 \%, 2.64 \%$ and $4.36 \%$ per annum, respectively, for the Fama-French three-factor model. Panel B presents the percentage of simulations that reject the null hypothesis that the respective factor risk premium is less than or equal to zero at the 5\% significance level. The row labeled "MKT or SMB or HML" presents the percentage of 1,000 repetitions that reject the null hypothesis that all of the risk premiums are less than or equal to zero at the $5 \%$ significance level.

Panel A: Test Size

\begin{tabular}{ccccccc}
\hline Risk & Test & \multicolumn{5}{c}{ Theoretical Percentiles } \\
Factor & Based on & $1 \%$ & $2.5 \%$ & $5 \%$ & $7.5 \%$ & $10 \%$ \\
\hline \multirow{5}{*}{ MKT } & OLS & $1.5 \%$ & $2.9 \%$ & $4.9 \%$ & $8.0 \%$ & $10.5 \%$ \\
& IV & $1.3 \%$ & $2.8 \%$ & $5.1 \%$ & $7.6 \%$ & $10.2 \%$ \\
\hline \multirow{6}{*}{ MKT } & OLS & $1.5 \%$ & $2.8 \%$ & $5.2 \%$ & $8.0 \%$ & $10.5 \%$ \\
& IV & $1.3 \%$ & $2.4 \%$ & $5.2 \%$ & $7.3 \%$ & $9.8 \%$ \\
HML & OLS & $1.7 \%$ & $2.2 \%$ & $5.1 \%$ & $8.0 \%$ & $10.4 \%$ \\
& IV & $1.3 \%$ & $2.7 \%$ & $5.2 \%$ & $7.8 \%$ & $9.9 \%$ \\
SMB & OLS & $1.6 \%$ & $2.9 \%$ & $4.8 \%$ & $7.9 \%$ & $10.3 \%$ \\
& IV & $1.1 \%$ & $2.7 \%$ & $5.0 \%$ & $7.7 \%$ & $10.2 \%$ \\
\hline
\end{tabular}


Panel B: Test Power

\begin{tabular}{ccc}
\hline Risk & \multicolumn{2}{c}{ Test Based on } \\
Factor & OLS & IV \\
\hline \multicolumn{3}{c}{ Single-factor CAPM } \\
\hline MKT & $84.2 \%$ & $85.6 \%$ \\
\hline MKT & Fama-French Three-factor Model \\
SMB & $78.7 \%$ & $83.8 \%$ \\
HML & $47.3 \%$ & $51.8 \%$ \\
MKT or SMB or HML & $89.0 \%$ & $91.5 \%$ \\
\hline
\end{tabular}


Table 4

Summary Statistics

This table presents the sample summary statistics. Capitalization is price multiplied by the number of shares outstanding. Book-to-market ratio is computed as in Davis et al. (2000). Excess return is computed relative to the one-month T-bill rate. Return volatility is the standard deviation of monthly returns. To obtain the summary statistics for capitalization, book-to-market ratio, and excess returns, we first compute the time-series average for each stock and then calculate the crosssectional statistics across stocks. The sample period is from January, 1956 through December, 2012.

\begin{tabular}{lccccc}
\hline & Mean & Median & Standard Deviation & Q1 & Q3 \\
\hline Number of stocks per month & 2,425 & 2,903 & 1,286 & 1,456 & 3,390 \\
Capitalization, \$ billion & 0.876 & 0.094 & 4.718 & 0.028 & 0.383 \\
Book-to-market ratio & 0.854 & 0.719 & 0.661 & 0.425 & 1.089 \\
Excess return (\%) & 0.535 & 0.856 & 5.610 & -0.201 & 1.770 \\
Return volatility (\%) & 3.140 & 1.941 & 6.366 & 1.018 & 3.408 \\
\hline
\end{tabular}




\section{Table 5 \\ Correlations Among Estimated Betas and SIZE and Book-to-Market Characteristics}

This table presents the average cross-sectional correlations among betas, SIZE, and BM. Betas are estimated for each month using daily returns data from the previous 36 months. SIZE is the natural logarithm of market capitalization and BM is the book-to-market ratio. Panel A reports the correlations under the CAPM and Panels B and C report the correlations under the Fama-French three-factor model. The sample period is from January, 1956 through December, 2012.

Panel A: Single-factor CAPM

\begin{tabular}{cccc}
\hline & & SIZE & BM \\
\hline Individual Stocks & MKT & -0.20 & -0.24 \\
25 Fama-French & MKT & -0.56 & -0.44 \\
\hline \begin{tabular}{l} 
portfolios \\
\hline
\end{tabular}
\end{tabular}

Panel B: Fama-French Three-factor Model: Individual Stocks

\begin{tabular}{cccccc}
\hline & MKT & SMB & HML & SIZE & BM \\
\hline MKT & 1 & & & & \\
SMB & 0.34 & 1 & & & \\
HML & 0.10 & 0.14 & 1 & & \\
SIZE & 0.18 & -0.45 & -0.13 & 1 & \\
BM & -0.13 & 0.06 & 0.29 & -0.34 & 1 \\
\hline
\end{tabular}

Panel C: Fama-French Three-factor Model: 25 SIZE and BM sorted Portfolios

\begin{tabular}{cccccc}
\hline & MKT & SMB & HML & SIZE & BM \\
\hline MKT & 1 & & & & \\
SMB & -0.08 & 1 & & & \\
HML & -0.08 & -0.15 & 1 & & \\
SIZE & 0.19 & -0.97 & -0.01 & 1 & \\
BM & 0.07 & -0.03 & 0.88 & -0.08 & 1 \\
\hline
\end{tabular}


Table 6

\section{Risk Premium Estimates with Individual Stocks:} CAPM and Fama-French Three-factor Model

This table reports risk premium estimates, in percent per month, and their tests using individual stocks as test assets. Panel A reports the test results using the IV method in Columns (1) to (5) and those using the OLS method in Columns (6) to (10) for comparison. Panels B and C report the asset pricing test results using the IV method for two subperiods. Rows labeled MKT, SMB, and HML are the risk premiums for the market, SMB and HML factors, respectively, and the corresponding t-statistics are in parentheses (bold if significant at the 5\% level). SIZE is the natural logarithm of market capitalization. BM is the book-to-market ratio at the end of the previous month and $\log \mathrm{BM}$ is the natural logarithm of BM. Betas for each month are estimated using daily returns data over the previous 36 months and cross-sectional regressions are fitted using the IV and OLS methods. The sample period is from January, 1956 through December, 2012. $\mathrm{N}$ is the average number of stocks in monthly cross-sectional regressions.

\begin{tabular}{|c|c|c|c|c|c|c|c|c|c|c|}
\hline & 1) & (2) & (3) & (4) & (5) & $(6)$ & $(7)$ & $(8)$ & (9) & $(10)$ \\
\hline & \multicolumn{10}{|c|}{ Panel A: 1956-2012, N=2425 } \\
\hline \multicolumn{6}{|c|}{ IV } & \multicolumn{5}{|c|}{ OLS } \\
\hline Const & $\begin{array}{l}1.028 \\
(7.89)\end{array}$ & $\begin{array}{l}\mathbf{0 . 7 2 5} \\
(6.00)\end{array}$ & $\begin{array}{l}2.906 \\
(4.31)\end{array}$ & $\begin{array}{l}2.729 \\
(4.55)\end{array}$ & $\begin{array}{l}3.007 \\
(4.92)\end{array}$ & $\begin{array}{l}\mathbf{0 . 9 5 1} \\
(7.41)\end{array}$ & $\begin{array}{l}\mathbf{0 . 8 4 7} \\
(7.51)\end{array}$ & $\begin{array}{l}3.301 \\
(4.49)\end{array}$ & $\begin{array}{l}3.538 \\
(5.66)\end{array}$ & $\begin{array}{l}3.695 \\
(5.78)\end{array}$ \\
\hline MKT & -0.246 & -0.288 & -0.090 & -0.018 & 0.019 & -0.101 & -0.196 & 0.076 & 0.120 & 0.130 \\
\hline SMB & $(-1.50)$ & $\begin{array}{c}(-1.60) \\
\mathbf{0 . 3 0 1} \\
(\mathbf{2 . 2 0})\end{array}$ & $(-0.31)$ & $\begin{array}{l}(-0.10) \\
-0.043 \\
(-0.42)\end{array}$ & $\begin{array}{c}(0.11) \\
-0.019 \\
(-0.19)\end{array}$ & & $\begin{array}{c}(-1.46) \\
0.213 \\
(2.16)\end{array}$ & $(0.44)$ & $\begin{array}{c}(0.83) \\
-0.073 \\
(-1.01)\end{array}$ & $\begin{array}{c}(0.91) \\
-0.064 \\
(-0.90)\end{array}$ \\
\hline HML & & $\begin{array}{l}0.344 \\
(2.55)\end{array}$ & & $\begin{array}{c}0.242 \\
(1.88)\end{array}$ & $\begin{array}{l}0.185 \\
(1.46)\end{array}$ & & $\begin{array}{l}0.225 \\
(2.79)\end{array}$ & & $\begin{array}{l}0.136 \\
(1.73)\end{array}$ & $\begin{array}{l}0.124 \\
(1.64)\end{array}$ \\
\hline SIZE & & & $\begin{array}{c}-0.120 \\
(-3.49)\end{array}$ & $\begin{array}{c}-0.118 \\
(-3.93)\end{array}$ & $\begin{array}{l}-0.122 \\
(-3.94)\end{array}$ & & & $\begin{array}{c}-0.143 \\
(-3.84)\end{array}$ & $\begin{array}{l}-0.155 \\
(-4.93)\end{array}$ & $\begin{array}{l}-0.155 \\
(-4.81)\end{array}$ \\
\hline $\mathrm{BM}$ & & & $\begin{array}{l}0.196 \\
(4.40)\end{array}$ & $\begin{array}{l}0.180 \\
(4.50)\end{array}$ & & & & $\begin{array}{l}0.186 \\
(4.25)\end{array}$ & $\begin{array}{l}0.141 \\
(3.60)\end{array}$ & \\
\hline $\log B M$ & & & & & $\begin{array}{l}\mathbf{0 . 1 7 7} \\
(4.31)\end{array}$ & & & & & $\begin{array}{l}\mathbf{0 . 1 3 3} \\
(\mathbf{3 . 3 2})\end{array}$ \\
\hline
\end{tabular}

\begin{tabular}{|c|c|c|c|c|c|c|c|c|}
\hline \multirow[b]{3}{*}{ Const } & \multicolumn{8}{|c|}{ Panel B: 1956-1985, N=1379 } \\
\hline & \multicolumn{4}{|c|}{ IV } & \multicolumn{4}{|c|}{ OLS } \\
\hline & $\begin{array}{l}1.242 \\
(6.62)\end{array}$ & $\begin{array}{l}0.720 \\
(4.06)\end{array}$ & $\begin{array}{l}3.341 \\
(3.30)\end{array}$ & $\begin{array}{l}3.088 \\
(3.36)\end{array}$ & $\begin{array}{c}1.078 \\
(5.91)\end{array}$ & $\begin{array}{l}\mathbf{0 . 8 9 1} \\
(5.63)\end{array}$ & $\begin{array}{l}3.285 \\
(3.23)\end{array}$ & $\begin{array}{l}3.343 \\
(3.99)\end{array}$ \\
\hline MKT & $\begin{array}{l}-0.410 \\
(-1.78)\end{array}$ & $\begin{array}{l}-0.399 \\
(-1.69)\end{array}$ & $\begin{array}{l}-0.200 \\
(-0.87)\end{array}$ & $\begin{array}{l}-0.055 \\
(-0.23)\end{array}$ & $\begin{array}{l}-0.268 \\
(-1.38)\end{array}$ & $\begin{array}{l}-0.319 \\
(-1.81)\end{array}$ & $\begin{array}{l}-0.134 \\
(-0.69)\end{array}$ & $\begin{array}{l}-0.076 \\
(-0.42)\end{array}$ \\
\hline SMB & & $\begin{array}{l}0.447 \\
(2.19)\end{array}$ & & $\begin{array}{l}0.095 \\
(0.67)\end{array}$ & & $\begin{array}{l}0.264 \\
(2.05)\end{array}$ & & $\begin{array}{l}-0.028 \\
(-0.34)\end{array}$ \\
\hline HML & & $\begin{array}{l}0.400 \\
(2.03)\end{array}$ & & $\begin{array}{l}0.257 \\
(1.41)\end{array}$ & & $\begin{array}{l}0.328 \\
(3.70)\end{array}$ & & $\begin{array}{l}0.185 \\
(2.28)\end{array}$ \\
\hline SIZE & & & $\begin{array}{l}-0.139 \\
(-2.67)\end{array}$ & $\begin{array}{l}-0.139 \\
(-2.98)\end{array}$ & & & $\begin{array}{l}-0.140 \\
(-2.72)\end{array}$ & $\begin{array}{l}-0.148 \\
(-3.41)\end{array}$ \\
\hline $\mathrm{BM}$ & & & $\begin{array}{l}0.230 \\
(3.44)\end{array}$ & $\begin{array}{l}\mathbf{0 . 2 0 7} \\
(\mathbf{3 . 3 3})\end{array}$ & & & $\begin{array}{l}0.229 \\
(3.46)\end{array}$ & $\begin{array}{l}0.172 \\
(2.82)\end{array}$ \\
\hline
\end{tabular}




\begin{tabular}{|c|c|c|c|c|c|c|c|c|}
\hline \multirow[b]{3}{*}{ Const } & & \multicolumn{7}{|c|}{ Panel C: 1986 to $2012, \mathrm{~N}=3583$} \\
\hline & \multicolumn{4}{|c|}{ IV } & \multicolumn{4}{|c|}{ OLS } \\
\hline & 0.853 & 0.712 & 2.320 & 2.558 & 0.854 & 0.813 & 3.084 & 3.623 \\
\hline & (4.97) & (4.37) & (2.74) & (3.26) & (4.89) & (4.57) & (2.97) & (3.97) \\
\hline \multirow[t]{2}{*}{ MKT } & -0.084 & -0.129 & 0.060 & 0.142 & 0.063 & -0.060 & 0.249 & 0.335 \\
\hline & $(-0.32)$ & $(-0.47)$ & $(0.21)$ & $(0.56)$ & $(0.26)$ & $(-0.29)$ & $(0.88)$ & $(1.45)$ \\
\hline \multirow[t]{2}{*}{ SMB } & & 0.116 & & -0.216 & & 0.157 & & -0.124 \\
\hline & & $(0.57)$ & & $(-1.42)$ & & $(1.04)$ & & $(-1.03)$ \\
\hline \multirow[t]{2}{*}{ HML } & & 0.331 & & 0.264 & & 0.114 & & 0.085 \\
\hline & & $(1.71)$ & & $(1.44)$ & & $(0.80)$ & & $(0.61)$ \\
\hline \multirow[t]{2}{*}{ SIZE } & & & -0.091 & -0.108 & & & -0.131 & -0.161 \\
\hline & & & $(-2.15)$ & $(-2.77)$ & & & $(-2.50)$ & $(-3.52)$ \\
\hline \multirow[t]{2}{*}{$\mathrm{BM}$} & & & 0.154 & 0.153 & & & 0.142 & 0.105 \\
\hline & & & $(\mathbf{2 . 7 5})$ & (3.14) & & & $(2.59)$ & $(\mathbf{2 . 2 3})$ \\
\hline
\end{tabular}




\section{Table 7}

\section{Risk Premium Estimates with Individual Stocks: Fama-French Five-factor Model}

This table reports risk premium estimates from the IV method, in percent per month, using individual stocks as test assets, and corresponding t-statistics in parentheses (bold if significant at the 5\% level). Rows labelled MKT, SMB, HML, RMW, and CMA are the risk premiums for the market, SMB, HML, RMW, and CMA factors, respectively. SIZE is the natural logarithm of market capitalization and BM is the book-to-market ratio at the end of the previous month. OP and INV are the operating profitability and investment/total asset, respectively. Betas for each month are estimated using daily returns data over the previous 36 months, and cross-sectional regressions are fitted using the IV method. The sample period is from January, 1967 through December, 2012. $\mathrm{N}$ is the average number of stocks in monthly cross-sectional regressions. Panel A reports the test results for the entire sample period, while Panels B and C report those for two subperiods.

\begin{tabular}{|c|c|c|c|c|c|c|}
\hline & (1) & (2) & (3) & (4) & (5) & (6) \\
\hline \multicolumn{7}{|c|}{ Panel A: 1967-2012, N=2811 } \\
\hline \multirow[t]{2}{*}{ Const } & 0.739 & 0.817 & 0.541 & 0.753 & 0.919 & 3.079 \\
\hline & (3.05) & (3.40) & $(1.92)$ & (2.97) & (3.90) & (4.19) \\
\hline \multirow[t]{2}{*}{ MKT } & & & -0.198 & & & 0.367 \\
\hline & & & $(-0.57)$ & & & $(1.06)$ \\
\hline \multirow[t]{2}{*}{ SMB } & & & 0.453 & & & -0.095 \\
\hline & & & $(1.85)$ & & & $(-0.50)$ \\
\hline \multirow[t]{2}{*}{ HML } & & & 0.766 & & & 0.354 \\
\hline & & & $(1.83)$ & & & $(0.87)$ \\
\hline \multirow[t]{2}{*}{ RMW } & 0.121 & & -0.237 & 0.207 & & -0.051 \\
\hline & $(0.59)$ & & $(-0.46)$ & $(1.07)$ & & $(-0.11)$ \\
\hline \multirow[t]{2}{*}{ CMA } & & 0.030 & 0.159 & & -0.043 & 0.049 \\
\hline & & $(0.13)$ & $(0.29)$ & & $(-0.18)$ & $(0.11)$ \\
\hline \multirow[t]{2}{*}{ SIZE } & & & & & & -0.153 \\
\hline & & & & & & $(-4.38)$ \\
\hline \multirow[t]{2}{*}{$\mathrm{BM}$} & & & & & & 0.178 \\
\hline & & & & & & (4.12) \\
\hline \multirow[t]{2}{*}{$\mathrm{OP}$} & & & & -0.001 & & 0.649 \\
\hline & & & & $(-0.00)$ & & $(6.10)$ \\
\hline \multirow[t]{2}{*}{ INV } & & & & & -0.963 & -0.709 \\
\hline & & & & & $(-6.62)$ & $(-9.25)$ \\
\hline
\end{tabular}




\begin{tabular}{|c|c|c|c|c|c|c|}
\hline \multicolumn{7}{|c|}{ Panel B: 1967-1988, N=1992 } \\
\hline \multirow[t]{2}{*}{ Const } & 0.640 & 0.767 & 0.304 & 0.692 & 0.894 & 2.670 \\
\hline & (1.69) & (2.04) & $(0.65)$ & $(1.73)$ & $(2.42)$ & (2.28) \\
\hline \multirow[t]{2}{*}{ MKT } & & & -0.213 & & & 0.217 \\
\hline & & & $(-0.41)$ & & & $(0.41)$ \\
\hline \multirow[t]{2}{*}{ SMB } & & & 0.496 & & & -0.097 \\
\hline & & & $(1.37)$ & & & $(-0.41)$ \\
\hline \multirow[t]{2}{*}{ HML } & & & 1.701 & & & 0.891 \\
\hline & & & $(2.90)$ & & & (1.63) \\
\hline \multirow[t]{2}{*}{ RMW } & 0.218 & & -0.910 & 0.142 & & -0.460 \\
\hline & $(0.66)$ & & $(-1.32)$ & $(0.45)$ & & $(-0.87)$ \\
\hline \multirow[t]{2}{*}{ CMA } & & 0.180 & 0.021 & & 0.123 & -0.084 \\
\hline & & $(0.42)$ & $(0.03)$ & & $(0.29)$ & $(-0.14)$ \\
\hline \multirow[t]{2}{*}{ SIZE } & & & & & & -0.149 \\
\hline & & & & & & $(-2.67)$ \\
\hline \multirow[t]{2}{*}{$\mathrm{BM}$} & & & & & & 0.291 \\
\hline & & & & & & (4.34) \\
\hline \multirow[t]{2}{*}{$\mathrm{OP}$} & & & & -0.186 & & 0.994 \\
\hline & & & & $(-0.64)$ & & $(5.36)$ \\
\hline \multirow[t]{2}{*}{ INV } & & & & & -1.197 & -0.909 \\
\hline & & & & & $(-4.39)$ & $(-6.65)$ \\
\hline \multicolumn{7}{|c|}{ Panel C: $1989-2012, \mathrm{~N}=3588$} \\
\hline \multirow[t]{2}{*}{ Const } & 0.845 & 0.903 & 0.770 & 0.793 & 0.979 & 3.434 \\
\hline & (2.79) & (3.01) & (2.38) & $(2.51)$ & (3.31) & (3.79) \\
\hline \multirow[t]{2}{*}{ MKT } & & & -0.200 & & & 0.513 \\
\hline & & & $(-0.44)$ & & & (1.11) \\
\hline \multirow[t]{2}{*}{ SMB } & & & 0.409 & & & -0.012 \\
\hline & & & $(1.23)$ & & & $(-0.04)$ \\
\hline \multirow[t]{2}{*}{ HML } & & & -0.123 & & & -0.395 \\
\hline & & & $(-0.21)$ & & & $(-0.63)$ \\
\hline \multirow[t]{2}{*}{ RMW } & 0.132 & & 0.396 & 0.081 & & 0.721 \\
\hline & $(0.45)$ & & $(0.52)$ & $(0.32)$ & & $(0.84)$ \\
\hline \multirow[t]{2}{*}{ CMA } & & -0.403 & 0.280 & & -0.300 & 0.294 \\
\hline & & $(-1.30)$ & $(0.37)$ & & $(-1.00)$ & $(0.42)$ \\
\hline \multirow[t]{2}{*}{ SIZE } & & & & & & -0.157 \\
\hline & & & & & & $(-3.70)$ \\
\hline \multirow[t]{2}{*}{$\mathrm{BM}$} & & & & & & 0.072 \\
\hline & & & & & & $(1.30)$ \\
\hline \multirow[t]{2}{*}{$\mathrm{OP}$} & & & & 0.147 & & 0.331 \\
\hline & & & & (1.03) & & (3.09) \\
\hline \multirow[t]{2}{*}{ INV } & & & & & -0.738 & -0.535 \\
\hline & & & & & $(-6.57)$ & $(-7.24)$ \\
\hline
\end{tabular}




\section{Table 8}

\section{Risk Premium Estimates with Individual Stocks: The q-factor Asset Pricing Model}

This table reports the risk premium estimates from the IV method, in percent per month, using individual stocks as test assets and the corresponding t-statistics in parentheses (bold if significant at the 5\% level). Rows labeled MKT, ME, I/A, and ROE report the risk premium estimates for the market, size, investment, and ROE factors, respectively. SIZE is the natural logarithm of market capitalization at the end of the previous month. OP and INV are the operating profitability and investment/total asset, respectively. Betas for each month are estimated using daily returns over the previous 36 months. The sample period is January, 1975 through December, 2012. N is the average number of stocks in monthly cross-sectional regressions.

\begin{tabular}{|c|c|c|c|c|c|c|c|c|}
\hline & (1) & (2) & (3) & (4) & (5) & (6) & (7) & (8) \\
\hline \multicolumn{9}{|c|}{ Panel A: $1975-2012, \mathrm{~N}=3162$} \\
\hline Const & $\begin{array}{l}1.206 \\
(8.30)\end{array}$ & $\begin{array}{c}0.893 \\
(5.00)\end{array}$ & $\begin{array}{l}\mathbf{0 . 9 0 7} \\
(\mathbf{4 . 0 3})\end{array}$ & $\begin{array}{l}\mathbf{0 . 8 9 0} \\
(4.01)\end{array}$ & $\begin{array}{r}\mathbf{0 . 8 5 6} \\
(3.68)\end{array}$ & $\begin{array}{l}1.120 \\
(4.56)\end{array}$ & $\begin{array}{l}\mathbf{0 . 8 0 9} \\
(3.55)\end{array}$ & $\begin{array}{l}4.268 \\
(5.39)\end{array}$ \\
\hline MKT & $\begin{array}{l}-0.061 \\
(-0.28)\end{array}$ & & & & $\begin{array}{l}-0.247 \\
(-0.86)\end{array}$ & & & $\begin{array}{l}0.437 \\
(1.20)\end{array}$ \\
\hline ME & & 0.110 & & & 0.222 & & & -0.118 \\
\hline I/A & & & $\begin{array}{l}-0.066 \\
(-0.28)\end{array}$ & & $\begin{array}{l}0.001 \\
(0.01)\end{array}$ & $\begin{array}{c}0.247 \\
(0.89)\end{array}$ & & $\begin{array}{l}-0.547 \\
(-0.83)\end{array}$ \\
\hline ROE & & & & $\begin{array}{l}-0.087 \\
(-0.36)\end{array}$ & $\begin{array}{l}-0.400 \\
(-0.77)\end{array}$ & & $\begin{array}{l}-0.100 \\
(-0.46)\end{array}$ & $\begin{array}{r}-0.632 \\
(-0.83)\end{array}$ \\
\hline SIZE & & & & & & & & $\begin{array}{c}-0.202 \\
(-5.41)\end{array}$ \\
\hline OP & & & & & & & $\begin{array}{l}2.699 \\
(3.74)\end{array}$ & $\begin{array}{l}3.734 \\
(4.97)\end{array}$ \\
\hline INV & & & & & & $\begin{array}{c}-0.651 \\
(-5.16)\end{array}$ & & $\begin{array}{r}-0.579 \\
(-6.54)\end{array}$ \\
\hline
\end{tabular}

Panel B: 1975-1992, N=2579

\begin{tabular}{lllllllll}
\hline Const & $\mathbf{1 . 0 4 0}$ & $\mathbf{0 . 9 0 0}$ & $\mathbf{1 . 1 3 3}$ & $\mathbf{0 . 7 7 8}$ & $\mathbf{0 . 7 1 0}$ & $\mathbf{1 . 1 2 5}$ & 0.687 & $\mathbf{4 . 1 1 6}$ \\
& $\mathbf{( 5 . 1 7 )}$ & $\mathbf{( 3 . 6 3 )}$ & $\mathbf{( 2 . 8 4 )}$ & $\mathbf{( 2 . 0 9 )}$ & $\mathbf{( 2 . 3 7 )}$ & $\mathbf{( 2 . 9 1 )}$ & $(1.88)$ & $\mathbf{( 3 . 3 8 )}$ \\
MKT & 0.179 & & & & -0.076 & & & 0.501 \\
& $(0.59)$ & & & & $(-0.21)$ & & & $(1.07)$ \\
ME & & 0.258 & & & 0.697 & & & 0.719 \\
& & $(1.07)$ & & & $(1.56)$ & & & $(1.21)$ \\
I/A & & & 0.729 & & -0.174 & 0.862 & & -0.527 \\
& & & $(1.72)$ & & $(-0.29)$ & $(1.46)$ & & $(-0.50)$ \\
ROE & & & & -0.252 & -0.336 & & $\mathbf{- 0 . 6 9 8}$ & -0.140 \\
& & & & $(-0.87)$ & $(-0.46)$ & & $\mathbf{( - 2 . 2 0 )}$ & $(-0.13)$ \\
SIZE & & & & & & & & $\mathbf{- 0 . 2 1 3}$
\end{tabular}




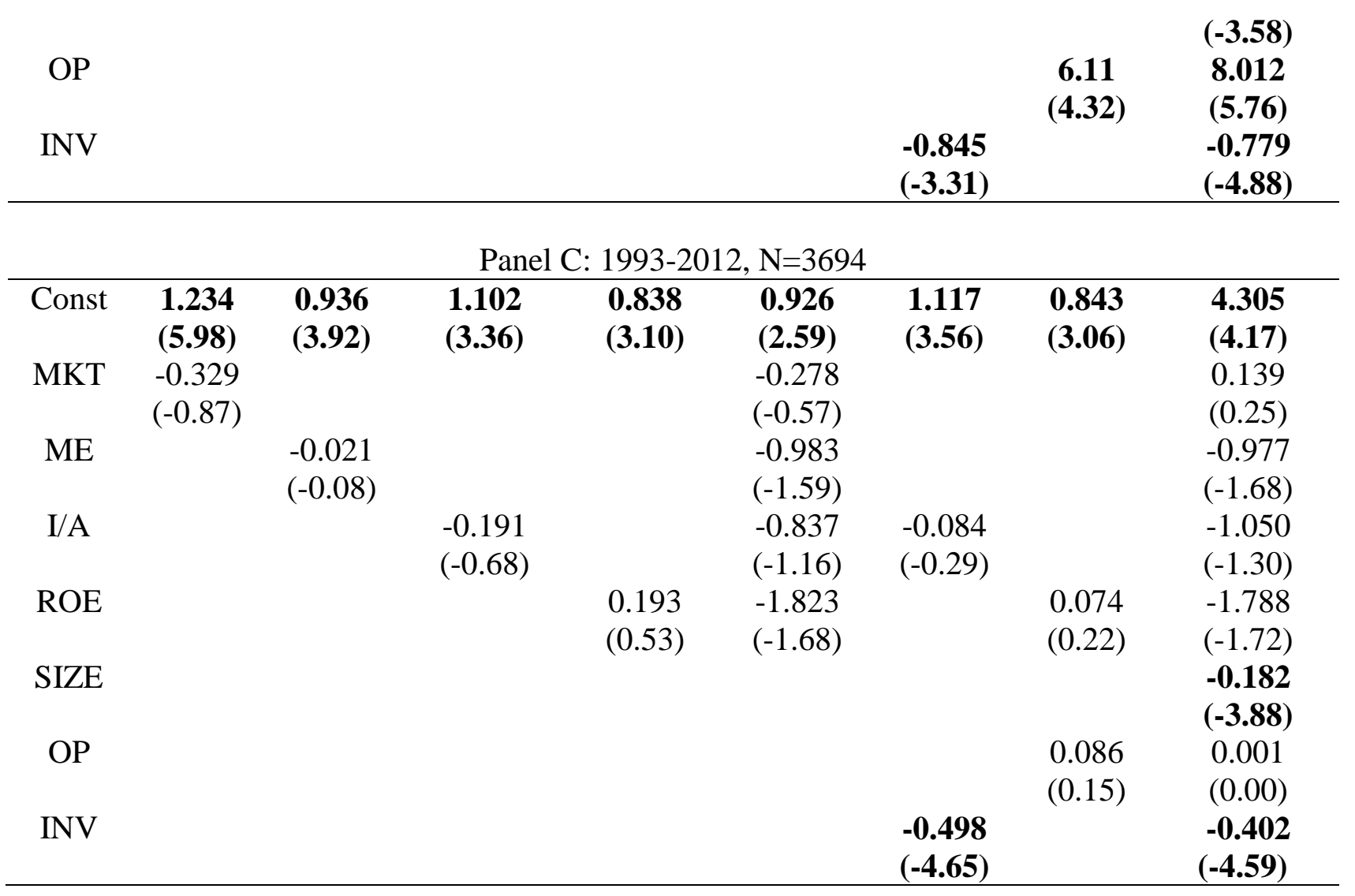




\section{Table 9}

\section{Risk Premium Estimates with Individual Stocks: Liquidity-adjusted CAPM (LCAPM)}

This table reports the risk premium estimates from the IV method, in percent per month, using individual stocks as test assets, and the corresponding t-statistics in parentheses (bold if significant at the 5\% level). The row labeled LMKT reports the premium estimates for liquidity-adjusted market risk under the liquidity-adjusted CAPM (LCAPM), and the row labeled Amihud illiquidity reports the slope coefficient on firm-specific Amihud illiquidity measure. Liquidity-adjusted market betas for each month are estimated using daily returns over the previous 36 months. The sample period is from January, 1959 through December, 2012. Following the literature, only NYSE/AMEX-listed stocks are included in the analyses. $\mathrm{N}$ is the average number of stocks in monthly cross-sectional regressions.

\begin{tabular}{clllllr}
\hline & \multicolumn{5}{c}{ Sample Period } \\
& $1959-2012, \mathrm{~N}=1283$ & \multicolumn{1}{c}{$1959-1985, \mathrm{~N}=1204$} & $1986-2012, \mathrm{~N}=1368$ \\
\hline Constant & $\mathbf{0 . 5 5 9}$ & $\mathbf{0 . 5 0 3}$ & $\mathbf{0 . 8 3 3}$ & $\mathbf{0 . 7 1 9}$ & 0.350 & 0.312 \\
& $\mathbf{( 3 . 8 5 )}$ & $\mathbf{( 3 . 4 8 )}$ & $\mathbf{( 4 . 3 2 )}$ & $\mathbf{( 3 . 7 1 )}$ & $(1.64)$ & $(1.44)$ \\
LMKT & 0.150 & 0.085 & -0.110 & -0.165 & 0.346 & 0.344 \\
& $(0.66)$ & $(0.38)$ & $(-0.34)$ & $(-0.52)$ & $(1.11)$ & $(1.10)$ \\
Amihud & & $\mathbf{0 . 2 2 0}$ & & $\mathbf{0 . 3 6 1}$ & & $\mathbf{0 . 0 6 1}$ \\
Illiquidity & & $\mathbf{( 4 . 2 1 )}$ & & $\mathbf{( 3 . 7 0 )}$ & & $\mathbf{( 2 . 7 8 )}$ \\
\hline
\end{tabular}




\section{Table 10}

\section{Risk Premium Estimates with Characteristics as Additional Instruments: IV Mean-estimator}

This table reports the slope coefficients of the following regression, fitted using the IV mean-estimator in Eq. (25):

$$
\overline{\mathrm{r}}_{\mathrm{i}, \mathrm{t}}=\gamma_{0, \mathrm{t}}+\sum_{\mathrm{k}=1}^{\mathrm{K}} \gamma_{\mathrm{k}, \mathrm{t}} \widehat{\beta}_{\mathrm{i}, \mathrm{k}, \mathrm{t}-1}+\sum_{\mathrm{j}=1}^{\mathrm{J}} \delta_{\mathrm{j}, \mathrm{t}} \overline{\mathrm{C}}_{\mathrm{i}, \mathrm{j}, \mathrm{t}-1}+\xi_{\mathrm{i}, \mathrm{t}}
$$

where $\overline{\mathrm{r}}_{\mathrm{i}, \mathrm{t}}$ is the average return over month $\mathrm{t}$ to month $\mathrm{t}+11$ and the independent and instrumental betas are estimated using daily returns over the past 36 months. $\overline{\mathrm{C}}_{\mathrm{i}, \mathrm{j}, \mathrm{t}-1}$ denotes the average of characteristic $j$ over the past 12 months. The columns titled " $\mathrm{T}_{\mathrm{m}}=12$ " and " $\mathrm{T}_{\mathrm{m}}=1$ " report the slope coefficients based on the IV mean-estimator and IV estimator (for comparison), respectively. The table reports the risk premium estimates for the CAPM, Fama-French three- and five-factors models, q-factor asset pricing model by HXZ, and liquidityadjusted CAPM. Rows labeled MKT, SMB, HML, RMW, CMA, ME, I/A, and ROE report the risk premiums for the market, SMB, HML, RMW, CMA, size, investment, and ROE factors, respectively. SIZE is the natural logarithm of market capitalization, BM is the book-to-market ratio, OP is the operating profitability, and INV is investment/total asset at the end of the previous month. LMKT is the liquidity-adjusted market risk premium under the LCAPM, and Amihud illiquidity is the slope coefficient on firm-specific Amihud illiquidity measure. We use Fama-MacBeth standard errors for $\mathrm{T}_{\mathrm{m}}=1$ and Hansen-Hodrick standard errors with 12 lags for $\mathrm{T}_{\mathrm{m}}=12$ to compute the t-statistics reported in parentheses (bold if significant at the 5\% level). The sample period for the CAPM, and Fama-French three-factor model (FF3M) is from January, 1956 through December, 2012. The sample periods for the Fama-French five-factor model (FF5M) and the q-factor asset pricing model (APM) are from January, 1967 through December, 2012 and from January, 1975 through December, 2012, respectively. The sample period for the liquidity-adjusted CAPM (LCAPM) is from January, 1959 through December, 2012. 


\begin{tabular}{|c|c|c|c|c|c|c|c|c|c|c|}
\hline & \multicolumn{2}{|c|}{ CAPM } & \multicolumn{2}{|c|}{ FF3M } & \multicolumn{2}{|c|}{ FF5M } & \multicolumn{2}{|c|}{ q-factor APM } & \multicolumn{2}{|c|}{ LCAPM } \\
\hline & $\mathrm{T}_{\mathrm{m}}=1$ & $\mathrm{~T}_{\mathrm{m}}=12$ & $\mathrm{~T}_{\mathrm{m}}=1$ & $\mathrm{~T}_{\mathrm{m}}=12$ & $\mathrm{~T}_{\mathrm{m}}=1$ & $\mathrm{~T}_{\mathrm{m}}=12$ & $T_{\mathrm{m}}=1$ & $\mathrm{~T}_{\mathrm{m}}=12$ & $\mathrm{~T}_{\mathrm{m}}=1$ & $\mathrm{~T}_{\mathrm{m}}=12$ \\
\hline Intercept & $\begin{array}{r}3.255 \\
(485)\end{array}$ & 2.565 & 3.102 & 2.479 & 3.079 & $\begin{array}{r}2.084 \\
(304\end{array}$ & $\begin{array}{l}4.268 \\
5.39\end{array}$ & 2.696 & $\begin{array}{c}0.503 \\
(2.48)\end{array}$ & $\mathbf{0 . 4 3 3}$ \\
\hline MKT & $\begin{array}{l}(\mathbf{4 . 8 5}) \\
0.001 \\
(0.01)\end{array}$ & $\begin{array}{c}(\mathbf{3 . 4 9}) \\
0.056 \\
(0.29)\end{array}$ & $\begin{array}{c}(\mathbf{5 . 2 1}) \\
0.032 \\
(019)\end{array}$ & $\begin{array}{c}(\mathbf{3 . 6 9}) \\
0.053 \\
(0.34)\end{array}$ & $\begin{array}{r}(\mathbf{4 . 1 9}) \\
0.367 \\
(1.06)\end{array}$ & $\begin{array}{c}(\mathbf{3 . 0 4}) \\
0.165 \\
(088)\end{array}$ & $\begin{array}{c}(\mathbf{5 . 3 9}) \\
0.437 \\
(1.20)\end{array}$ & $\begin{array}{r}(\mathbf{3 . 7 7}) \\
0.335 \\
(1.57)\end{array}$ & (3.48) & (2.17) \\
\hline LMKT & & & & & & & & & $\begin{array}{r}0.085 \\
(0.38)\end{array}$ & $\begin{array}{l}0.021 \\
(0.93)\end{array}$ \\
\hline SMB & & & $\begin{array}{l}-0.072 \\
(-0.71)\end{array}$ & $\begin{array}{l}0.042 \\
(0.49)\end{array}$ & $\begin{array}{l}-0.095 \\
(-0.50)\end{array}$ & $\begin{array}{r}0.123 \\
(1.41)\end{array}$ & & & & \\
\hline HML & & & $\begin{array}{l}0.196 \\
(1.55)\end{array}$ & $\begin{array}{l}0.106 \\
(0.86)\end{array}$ & $\begin{array}{r}0.354 \\
(0.87)\end{array}$ & $\begin{array}{r}0.141 \\
(0.77)\end{array}$ & & & & \\
\hline RMW & & & & & $\begin{array}{l}-0.051 \\
(-0.11)\end{array}$ & $\begin{array}{l}0.090 \\
(0.42)\end{array}$ & & & & \\
\hline CMA & & & & & $\begin{array}{r}0.049 \\
(0.11)\end{array}$ & $\begin{array}{r}0.653 \\
(1.88)\end{array}$ & & & & \\
\hline ME & & & & & & & $\begin{array}{l}-0.118 \\
(-0.28)\end{array}$ & $\begin{array}{r}0.140 \\
(0.94)\end{array}$ & & \\
\hline I/A & & & & & & & $\begin{array}{l}-0.547 \\
(-0.83)\end{array}$ & $\begin{array}{l}-0.242 \\
(-0.69)\end{array}$ & & \\
\hline ROE & & & & & & & $\begin{array}{l}-0.632 \\
(-0.83)\end{array}$ & $\begin{array}{l}-0.354 \\
(-0.94)\end{array}$ & & \\
\hline SIZE & $\begin{array}{l}-0.139 \\
(-4.05)\end{array}$ & $\begin{array}{c}-\mathbf{0 . 1 0 3} \\
(-2.78)\end{array}$ & $\begin{array}{l}-\mathbf{- 0 . 1 3 6} \\
(-4.55)\end{array}$ & $\begin{array}{r}-0.101 \\
(-3.03)\end{array}$ & $\begin{array}{r}-0.153 \\
(-4.38)\end{array}$ & $\begin{array}{r}-0.089 \\
(-2.61)\end{array}$ & $\begin{array}{r}-0.202 \\
(-5.41)\end{array}$ & $\begin{array}{l}-0.111 \\
(-3.40)\end{array}$ & & \\
\hline BM & $\begin{array}{l}0.166 \\
(3.73)\end{array}$ & $\begin{array}{l}0.191 \\
(2.91)\end{array}$ & $\begin{array}{l}\mathbf{0 . 1 5 3} \\
(\mathbf{3 . 8 2})\end{array}$ & $\begin{array}{l}0.173 \\
(2.95)\end{array}$ & $\begin{array}{l}0.178 \\
(4.12)\end{array}$ & $\begin{array}{l}\mathbf{0 . 1 3 9} \\
(\mathbf{2 . 0 5})\end{array}$ & & & & \\
\hline OP & & & & & $\begin{array}{l}0.649 \\
(6.10)\end{array}$ & $\begin{array}{l}0.258 \\
(1.35)\end{array}$ & $\begin{array}{r}3.734 \\
(4.97)\end{array}$ & $\begin{array}{l}-1.783 \\
(-1.37)\end{array}$ & & \\
\hline INV & & & & & $\begin{array}{r}-0.709 \\
(-9.25)\end{array}$ & $\begin{array}{l}-0.615 \\
(-3.61)\end{array}$ & $\begin{array}{l}-0.579 \\
(-6.54)\end{array}$ & $\begin{array}{l}-0.324 \\
(-1.84)\end{array}$ & & \\
\hline $\begin{array}{l}\text { Amihud } \\
\text { Illiquidity }\end{array}$ & & & & & & & & & $\begin{array}{r}0.220 \\
(4.21)\end{array}$ & $\begin{array}{l}0.152 \\
(4.34)\end{array}$ \\
\hline
\end{tabular}




\section{Table 11}

\section{Strength of Instruments}

This table presents the average cross-sectional correlations between odd- and even-month betas (in the columns labeled Corr (Odd, Even)) for the CAPM, Fama-French three- and five-factor models, q-factor asset pricing model by HXZ, and liquidity-adjusted CAPM by Acharya and Pedersen. The critical value for the weak instruments test proposed by Nelson and Startz (1990) is .057 , based on the smallest number of stocks in any month of the sample period. The square root of the correlation of odd- and even-month betas is the correlation between the unobservable "true" betas and the corresponding beta estimates based on the IV method (in the columns labeled Corr (True Beta, Beta Est.)).

Panel A: CAPM

\begin{tabular}{ccc}
\hline \multirow{2}{*}{ Sample period } & Corr (Odd, Even) & Corr (True Beta, Beta Est.) \\
\cline { 2 - 3 } & MKT & MKT \\
\hline $1956-2012$ & 0.72 & 0.85 \\
\hline
\end{tabular}

Panel B: Fama-French Three-factor Model

\begin{tabular}{ccccccc}
\hline \multirow{2}{*}{ Sample period } & \multicolumn{3}{c}{ Corr (Odd, Even) } & \multicolumn{3}{c}{ Corr (True Beta, Beta Est.) } \\
\cline { 2 - 7 } & MKT & SMB & HML & MKT & SMB & HML \\
\hline $1956-2012$ & 0.59 & 0.48 & 0.33 & 0.77 & 0.69 & 0.57 \\
\hline
\end{tabular}

Panel C: Fama-French Five-factor Model

\begin{tabular}{ccccccccccc}
\hline \multirow{2}{*}{$\begin{array}{c}\text { Sample } \\
\text { period }\end{array}$} & \multicolumn{4}{c}{ Corr (Odd, Even) } & \multicolumn{4}{c}{ Corr (True Beta, Beta Est.) } \\
\cline { 2 - 12 } & MKT & SMB & HML & RMW & CMA & MKT & SMB & HML & RMW & CMA \\
\hline $1964-2012$ & 0.43 & 0.37 & 0.21 & 0.16 & 0.13 & 0.66 & 0.61 & 0.46 & 0.40 & 0.36 \\
\hline
\end{tabular}

Panel D: q-factor Asset Pricing Model

\begin{tabular}{ccccccccc}
\hline Sample & \multicolumn{4}{c}{ Corr (Odd, Even) } & \multicolumn{4}{c}{ Corr (True Beta, Beta Est.) } \\
\cline { 2 - 9 } period & MKT & ME & I/A & ROE & MKT & ME & I/A & ROE \\
\hline $1972-2012$ & 0.49 & 0.37 & 0.19 & 0.21 & 0.70 & 0.61 & 0.44 & 0.46 \\
\hline
\end{tabular}

Panel E: Liquidity-adjusted CAPM (LCAPM)

\begin{tabular}{ccc}
\hline \multirow{2}{*}{ Sample period } & Corr (Odd, Even) & Corr (True Beta, Beta Est.) \\
\cline { 2 - 3 } & LMKT & LMKT \\
\hline $1959-2012$ & 0.58 & 0.76 \\
\hline
\end{tabular}




\section{Appendix}

\section{Appendix A. Consistency of the IV Estimator with Time-varying Betas and Simulation Evidence}

The appendix shows that the IV estimator is $\mathrm{N}$-consistent when betas are time-varying. For ease of exposition, we present the proposition and proof for a single factor model where time-variation in beta is captured by white noise. Appendix F in the Online Appendix contains the proposition and its proof for multifactor models with time-varying betas that follow any covariance stationary process.

Proposition: Suppose that stock returns follow an approximate factor structure with one common factor, and betas of stocks vary over time as follows. Let $\beta_{\mathrm{i}, \mathrm{t}}$ be the beta of stock $\mathrm{i}$ in time $\mathrm{t}$ and $\beta_{\mathrm{i}}$ be its unconditional mean. We have

$$
\beta_{i, t}=\beta_{i}+u_{i, t}
$$

where $\mathrm{u}_{\mathrm{i}, \mathrm{t}}$ is white noise (i.e. $\mathrm{u}_{\mathrm{i}, \mathrm{t} 1}$ and $\mathrm{u}_{\mathrm{i}, \mathrm{t} 2}$ are uncorrelated for $\mathrm{t} 1 \neq \mathrm{t} 2$ ) and uncorrelated across stocks. Let $\gamma_{\mathrm{t}}$ be the ex-ante risk premium in time $\mathrm{t}$. Under mild regularity conditions, the IV estimator in Eq. (4), $\hat{\gamma}_{\mathrm{t}}$ is N-consistent for any $\mathrm{t}$ not in the period used to estimate IV beta.

Proof: Under the one factor model, the expected return conditioning on $\beta_{\mathrm{i}, \mathrm{t}}, \gamma_{\mathrm{t}}$ and $\gamma_{0, \mathrm{t}}$ is given by:

$$
E\left(\mathrm{r}_{\mathrm{i}, \mathrm{t}} \mid \beta_{\mathrm{i}, \mathrm{t}}, \gamma_{\mathrm{t}}, \gamma_{0, \mathrm{t}}\right)=\gamma_{0, \mathrm{t}}+\beta_{\mathrm{i}, \mathrm{t}} \gamma_{\mathrm{t}}=\gamma_{0, \mathrm{t}}+\left(\beta_{\mathrm{i}}+\mathrm{u}_{\mathrm{i}, \mathrm{t}}\right) \gamma_{\mathrm{t}}=\gamma_{0, \mathrm{t}}+\beta_{\mathrm{i}} \gamma_{\mathrm{t}}+\mathrm{u}_{\mathrm{i}, \mathrm{t}} \gamma_{\mathrm{t}}
$$

Let $\mathrm{f}_{\mathrm{t}}$ be the factor. Define $\Gamma_{\mathrm{t}}=\gamma_{\mathrm{t}}+\mathrm{f}_{\mathrm{t}}-E\left(\mathrm{f}_{\mathrm{t}} \mid \beta_{\mathrm{i}, \mathrm{t}}, \gamma_{\mathrm{t}}, \gamma_{0, \mathrm{t}}\right)$ as the ex-post risk premium.

Following Eq. (2) for one factor model and time-varying beta,

$$
r_{i, t}=\alpha_{i, t}+\beta_{i, t} f_{t}+\varepsilon_{i, t}
$$

Take the following conditional expectation of Eq. (29),

$$
E\left(\mathrm{r}_{\mathrm{i}, \mathrm{t}} \mid \beta_{\mathrm{i}, \mathrm{t}}, \gamma_{\mathrm{t}}, \gamma_{0, \mathrm{t}}\right)=\alpha_{\mathrm{i}, \mathrm{t}}+\beta_{\mathrm{i}, \mathrm{t}} E\left(\mathrm{f}_{\mathrm{t}} \mid \beta_{\mathrm{i}, \mathrm{t}}, \gamma_{\mathrm{t}}, \gamma_{0, \mathrm{t}}\right)
$$

From Eq. (28) and Eq. (30), $\alpha_{i, t}=\gamma_{0, t}+\beta_{i, t} \gamma_{t}-\beta_{i, t} E\left(f_{t} \mid \beta_{i, t}, \gamma_{t}, \gamma_{0, t}\right)$. Replacing $\alpha_{i, t}$ in Eq. (29), we have the following expression for return in terms of ex-post risk premium:

$$
r_{i, t}=\gamma_{0, t}+\beta_{i, t} \Gamma_{t}+\varepsilon_{i, t}=\gamma_{0, t}+\left(\beta_{i}+u_{i, t}\right) \Gamma_{t}+\varepsilon_{i, t}=\gamma_{0, t}+\beta_{i} \Gamma_{t}+u_{i, t} \Gamma_{t}+\varepsilon_{i, t}
$$


Consider the following IV cross-sectional regression:

$$
r_{i, t}=\gamma_{0, t}+\Gamma_{t} \hat{\beta}_{E V, i}+\xi_{i, t}
$$

where $\widehat{\beta}_{\mathrm{EV}, \mathrm{i}}$ is estimated using a half of the sample period, and $\xi_{\mathrm{i}, \mathrm{t}}$ (which can be written as $\mathrm{u}_{\mathrm{i}, \mathrm{t}} \Gamma_{\mathrm{t}}+\left(\beta_{\mathrm{i}}-\widehat{\beta}_{\mathrm{EV}, \mathrm{i}}\right) \Gamma_{\mathrm{t}}+\varepsilon_{\mathrm{i}, \mathrm{t}}$ based on Eqs. (31) and (32) $\left.{ }^{27}\right)$ is the error in the regression. Let $\widehat{\beta}_{\mathrm{IV}, \mathrm{i}}$ be the instrumental variable, which is estimated using the other half of the sample period. We can express estimates of betas as:

$$
\begin{gathered}
\widehat{\beta}_{\mathrm{EV}, \mathrm{i}}=\beta_{\mathrm{i}}+\eta_{\mathrm{EV}, \mathrm{i}} \\
\widehat{\beta}_{\mathrm{IV}, \mathrm{i}}=\beta_{\mathrm{i}}+\eta_{\mathrm{IV}, \mathrm{i}}
\end{gathered}
$$

Since we estimate betas using linear regressions, we can express $\eta$ 's as linear combinations of u and $\varepsilon$. Specifically,

$$
\begin{aligned}
& \eta_{E V, i}=\frac{2}{T}\left(\sum_{s \in E V} \omega_{1, i, s} u_{i, s}+\sum_{s \in E V} \omega_{2, i, s} \varepsilon_{i, s}\right) \\
& \eta_{I V, i}=\frac{2}{T}\left(\sum_{s \in I V} \omega_{1, i, s} u_{i, s}+\sum_{s \in I V} \omega_{2, i, s} \varepsilon_{i, s}\right)
\end{aligned}
$$

where $\omega_{1, \mathrm{i}, \mathrm{s}}$ and $\omega_{2, \mathrm{i}, \mathrm{s}}$ are weights and T/2 is the number of observations used to estimate $\widehat{\beta}_{\mathrm{EV}, \mathrm{i}}$ and $\widehat{\beta}_{I V, i}$. Assume that (i) betas are uncorrelated with $u_{i, t}$ and $\varepsilon_{i, t}$ cross-sectionally, i.e. $\operatorname{cov}\left(\beta_{i}, u_{i, t}\right)=$ $0, \operatorname{cov}\left(\beta_{\mathrm{i}}, \varepsilon_{\mathrm{i}, \mathrm{t}}\right)=0$, for any $\mathrm{t}$, (ii) both $\varepsilon_{\mathrm{i}, \mathrm{t}}$ and $\mathrm{u}_{\mathrm{i}, \mathrm{t}}$ are white noises. Given that $\widehat{\beta}_{\mathrm{EV}, \mathrm{i}}$ and $\widehat{\beta}_{\mathrm{IV}, \mathrm{i}}$ are estimated over separate data sample periods, from Eq. (35), Eq. (36) and assumptions (i) and (ii), we can show that

$$
\operatorname{cov}\left(\eta_{\mathrm{EV}, \mathrm{i}}, \eta_{\mathrm{IV}, \mathrm{i}}\right)=0, \operatorname{cov}\left(\beta_{\mathrm{i}}, \eta_{\mathrm{IV}, \mathrm{i}}\right)=0, \operatorname{cov}\left(\beta_{\mathrm{i}}, \eta_{\mathrm{EV}, \mathrm{i}}\right)=0
$$

Also, because both $\varepsilon_{i, t}$ and $u_{i, t}$ are white noises, $\gamma_{0, t}$ and $\Gamma_{t}$ are fixed at time $t$, and $t$ is not in the period used to estimate IV beta,

\footnotetext{
${ }^{27}$ From Eq. (31), $r_{i, t}=\gamma_{0, t}+\beta_{i, t} \Gamma_{t}+\varepsilon_{i, t}=\gamma_{0, t}+\widehat{\beta}_{E V, i} \Gamma_{t}+u_{i, t} \Gamma_{t}+\left(\beta_{i}-\widehat{\beta}_{E V, i}\right) \Gamma_{t}+\varepsilon_{i, t}$. Define $\xi_{i, t}=u_{i, t} \Gamma_{t}+\left(\beta_{i}-\right.$
} $\left.\widehat{\beta}_{\mathrm{EV}, \mathrm{i}}\right) \Gamma_{\mathrm{t}}+\varepsilon_{\mathrm{i}, \mathrm{t}}$, we arrive at Eq. (32). 


$$
\operatorname{cov}\left(\mathrm{r}_{\mathrm{i}, \mathrm{t}}, \eta_{\mathrm{IV}, \mathrm{i}}\right)=0 .
$$

Therefore, combining Eq. (37), Eq. (38) and assumption (i), we have

$$
\hat{\gamma}_{\mathrm{t}} \rightarrow \frac{\operatorname{cov}\left(\mathrm{r}_{\mathrm{i}, \mathrm{t}}, \hat{\beta}_{\mathrm{IV}, \mathrm{i}}\right)}{\operatorname{cov}\left(\hat{\beta}_{\mathrm{EV}, \mathrm{i}}, \hat{\beta}_{\mathrm{IV}, \mathrm{i}}\right)}=\frac{\operatorname{cov}\left(\mathrm{r}_{\mathrm{i}, \mathrm{t}}, \beta_{\mathrm{i}}\right)}{\operatorname{var}\left(\beta_{\mathrm{i}}\right)}=\frac{\operatorname{cov}\left(\gamma_{0, \mathrm{t}}+\Gamma_{\mathrm{t}} \beta_{\mathrm{i}}+\Gamma_{\mathrm{t}} \mathrm{u}_{\mathrm{i}, \mathrm{t}}+\varepsilon_{\mathrm{i}, \mathrm{t}}, \beta_{\mathrm{i}}\right)}{\operatorname{var}\left(\beta_{\mathrm{i}}\right)}=\Gamma_{\mathrm{t}}
$$

as $\mathrm{N}$ converges to infinity.

When $u_{i, t}$ in Eq. (27) follows any stationary and ergodic process, in Appendix $F$ of Online Appendix, we show that the IV estimator is consistent when we allow T to converge to infinity first, and then allow $\mathrm{N}$ to converge to infinity.

\section{Simulations with Time-varying Betas}

This section describes our procedure for the simulations with time-varying betas discussed in Section 3.3. The simulation assumes that $\beta_{\mathrm{i}, \mathrm{t}}$, the beta of stock $\mathrm{i}$ in month $\mathrm{t}$, follows an $\operatorname{AR}(1)$ process. Specifically:

$$
\beta_{\mathrm{i}, \mathrm{t}}-\beta_{\mathrm{i}}=\rho\left(\beta_{\mathrm{i}, \mathrm{t}-1}-\beta_{\mathrm{i}}\right)+\mathrm{u}_{\mathrm{i}, \mathrm{t}}
$$

where $\mathrm{u}_{\mathrm{i}, \mathrm{t}}$ is the shock to beta, and $\beta_{\mathrm{i}}$ is the unconditional mean of beta. We first estimate $\rho$ from real data, which we then use in the simulation. Specifically, we first estimate the three-year rolling betas for each stock, producing monthly time-varying betas. We then trim these beta estimates at the $2.5 \%$ and $97.5 \%$ levels, and shrink them by applying a simple adjustment rule: adjusted beta $=$ $2 / 3 \times$ beta estimate $+1 / 3$. We then compute the average autocorrelation of these betas across all stocks, which equals .96 . Table A1 presents the simulation parameters with time-varying betas under single-factor and three-factor models.

To generate time-varying betas, we first randomly generate the time-series mean of each beta as we did for the constant-beta simulations. We next draw $u_{i, t}$ from a normal distribution

with mean zero and standard deviation equal to $\sqrt{1-\rho^{2}}$ times the average of time-series standard 
deviation of the corresponding beta. We then compute $\beta_{i, t}$ through the AR(1) specification above. We assume that $\beta_{\mathrm{i}, \mathrm{t}}$ stays constant for 21 trading days for a given month t. Finally, using this timevarying beta, we generate daily returns by following the same simulation procedure described in Section 3.1. We conduct the same IV estimation procedure for risk premiums as in the simulations with constant betas. This simulation procedure is used for the single factor CAPM and the FamaFrench three-factor model. Table A2 presents the biases and RMSEs of IV risk premium estimates with time-varying betas, and Table A3 presents the size and power of IV tests with time-varying betas. The results here are similar to the corresponding results in Tables 2 and 3.

We also experiment with less persistent time-varying betas that have different values of $\rho$, ranging from 0.56 to 0.96 . The results from these additional simulations with different $\rho \mathrm{s}$ are similar to the corresponding results in Tables A2 and A3. For example, with $\rho=0.56$, under the single factor CAPM, we find that the ex-ante and ex-post biases of IV market risk premium estimates are $-1.0 \%$ and $-1.5 \%$, respectively, while those biases of OLS market risk premium estimates are $-28.2 \%$ and $-28.6 \%$, respectively. With $\rho=0.56$, under the Fama-French three-factor model, the ex-ante and ex-post biases of IV risk premium estimates range from $-3.5 \%$ to $0.0 \%$, while those biases of OLS risk premium estimates range from $-64.7 \%$ to $-38.1 \%$. The magnitudes of these biases of IV and OLS risk premium estimates are similar to those with $\rho=0.96$ in Table A2. When $\rho=0.76$ is used, under the single factor CAPM, we find that the ex-ante and ex-post biases of IV market risk premium estimates are $-2.0 \%$ and $-4.2 \%$, respectively, while those biases of OLS market risk premium estimates are $-28.4 \%$ and $-30.5 \%$, respectively. With $\rho=0.76$, under the Fama-French three-factor model, the ex-ante and ex-post biases of IV risk premium estimates range from $-5.7 \%$ to $-2.1 \%$, while the biases of OLS risk premium estimates range from $-65.4 \%$ to $-37.9 \%$. We thus conclude that the different degree of persistence in time-varying betas does not affect the small sample properties of IV risk premium estimator significantly. 


\section{Table A1}

Simulation Parameters for Time-varying Betas

Averages of $\mathrm{AR}(1)$ coefficients $(=\rho)$ of time-varying betas and their time-series standard deviations

\begin{tabular}{llcccc}
\hline & & \multicolumn{2}{c}{ Single Factor Model } & \multicolumn{2}{c}{ Fama-French } \\
& & $\rho$ & Three-factor Model \\
& & $\rho$ & StdDev & $\rho$ & StdDev \\
\hline Betas & MKT & 0.96 & 0.15 & 0.96 & 0.15 \\
& SMB & & & 0.96 & 0.19 \\
& HML & & & 0.96 & 0.21 \\
\hline
\end{tabular}

TABLE A2

Small Sample Properties of IV Risk Premium Estimates with Time-varying Betas

Panel A: Single-factor CAPM

\begin{tabular}{cccccc}
\hline $\begin{array}{c}\text { Risk } \\
\text { Factor }\end{array}$ & Estimator & $\begin{array}{c}\text { Ex-ante } \\
\text { Bias (\%) }\end{array}$ & $\begin{array}{c}\text { Ex-post } \\
\text { Bias (\%) }\end{array}$ & $\begin{array}{c}\text { Ex-ante } \\
\text { RMSE }\end{array}$ & $\begin{array}{c}\text { Ex-post } \\
\text { RMSE }\end{array}$ \\
\hline MKT & OLS & -25.7 & -27.0 & 0.184 & 0.147 \\
& IV & -1.5 & -2.8 & 0.182 & 0.078 \\
\hline
\end{tabular}

Panel B: Fama-French Three-factor Model

\begin{tabular}{cccccc}
\hline Risk & Estimator & $\begin{array}{c}\text { Ex-ante } \\
\text { Bias (\%) }\end{array}$ & $\begin{array}{c}\text { Ex-post } \\
\text { Bias (\%) }\end{array}$ & $\begin{array}{c}\text { Ex-ante } \\
\text { RMSE }\end{array}$ & $\begin{array}{c}\text { Ex-post } \\
\text { RMSE }\end{array}$ \\
\hline MKT & OLS & -35.4 & -36.1 & 0.212 & 0.189 \\
& IV & -1.5 & -2.2 & 0.176 & 0.086 \\
\hline SMB & OLS & -61.0 & -60.1 & 0.146 & 0.144 \\
& IV & -4.2 & -3.4 & 0.126 & 0.094 \\
\hline HML & OLS & -56.8 & -57.6 & 0.213 & 0.216 \\
& IV & -1.9 & -2.7 & 0.112 & 0.084 \\
\hline
\end{tabular}




\section{TABLE A3}

Size and Power of the IV Tests with Time-varying Betas

Panel A: Test Size

\begin{tabular}{ccccccc}
\hline Risk & Test & \multicolumn{5}{c}{ Theoretical Percentiles } \\
Factor & Based on & $1 \%$ & $2.5 \%$ & $5 \%$ & $7.5 \%$ & $10 \%$ \\
\hline & \multicolumn{5}{c}{ Single-factor CAPM } \\
\hline MKT & OLS & $1.8 \%$ & $3.2 \%$ & $4.1 \%$ & $8.2 \%$ & $10.9 \%$ \\
& IV & $1.3 \%$ & $2.7 \%$ & $4.7 \%$ & $7.9 \%$ & $10.1 \%$ \\
\hline \multicolumn{6}{c}{ Fama-French Three-factor Model } \\
\hline MKT & OLS & $1.9 \%$ & $3.1 \%$ & $4.1 \%$ & $8.3 \%$ & $11.1 \%$ \\
& IV & $1.4 \%$ & $2.8 \%$ & $4.6 \%$ & $7.7 \%$ & $10.3 \%$ \\
\hline SMB & OLS & $1.7 \%$ & $3.3 \%$ & $4.9 \%$ & $7.1 \%$ & $9.5 \%$ \\
& IV & $1.2 \%$ & $2.9 \%$ & $5.2 \%$ & $7.3 \%$ & $9.7 \%$ \\
\hline HML & OLS & $1.6 \%$ & $2.9 \%$ & $4.7 \%$ & $7.8 \%$ & $10.5 \%$ \\
& IV & $1.4 \%$ & $2.6 \%$ & $4.9 \%$ & $7.2 \%$ & $9.8 \%$ \\
\hline
\end{tabular}

Panel B: Test Power

\begin{tabular}{ccc}
\hline Risk & \multicolumn{2}{c}{ Test Based on } \\
Factor & OLS & IV \\
\hline \multicolumn{3}{c}{ Single-factor CAPM } \\
\hline MKT & $85.2 \%$ & $85.4 \%$ \\
\hline FKT & $79.0 \%$ & $84.2 \%$ \\
SMB & $45.4 \%$ & $52.9 \%$ \\
HML & $91.0 \%$ & $91.7 \%$ \\
MKT or SMB or HML & $99.5 \%$ & $99.7 \%$ \\
\hline
\end{tabular}




\section{Appendix B. Innovations in Illiquidity Costs}

We follow Acharya and Pedersen (2005) and fit the following time-series regression to estimate expected and unexpected components of market-wide illiquidity cost $\left(\tilde{\mathrm{c}}_{\mathrm{MKT}, \tau}=\right.$ $\left.\mathrm{c}_{\mathrm{MKT}, \tau}-E_{\tau-1}\left(\mathrm{c}_{\mathrm{MKT}, \tau}\right)\right)$ :

$0.25+0.3 \overline{\mathrm{ILLIQ}}_{\mathrm{MKT}, \tau} * \mathrm{P}_{\mathrm{MKT}, \mathrm{t}-1}=\alpha_{0}+\sum_{\mathrm{d}=1}^{\mathrm{D}} \alpha_{\mathrm{d}}\left(0.25+0.3 \overline{\mathrm{ILLIQ}}_{\mathrm{MKT}, \tau-\mathrm{d}} * \mathrm{P}_{\mathrm{MKT}, \mathrm{t}-1}\right)+\tilde{\mathrm{c}}_{\mathrm{MKT}, \tau}$,

where $\overline{\operatorname{ILLIQ}}_{\mathrm{MKT}, \tau}$ is the value-weighted average of $\min \left(\mathrm{ILLIQ}_{\mathrm{i}, \tau}, \frac{30-0.25}{0.30 \mathrm{P}_{\mathrm{MKT}, \mathrm{t}-1}}\right)$, which Acharya and Pedersen define as un-normalized illiquidity, truncated for outliers. These variables are defined based on Eqs. (16) and (17). We cannot reject the hypothesis that the residuals are white noise based on the Durbin-Watson tests for $\mathrm{D}=2$. The results we report in the text are based on the application of the $\mathrm{AR}(2)$ model to estimate expected and unexpected components of illiquidity cost for the market, as well as for individual stocks. We repeat the tests with D ranging from 2 to 6 and find that the results are not sensitive to the choice of D.

\section{Appendix C. Proof of Proposition 2}

Let $\mathrm{X}_{\mathrm{IV}, \mathrm{t}-1}=\left(\begin{array}{ccc}1 & \ldots & 1 \\ \widehat{\beta}_{\mathrm{IV}, \mathrm{i}, \mathrm{t}-1} & \ldots & \widehat{\beta}_{\mathrm{IV}, \mathrm{N}, \mathrm{t}-1} \\ \overline{\mathrm{C}}_{1, \mathrm{t}-1} & \ldots & \overline{\mathrm{C}}_{\mathrm{N}, \mathrm{t}-1}\end{array}\right), \mathrm{X}_{\mathrm{EV}, \mathrm{t}-1}=\left(\begin{array}{ccc}1 & \ldots & 1 \\ \widehat{\beta}_{\mathrm{EV}, \mathrm{i}, \mathrm{t}-1} & \ldots & \widehat{\beta}_{\mathrm{EV}, \mathrm{N}, \mathrm{t}-1} \\ \overline{\mathrm{C}}_{1, \mathrm{t}-1} & \ldots & \overline{\mathrm{C}}_{\mathrm{N}, \mathrm{t}-1}\end{array}\right)$

the estimator is $\quad \hat{\gamma}_{t}^{\prime}=\left(\frac{1}{N} X_{I V, t-1}\left(X_{E V, t-1}\right)^{\prime}\right)^{-1}\left(\frac{1}{N} X_{I V, t-1} \bar{r}_{t}^{\prime}\right)$, where $\bar{r}_{t}=\left[\overline{\mathrm{r}}_{1, t}, \cdots, \overline{\mathrm{r}}_{\mathrm{N}, \mathrm{t}}\right]$.

Denote $\hat{\gamma}_{\mathrm{t}}=\left[\hat{\gamma}_{0, \mathrm{t}}, \hat{\gamma}_{\beta, \mathrm{t}}, \hat{\gamma}_{\mathrm{C}, \mathrm{t}}\right]$, where $\hat{\gamma}_{0, \mathrm{t}}, \hat{\gamma}_{\beta, \mathrm{t}}, \hat{\gamma}_{\mathrm{C}, \mathrm{t}}$ are the estimated intercept and slope coefficients of beta and characteristic, respectively, in the cross-sectional regression. We will show that as $\mathrm{N}$, $\mathrm{T}$ and $\mathrm{T}_{\mathrm{m}}$ approach to infinity, the slope coefficient of beta in the cross-sectional regression converges to the ex-post factor risk premium $\Gamma_{t}$ (which is defined as $\Gamma_{t}=\frac{1}{T_{m}} \sum_{\tau=0}^{T_{m}-1}\left(\gamma+f_{t+\tau}-\right.$ 
$\left.E\left(\mathrm{f}_{\mathrm{t}+\tau} \mid \beta_{\mathrm{i}, \mathrm{t}+\tau}\right)\right)$ where $\gamma$ and $\mathrm{f}_{\mathrm{t}+\tau}$ are constant ex-ante risk premium ${ }^{28}$ and factor in time $\mathrm{t}+\tau$, respectively). The proofs for the estimated intercept and slope coefficient of the characteristic are similar. $^{29}$

With some algebra, we can show that $\hat{\gamma}_{\beta, t}=\frac{\text { num }}{\text { den }}$, where

$$
\begin{aligned}
\operatorname{num}= & \left(\widehat{\operatorname{cov}}\left(\widehat{\beta}_{\mathrm{EV}, \mathrm{i}, \mathrm{t}-1}, \overline{\mathrm{C}}_{\mathrm{i}, \mathrm{t}-1}\right) \hat{E}\left(\overline{\mathrm{C}}_{\mathrm{i}, \mathrm{t}-1}\right)-\widehat{\operatorname{var}}\left(\overline{\mathrm{C}}_{\mathrm{i}, \mathrm{t}-1}\right) \widehat{E}\left(\widehat{\beta}_{\mathrm{EV}, \mathrm{i}, \mathrm{t}-1}\right)\right) \hat{E}\left(\overline{\mathrm{r}}_{\mathrm{i}, \mathrm{t}}\right)+ \\
& \widehat{\operatorname{var}}\left(\overline{\mathrm{C}}_{\mathrm{i}, \mathrm{t}-1}\right) \hat{E}\left(\widehat{\beta}_{\mathrm{IV}, \mathrm{i}, \mathrm{t}-1} \overline{\mathrm{r}}_{\mathrm{i}, \mathrm{t}}\right)-\widehat{\operatorname{cov}}\left(\widehat{\beta}_{\mathrm{EV}, \mathrm{i}, \mathrm{t}-1}, \overline{\mathrm{C}}_{\mathrm{i}, \mathrm{t}-1}\right) \hat{E}\left(\overline{\mathrm{C}}_{\mathrm{i}, \mathrm{t}-1} \overline{\mathrm{r}}_{\mathrm{i}, \mathrm{t}}\right), \\
\operatorname{den}= & \widehat{\operatorname{cov}}\left(\widehat{\beta}_{\mathrm{IV}, \mathrm{i}, \mathrm{t}-1}, \widehat{\beta}_{\mathrm{EV}, \mathrm{i}, \mathrm{t}-1}\right) \widehat{\operatorname{var}}\left(\overline{\mathrm{C}}_{\mathrm{i}, \mathrm{t}-1}\right)-\widehat{\operatorname{cov}}\left(\overline{\mathrm{C}}_{\mathrm{i}, \mathrm{t}-1}, \widehat{\beta}_{\mathrm{EV}, \mathrm{i}, \mathrm{t}-1}\right) \widehat{\operatorname{cov}}\left(\overline{\mathrm{C}}_{\mathrm{i}, \mathrm{t}-1}, \widehat{\beta}_{\mathrm{IV}, \mathrm{i}, \mathrm{t}-1}\right) .
\end{aligned}
$$

Here $\widehat{E}, \widehat{C O V}$ and $\widehat{v a r}$ denote the cross-sectional sample mean, covariance and variance, respectively.

Given that $\beta_{\mathrm{i}, \mathrm{t}-1}$ is an $\mathrm{AR}(1)$ process, let $\beta_{\mathrm{i}}$ be the unconditional mean of beta for stock $\mathrm{i}$, we can write $\beta_{\mathrm{i}, \mathrm{t}-1}=\beta_{\mathrm{i}}+\vartheta_{\mathrm{i}, \mathrm{t}-1}$, where $\vartheta_{\mathrm{i}, \mathrm{t}-1}$ is a stationary and ergodic process. ${ }^{30} \mathrm{We}$ estimate $\mathrm{EV}$ and IV betas using separate periods spanning from time $t-T$ to time $t-1$. With some algebra, the estimated betas can be written as

$$
\begin{gathered}
\widehat{\beta}_{\mathrm{EV}, \mathrm{i}, \mathrm{t}-1}=\beta_{\mathrm{i}}+\eta_{\mathrm{EV}, \mathrm{i}, \mathrm{t}-1} \\
\widehat{\beta}_{\mathrm{IV}, \mathrm{i}, \mathrm{t}-1}=\beta_{\mathrm{i}}+\eta_{\mathrm{IV}, \mathrm{i}, \mathrm{t}-1} .
\end{gathered}
$$

Here

$$
\begin{aligned}
& \eta_{\mathrm{EV}, \mathrm{i}, \mathrm{t}-1}=\frac{2}{\mathrm{~T}}\left(\sum_{\mathrm{s} \in \mathrm{EV}} \omega_{1, \mathrm{i}, \mathrm{s}} \vartheta_{\mathrm{i}, \mathrm{s}}+\sum_{\mathrm{s} \in \mathrm{EV}} \omega_{2, \mathrm{i}, \mathrm{s}} \varepsilon_{\mathrm{i}, \mathrm{s}}\right) \\
& \eta_{\mathrm{IV}, \mathrm{i}, \mathrm{t}-1}=\frac{2}{\mathrm{~T}}\left(\sum_{\mathrm{s} \in \mathrm{IV}} \omega_{1, \mathrm{i}, \mathrm{s}} \vartheta_{\mathrm{i}, \mathrm{s}}+\sum_{\mathrm{s} \in \mathrm{IV}} \omega_{2, \mathrm{i}, \mathrm{s}} \varepsilon_{\mathrm{i}, \mathrm{s}}\right)
\end{aligned}
$$

where $\varepsilon_{i, s}$ is the error in Eq. (29), $\omega_{1, i, s}$ and $\omega_{2, i, s}$ are weights, and T/2 is the number of observations used to estimate $\widehat{\beta}_{\mathrm{EV}, \mathrm{i}, \mathrm{t}-1}$ and $\widehat{\beta}_{\mathrm{IV}, \mathrm{i}, \mathrm{t}-1}$, and EV or IV period ends in time t-1. We can

\footnotetext{
${ }^{28}$ In this appendix, the true values of intercept, risk premium and slope coefficient for characteristic are assumed to be constant. We relax these assumptions in Appendix G of the Internet Appendix.

${ }^{29} \mathrm{We}$ will discuss all relevant assumptions and provide a more general proof in Appendix $\mathrm{G}$ of the Internet Appendix.

${ }^{30}$ From the assumption that $\beta_{\mathrm{i}, \mathrm{t}}=\theta+\rho \beta_{\mathrm{i}, \mathrm{t}-1}+\mathrm{u}_{\mathrm{i}, \mathrm{t}}$ in Eq. (19), we can show that $\beta_{\mathrm{i}, \mathrm{t}}=\frac{\theta}{1-\rho}+\frac{\mathrm{u}_{\mathrm{i}, \mathrm{t}}}{1-\rho \mathrm{L}}$ where $\mathrm{L}$ is the lag operator. Hence $\beta_{\mathrm{i}}=\frac{\theta}{1-\rho}$ and $\vartheta_{\mathrm{i}, \mathrm{t}}=\frac{\mathrm{u}_{\mathrm{i}, \mathrm{t}}}{1-\rho \mathrm{L}}$ is a stationary and ergodic process.
} 
show that as $\mathrm{T}$ approaches to infinity, both $\eta_{\mathrm{EV}, \mathrm{i}, \mathrm{t}-1}$ and $\eta_{\mathrm{IV}, \mathrm{i}, \mathrm{t}-1}$ converge to zero, i.e., the beta estimates converge to the unconditional mean of beta $\left(\beta_{\mathrm{i}}\right)$. Similarly, given that a process for characteristic is also an $\operatorname{AR}(1)$, let $C_{i}$ be the unconditional mean of the characteristic for stock $i$, the average value of characteristic can be written as $\bar{C}_{i, t-1}=C_{i}+v_{i, t-1}$, where $v_{i, t-1}$ converges to zero as $\mathrm{T}_{\mathrm{m}}$ approaches to infinity. In addition, the average return can be written as $\overline{\mathrm{r}}_{\mathrm{i}, \mathrm{t}}=\gamma_{0}+$ $\beta_{\mathrm{i}} \Gamma_{\mathrm{t}}+\zeta_{\mathrm{i}, \mathrm{t}}$, where $\zeta_{\mathrm{i}, \mathrm{t}}$ converges to zero as $\mathrm{T}_{\mathrm{m}}$ approaches to infinity. ${ }^{31}$

Therefore, the cross-sectional mean of the characteristic is

$$
\widehat{E}\left(\overline{\mathrm{C}}_{\mathrm{i}, \mathrm{t}-1}\right)=\frac{1}{\mathrm{~N}} \sum_{\mathrm{i}=1}^{\mathrm{N}} \overline{\mathrm{C}}_{\mathrm{i}, \mathrm{t}-1}=\frac{1}{\mathrm{~N}} \sum_{\mathrm{i}=1}^{\mathrm{N}} \mathrm{C}_{\mathrm{i}}+\frac{1}{\mathrm{~N}} \sum_{\mathrm{i}=1}^{\mathrm{N}} \mathrm{v}_{\mathrm{i}, \mathrm{t}-1} \rightarrow E\left(\mathrm{C}_{\mathrm{i}}\right)
$$

as both $\mathrm{N}$ and $\mathrm{T}_{\mathrm{m}}$ approach to infinity, with the regularity assumption that, for any $\mathrm{t}$ and $\mathrm{s}, \mathrm{v}_{\mathrm{i}, \mathrm{t}}$ and $v_{\mathrm{j}, \mathrm{s}}$ are uncorrelated when $\mathrm{i}$ and $\mathrm{j}$ are different. ${ }^{32}$ Similarly, we can show that

$$
\widehat{\operatorname{cov}}\left(\widehat{\beta}_{\mathrm{EV}, \mathrm{i}, \mathrm{t}-1}, \overline{\mathrm{C}}_{\mathrm{i}, \mathrm{t}-1}\right) \rightarrow \operatorname{cov}\left(\beta_{\mathrm{i}}, \mathrm{C}_{\mathrm{i}}\right)
$$

as $\mathrm{N}, \mathrm{T}$ and $\mathrm{T}_{\mathrm{m}}$ approach to infinity, with similar regularity assumptions. We can apply the same logic to all the cross-sectional sample means, covariances and variances in num and den; therefore,

$$
\begin{gathered}
\operatorname{num} \rightarrow\left(\operatorname{cov}\left(\beta_{\mathrm{i}}, \mathrm{C}_{\mathrm{i}}\right) E\left(\mathrm{C}_{\mathrm{i}}\right)-\operatorname{var}\left(\mathrm{C}_{\mathrm{i}}\right) E\left(\beta_{\mathrm{i}}\right)\right) E\left(\beta_{\mathrm{i}}\right) \Gamma_{\mathrm{t}}+\operatorname{var}\left(\mathrm{C}_{\mathrm{i}}\right) E\left(\left(\beta_{\mathrm{i}}\right)^{2}\right) \Gamma_{\mathrm{t}}- \\
\operatorname{cov}\left(\beta_{\mathrm{i}}, \mathrm{C}_{\mathrm{i}}\right) E\left(\mathrm{C}_{\mathrm{i}} \beta_{\mathrm{i}}\right) \Gamma_{\mathrm{t}}=\left(\operatorname{var}\left(\beta_{\mathrm{i}}\right) \operatorname{var}\left(\mathrm{C}_{\mathrm{i}}\right)-\left(\operatorname{cov}\left(\mathrm{C}_{\mathrm{i}}, \beta_{\mathrm{i}}\right)\right)^{2}\right) \Gamma_{\mathrm{t}}
\end{gathered}
$$

when $\mathrm{N}, \mathrm{T}$ and $\mathrm{T}_{\mathrm{m}}$ approach to infinity; and

$$
\text { den } \rightarrow \operatorname{var}\left(\beta_{\mathrm{i}}\right) \operatorname{var}\left(\mathrm{C}_{\mathrm{i}}\right)-\left(\operatorname{cov}\left(\mathrm{C}_{\mathrm{i}}, \beta_{\mathrm{i}}\right)\right)^{2}
$$

when $\mathrm{N}, \mathrm{T}$ and $\mathrm{T}_{\mathrm{m}}$ approach to infinity. This implies that the estimated risk premium $\hat{\gamma}_{\beta, \mathrm{t}} \rightarrow \Gamma_{\mathrm{t}}$

\footnotetext{
${ }^{31}$ Following the similar derivation in Appendix A (Eqs. (28)-(31)), we can show that $r_{i, t+\tau}=\gamma_{0}+\beta_{\mathrm{i}, \mathrm{t}+\tau}\left(\gamma+\mathrm{f}_{\mathrm{t}+\tau}-\right.$ $\left.E\left(\mathrm{f}_{\mathrm{t}+\tau} \mid \beta_{\mathrm{i}, \mathrm{t}+\tau}\right)\right)+\varepsilon_{\mathrm{i}, \mathrm{t}+\tau}$. Given that $\beta_{\mathrm{i}, \mathrm{t}+\tau}=\beta_{\mathrm{i}}+\vartheta_{\mathrm{i}, \mathrm{t}+\tau}$, we can show that $\overline{\mathrm{r}}_{\mathrm{i}, \mathrm{t}}=\gamma_{0}+\beta_{\mathrm{i}} \frac{1}{\mathrm{~T}_{\mathrm{m}}} \sum_{\tau=0}^{\mathrm{T}_{\mathrm{m}}-1}\left(\gamma+\mathrm{f}_{\mathrm{t}+\tau}-\right.$ $\left.E\left(\mathrm{f}_{\mathrm{t}+\tau} \mid \beta_{\mathrm{i}, \mathrm{t}+\tau}\right)\right)+\zeta_{\mathrm{i}, \mathrm{t}}$, where $\zeta_{\mathrm{i}, \mathrm{t}}=\frac{1}{\mathrm{~T}} \sum_{\tau=0}^{\mathrm{T}_{m}-1}\left(\varepsilon_{\mathrm{i}, \mathrm{t}+\tau}+\vartheta_{\mathrm{i}, \mathrm{t}+\tau}\left(\gamma+\mathrm{f}_{\mathrm{t}+\tau}-E\left(\mathrm{f}_{\mathrm{t}+\tau} \mid \beta_{\mathrm{i}, \mathrm{t}+\tau}\right)\right)\right)$. Since both $\varepsilon_{\mathrm{i}, \mathrm{t}}$ and $\vartheta_{\mathrm{i}, \mathrm{t}}$ are stationary and ergodic, $\zeta_{\mathrm{i}, \mathrm{t}}$ converges to zero as $\mathrm{T}_{\mathrm{m}}$ approaches to infinity.

${ }^{32}$ We will state all the regularity assumptions formally in Appendix G in the Internet Appendix.
} 
when $\mathrm{N}, \mathrm{T}$ and $\mathrm{T}_{\mathrm{m}}$ approach to infinity.

\section{Details of Simulations with Time-varying Betas and Characteristics}

This section describes the procedure that we use for the simulations with time-varying betas and time-varying characteristics discussed in Section 5.1. We assume that $\beta_{i, t}$ and $c_{i, t}$, i.e., the beta and corresponding characteristic of stock i in month $t$, follow AR(1) processes:

$$
\begin{aligned}
\beta_{i, t}-\beta_{i} & =\rho\left(\beta_{i, t-1}-\beta_{i}\right)+u_{i, t} \\
c_{i, t}-\beta_{i} & =\rho\left(c_{i, t-1}-\beta_{i}\right)+e_{i, t}
\end{aligned}
$$

where $u_{i, t}$ and $e_{i, t}$ are the shocks to beta and characteristic, respectively, the shock to the characteristic is defined as $e_{i, t}=u_{i, t+1}+\delta_{i, t}$, and $\beta_{i}$ is the unconditional mean of beta. We set $\rho$ to 0.96 , i.e., beta and characteristic have the same persistence. Note that $\beta_{\mathrm{i}, \mathrm{t}}$ and $\mathrm{c}_{\mathrm{i}, \mathrm{t}}$ are correlated through $\beta_{\mathrm{i}}$ cross-sectionally and $\beta_{\mathrm{i}, \mathrm{t}}$ and $\mathrm{c}_{\mathrm{i}, \mathrm{t}-1}$ are correlated through $\mathrm{u}_{\mathrm{i}, \mathrm{t}}$ crosssectionally.

We generate the time-varying betas and daily and monthly returns by following the same simulation procedure described in Appendix A. To generate the time-varying characteristic, we independently generate the shock to characteristic $\delta_{i, t}$ and combine it with the shock to future beta $\mathrm{u}_{\mathrm{i}, \mathrm{t}+1}$. The standard deviation of $\delta_{\mathrm{i}, \mathrm{t}}$ is determined based on the time-series average of crosssectional correlation between $\beta_{i, t}$ and $c_{i, t}$, whose information is presented in Panel $\mathrm{B}$ of Table $5 .{ }^{33}$ For the IV mean-estimator, we use the average characteristic over the past twelve months as additional instrumental variable and control variable, and we use the average return over the sample period from month $\mathrm{t}$ to month $\mathrm{t}+11$ as the dependent variable.

The simulation procedure is applied for the single-factor CAPM and the Fama-French three-factor model. Table A4 presents the ex-ante biases and RMSEs of risk premium estimates and slope coefficients of characteristics, and Table A5 presents the size and power of the corresponding IV tests, where the theoretical percentile for the size is 5\%. For comparison, the results for the OLS estimator are also provided in Tables A4 and A5.

\footnotetext{
33 To simulate time-varying market beta and corresponding characteristic, the average of cross-sectional correlation is set to the average of absolute value of Corr (SMB beta, SIZE) and Corr (HML beta, BM).
} 


\section{TABLE A4}

Small Sample Properties of the IV Mean-estimator with Time-varying Betas and Characteristics

Panel A: Single-factor CAPM

\begin{tabular}{cccccc}
\hline \multirow{2}{*}{$\begin{array}{c}\text { Risk } \\
\text { Factor }\end{array}$} & Estimator & $\begin{array}{c}\text { Ex-ante } \\
\text { Bias (\%) }\end{array}$ & $\begin{array}{c}\text { Ex-ante } \\
\text { RMSE }\end{array}$ & $\begin{array}{c}\text { Ex-ante } \\
\text { Bias (\%) }\end{array}$ & $\begin{array}{c}\text { Ex-ante } \\
\text { RMSE }\end{array}$ \\
\cline { 3 - 6 } & & \multicolumn{2}{c}{ Risk Premium } & $\begin{array}{c}\text { Slope Coefficient } \\
\text { on Characteristic }\end{array}$ \\
\hline \multirow{2}{*}{ MKT } & OLS & -29.1 & 0.196 & 4.1 & 0.027 \\
& IV Mean & -5.1 & 0.058 & 0.1 & 0.007 \\
\hline
\end{tabular}

Panel B: Fama-French Three-factor Model

\begin{tabular}{cccccc}
\hline \multirow{2}{*}{$\begin{array}{c}\text { Risk } \\
\text { Factor }\end{array}$} & \multirow{2}{*}{ Estimator } & $\begin{array}{c}\text { Ex-ante } \\
\text { Bias (\%) }\end{array}$ & $\begin{array}{c}\text { Ex-ante } \\
\text { RMSE }\end{array}$ & $\begin{array}{c}\text { Ex-ante } \\
\text { Bias (\%) }\end{array}$ & $\begin{array}{c}\text { Ex-ante } \\
\text { RMSE }\end{array}$ \\
\cline { 3 - 6 } & & \multicolumn{2}{c}{ Risk Premium } & \multicolumn{2}{c}{$\begin{array}{c}\text { Slope Coefficient } \\
\text { on Characteristic }\end{array}$} \\
\hline \multirow{2}{*}{ MKT } & OLS & -37.6 & 0.222 & 5.5 & 0.033 \\
& IV Mean & -5.2 & 0.059 & 0.1 & 0.007 \\
\hline \multirow{2}{*}{ SMB } & OLS & -67.6 & 0.158 & 18.1 & 0.048 \\
& IV Mean & -4.5 & 0.043 & -0.2 & 0.012 \\
\hline \multirow{2}{*}{ HML } & OLS & -60.6 & 0.227 & 6.7 & 0.028 \\
& IV Mean & -6.5 & 0.042 & 0.1 & 0.005 \\
\hline
\end{tabular}


TABLE A5

Size and Power of the Tests by the IV Mean-estimator with Time-varying Betas and Characteristics

Panel A: Single-factor CAPM

\begin{tabular}{|c|c|c|c|c|}
\hline \multirow{2}{*}{$\begin{array}{l}\text { Risk } \\
\text { Factor }\end{array}$} & \multirow{2}{*}{$\begin{array}{c}\text { Test } \\
\text { Based on }\end{array}$} & $\begin{array}{c}\text { Size } \\
\text { (Theoretical: 5\%) }\end{array}$ & Power & $\begin{array}{c}\text { Size } \\
\text { (Theoretical: 5\%) }\end{array}$ \\
\hline & & $\begin{array}{c}\text { Risk } \\
\text { Premium }\end{array}$ & Risk Premium & $\begin{array}{l}\text { Slope Coefficient } \\
\text { on Characteristic }\end{array}$ \\
\hline MKT & $\begin{array}{l}\text { OLS } \\
\text { IV Mean }\end{array}$ & $\begin{array}{l}4.0 \% \\
5.4 \%\end{array}$ & $\begin{array}{l}83.7 \% \\
99.9 \%\end{array}$ & $\begin{array}{l}4.5 \% \\
4.7 \%\end{array}$ \\
\hline
\end{tabular}

Panel B: Fama-French Three-factor Model

\begin{tabular}{ccccc}
\hline \multirow{2}{*}{$\begin{array}{c}\text { Risk } \\
\text { Factor }\end{array}$} & Test & $\begin{array}{c}\text { Size } \\
\text { (Theoretical: 5\%) }\end{array}$ & Power & $\begin{array}{c}\text { Size } \\
\text { (Theoretical: 5\%) }\end{array}$ \\
\cline { 3 - 5 } & Based on & $\begin{array}{c}\text { Risk } \\
\text { Premium }\end{array}$ & $\begin{array}{c}\text { Risk } \\
\text { Premium }\end{array}$ & $\begin{array}{c}\text { Slope Coefficient } \\
\text { on Characteristic }\end{array}$ \\
\hline \multirow{2}{*}{ MKT } & OLS & $5.7 \%$ & $77.6 \%$ & $4.5 \%$ \\
& IV Mean & $5.5 \%$ & $99.9 \%$ & $4.9 \%$ \\
\hline \multirow{2}{*}{ SMB } & OLS & $5.8 \%$ & $36.7 \%$ & $4.8 \%$ \\
& IV Mean & $4.6 \%$ & $99.1 \%$ & $4.9 \%$ \\
\hline \multirow{2}{*}{ HML } & OLS & $5.6 \%$ & $82.8 \%$ & $5.4 \%$ \\
& IV Mean & $5.3 \%$ & $99.9 \%$ & $4.7 \%$ \\
\hline
\end{tabular}




\section{Appendix D. Proof of Proposition 3}

For expositional convenience, we assume that the even-month beta is the independent variable and odd-month beta is its instrumental variable. We need to show that the correlation of true beta $(x)$ and estimated beta $\left(x^{*}\right)$ from even months is the square root of the correlation of independent beta $\left(x^{*}\right)$ and its instrumental beta $(z)$, i.e.,

$$
\operatorname{correlation}\left(\mathrm{x}, \mathrm{x}^{*}\right)=\sqrt{\operatorname{correlation}\left(\mathrm{x}^{*}, \mathrm{z}\right)}
$$

where $\mathrm{x}^{*}=\mathrm{x}+\mathrm{u}_{\text {even, }} \mathrm{z}=\mathrm{x}+\mathrm{u}_{\text {odd }}$

and $\mathrm{x}, \mathrm{u}_{\mathrm{even}}$, and $\mathrm{u}_{\mathrm{odd}}$ are mutually independent and $\sigma_{\mathrm{u}}^{2}=\sigma_{\mathrm{u}_{\mathrm{odd}}}^{2}=\sigma_{\mathrm{u}_{\text {even }}}^{2}$.

By the definition of correlation, we have

$$
\begin{gathered}
\operatorname{correlation}\left(\mathrm{x}^{*}, \mathrm{z}\right)=\frac{\operatorname{cov}\left(\mathrm{x}^{*}, \mathrm{z}\right)}{\sqrt{\operatorname{var}\left(\mathrm{x}^{*}\right) \operatorname{var}(\mathrm{z})}}=\frac{\sigma_{\mathrm{x}}^{2}}{\sigma_{\mathrm{x}}^{2}+\sigma_{\mathrm{u}}^{2}} \\
\operatorname{correlation}\left(\mathrm{x}^{*}, \mathrm{x}\right)=\frac{\operatorname{cov}\left(\mathrm{x}^{*}, \mathrm{x}\right)}{\sqrt{\operatorname{var}\left(\mathrm{x}^{*}\right) \operatorname{var}(\mathrm{x})}}=\frac{\sigma_{\mathrm{x}}^{2}}{\sqrt{\sigma_{\mathrm{x}}^{2}\left(\sigma_{\mathrm{x}}^{2}+\sigma_{\mathrm{u}}^{2}\right)}}=\sqrt{\operatorname{correlation}\left(\mathrm{x}^{*}, \mathrm{z}\right)}
\end{gathered}
$$




\section{References}

Acharya, V., Pedersen, L.H., 2005. Asset pricing with liquidity risk. Journal of Financial Economics 77, 375-410.

Aharoni, G., Bruce, G., Zeng, Q., 2013. Stock returns and the Miller Modigliani valuation formula: Revisiting the Fama French analysis. Journal of Financial Economics 110(2), 347-357.

Ait-Sahalia, Y., Parker, J.A., Yogo, M., 2004. Luxury goods and the equity premium. Journal of Finance 59, 2959-3004.

Amihud, Y., 2002. Illiquidity and stock Returns: Cross-section and time-series effects. Journal of Financial Markets 5, 31-56.

Amihud, Y., Mendelson, H., 1986. Asset pricing and the bid-ask spread. Journal of Financial Economics 17, 223-249.

Arnott, R., Hsu, J., Moore, P., 2005. Fundamental indexation. Financial Analysts Journal 61, 83-99.

Berk, J.B., Green, R.C., Naik, V., 1999. Optimal investment, growth options and security returns. Journal of Finance 54, 1153-1607.

Black, F., Jensen, M.C., Scholes, M., 1972. The capital asset pricing model: Some empirical tests. Michael C. Jensen, ed: Studies in the Theory of Capital Markets, 79-121.

Blume, M., Friend, I., 1973. A new look at the Capital Asset Pricing Model. Journal of Finance 28, 19-34.

Brennan, M., Chordia, T., Subrahmanyam, A., 1998. Alternative factor specifications, security characteristics, and the cross-section of expected returns. Journal of Financial Economics $49,345-373$.

Campbell, J., Vuolteenaho, T., 2004. Bad beta, good beta. American Economic Review 94, 1249-1275.

Carlson, M., Fisher, A., Giammarino, R., 2004. Corporate investment and asset price dynamics: Implications for the cross-section of returns. Journal of Finance 59, 2577-2603.

Carlson, M., Fisher, A., Giammarino, R., 2006. Corporate investment and asset price dynamics: Implications for SEO event studies and long-run performance. Journal of Finance 61 (3), 1009-1034.

Chan, K.C., Chen, N., 1988. An unconditional asset pricing test and the role of firm size as an instrumental variable for risk. Journal of Finance 43, 309-325. 
Chordia, T., Goyal, A., Shanken, J., 2015. Cross-sectional asset pricing with individual stocks: Betas versus characteristics. Working paper, Emory University.

Cochrane J., 1991. Production-based asset pricing and the link between stock returns and economic fluctuations. Journal of Finance 46, 209-237.

Cochrane J., 1996. A Cross-sectional test of an investment-based asset pricing model. Journal of Political Economy 104, 572-621.

Cochrane, J., 2011. Presidential Address: Discount rates. Journal of Finance 66, $1047-$ 1108.

Dimson E., 1979. Risk measurement when shares are subject to infrequent trading. Journal of Financial Economics 7, 197-226.

Eisfeldt A., Papanikolaou, D., 2013. Organization capital and the cross-section of expected returns. Journal of Finance 68, 1365-1406.

Fama E., French, K., 1993. Common risk factors in the returns on stocks and bonds. Journal of Financial Economics 33, 3-56.

Fama, E., French, K., 2014. A five-factor asset pricing model. Journal of Financial Economics 116, 1-22.

Fama, E.F., MacBeth, J.D., 1973. Risk, return and equilibrium: Empirical tests. Journal of Political Economy 81, 607-636.

Hou, K., Xue, C., Zhang, L., 2015. Digesting anomalies: An investment approach. Review of Financial Studies, 28 (3), 650-705.

Jagannathan R., Wang, Z., 1996. The conditional CAPM and the cross-section of expected returns. Journal of Finance 51, 3-53.

Jagannathan R., Wang, Z., 1998. An asymptotic theory for estimating beta-pricing models using cross-sectional regression. Journal of Finance 53, 1285-1309.

Jegadeesh N., 1992. Does market risk really explain the size effect? Journal of Financial and Quantitative Analysis 27, 337-351.

Kan R., Robotti, C., Shanken, J., 2013. Pricing model performance and the two-pass crosssectional regression methodology. Journal of Finance 68, 2617-2649.

Kim D., 1995. The errors-in-variables problem in the cross-section of expected stock returns. Journal of Finance 50, 1605-1634.

Kim S., Skoulakis, G., 2014. Estimating and testing linear factor models using large cross 
sections: The regression-calibration approach. Working paper, Georgia Institute of Technology.

Kinal, T. W., 1980. The existence of moments of k-class estimators. Econometrica 48, 24149.

Lettau M., Ludvigson, S., 2001. Resurrectng the (C)CAPM: A cross-sectional test when risk premia are time-varying. Journal of Political Economy 109, 1238-1287.

Lewellen J., Nagel, S., Shanken, J., 2010. A skeptical appraisal of asset pricing tests. Journal of Financial Economics 96, 175-194.

Li Q., Vassalou, M., Xing, Y., 2006. Sector investment growth rates and the cross section of equity returns. Journal of Business 89, 1637-1665.

Lintner J., 1965. The valuation of risk assets and the selection of risky investments in stock portfolios and capital budgets. Review of Economics and Statistics 47 (1), 13-37.

Litzenberger, R.H., Ramaswamy, K., 1979. The effect of personal taxes and dividends of capital asset prices: The theory and evidence. Journal of Financial Economics 7, 163-196.

Liu L.X., Whited, T., Zhang, L., 2009. Investment-based expected stock returns. Journal of Political Economy 117, 1105-1139.

Merton R., 1973. An intertemporal asset pricing model. Econometrica 41, 867-888.

Nelson, C., Startz, R., 1990. The distribution of the instrumental variable estimator and its $\mathrm{t}$ ratio when the instrument is a poor one. Journal of Business 63, S125-S140.

Novy-Marx, R., 2013. The other side of value: The gross profitability premium. Journal of Financial Economics 108, 1-28.

Pastor, L., Stambaugh, R., 2003. Liquidity risk and expected stock returns. Journal of Political Economy 111, 642-685.

Ross, S.A., 1976, The arbitrage theory of capital asset pricing. Journal of Economic Theory 13, 341-360.

Shanken, J., 1992. On the estimation of beta-pricing models. Review of Financial Studies $5,1-33$.

Shanken, J., Zhou, G., 2007. Estimating and testing beta pricing models: Alternative methods and their performance in simulations. Journal of Financial Economics 84, 40-86.

Sharpe, W., 1964. Capital asset prices: A theory of market equilibrium under conditions of risk. Journal of Finance 19 (3), 425-442.

Staiger D., Stock, J., 1997. Instrumental variables regression with weak instruments. 
Econometrica 65, 557-586.

Theil H., 1971. Principles of Econometrics, $1^{\text {st }}$ Edition, John-Wiley \& Sons, New York. Vasicek, O., 1973. A note on using cross-sectional information in Bayesian estimation of security betas. Journal of Finance 28, 1233-1239.

Zhang, L., 2005. The value premium. Journal of Finance 60(1), 67-103. 


\section{Internet Appendix}

to

\section{Empirical Tests of Asset Pricing Models with Individual Assets: \\ Resolving the Errors-in-Variables Bias in Risk Premium Estimation}

by

Narasimhan Jegadeesh, Joonki Noh, Kuntara Pukthuanthong, Richard Roll, and Junbo Wang

\section{Appendix E. Proof of Proposition 1}

Let $\boldsymbol{\beta}$ be the matrix of true values of betas for all factors and assets. When there are $\mathrm{K}$ factors and $\mathrm{N}$ assets, it is a $\mathrm{K} \times \mathrm{N}$ matrix. Next, let $\hat{\boldsymbol{\beta}}_{\mathrm{IV}}$ and $\hat{\boldsymbol{\beta}}_{\mathrm{EV}}(\mathrm{K} \times \mathrm{N}$ matrix $)$ be estimated betas, where "IV" subscript indicates the beta instruments and the "EV" subscript denotes the corresponding explanatory variables, respectively. We define IV and EV periods as separate periods of data used to estimate IV and EV betas, respectively, which can be either odd months or even months over a rolling estimation window. For example, if IV period includes odd months, EV period includes even months. The symbol “^” indicates an estimate. Define $\hat{\mathbf{B}}_{\mathrm{IV}} \equiv\left[\mathbf{1}_{1 \times N} ; \hat{\boldsymbol{\beta}}_{\mathrm{IV}}\right]$ and $\hat{\mathbf{B}}_{\mathrm{EV}} \equiv\left[\mathbf{1}_{1 \times \mathrm{N}} ; \hat{\boldsymbol{\beta}}_{\mathrm{EV}}\right]$, where $\mathbf{1}_{1 \times \mathrm{N}}$ denotes a $1 \times \mathrm{N}$ vector of ones ${ }^{1}$ and the operator "“;" stacks the first row vector on top of the second matrix. Hence, $\hat{\mathbf{B}}_{\mathrm{IV}}$ and $\hat{\mathbf{B}}_{\mathrm{EV}}$ are $(\mathrm{K}+1) \times \mathrm{N}$ matrices, each of which contains a vector of ones and K estimated factor loadings for $\mathrm{N}$ assets. Similarly, define $\mathrm{B} \equiv\left[\mathbf{1}_{1 \times \mathrm{N}} ; \boldsymbol{\beta}\right]$ as the matrix that contains a vector of ones and the matrix of true betas. Equivalently, we can write this matrix as $\mathrm{N}$ column vectors, i.e. $\mathbf{B}=\left[\mathbf{b}^{1}, \cdots, \mathbf{b}^{\mathrm{N}}\right]$, where $\mathbf{b}^{\mathrm{i}}=\left[1 ; \beta_{1}^{\mathrm{i}} ; \cdots ; \beta_{\mathrm{K}}^{\mathrm{i}}\right]$ for asset $\mathrm{i}^{2}$

Assuming that we have T+1 months, we use T months to estimate IV and EV betas, and run a cross-sectional regression in time $\mathrm{T}+1$. Define $\mathbf{r}_{\mathrm{t}}$ as the $1 \times \mathrm{N}$ vector of excess returns in time

\footnotetext{
${ }^{1}$ We will use this convention to define vectors or matrices of ones and zeros.

${ }^{2}$ Note that we use superscript $\mathrm{i}$ to indicate asset $\mathrm{i}$ in the Internet Appendix.
} 
t. Let $\mathbf{f}_{\mathrm{t}}$ denote the factor realization in time $\mathrm{t}$; it is a $1 \times \mathrm{K}$ vectors. And let $\boldsymbol{\varepsilon}_{\mathrm{t}}=\left[\varepsilon_{\mathrm{t}}^{1}, \varepsilon_{\mathrm{t}}^{2}, \cdots, \varepsilon_{\mathrm{t}}^{\mathrm{N}}\right]$. It is a $1 \times \mathrm{N}$ vector of regression residuals in time $\mathrm{t}$ for $\mathrm{N}$ assets in Eq. (2) in the main text. Assume that factors have zero means (or they are demeaned factors). The first-stage time-series regression (Eq.(2) in the main text) can be written as $\mathbf{r}_{t}=\boldsymbol{\alpha}+\mathbf{f}_{t} \boldsymbol{\beta}+\boldsymbol{\varepsilon}_{\mathrm{t}}$ where $\boldsymbol{\alpha}=\left[\alpha^{1}, \cdots, \alpha^{\mathrm{N}}\right]$, which is a $1 \times \mathrm{N}$ vector.

Using OLS methods, we estimate IV and EV betas over the IV and EV periods, respectively. Assuming that $\mathrm{T}$ is even, the estimation error for IV beta can be expressed as follows:

$$
\hat{\boldsymbol{\beta}}_{\mathrm{IV}}-\boldsymbol{\beta}=\left(\mathbf{F}_{\mathrm{IV}}^{\mathrm{d}} \mathbf{F}_{\mathrm{IV}}^{\mathrm{d}}\right)^{-1} \mathbf{F}_{\mathrm{IV}}^{\mathrm{d}} \mathbf{\Omega}_{\mathrm{IV}}^{\mathrm{d}} \equiv \mathbf{u}_{\mathrm{IV}}
$$

where $\mathbf{F}_{\mathrm{IV}}^{\mathrm{d}} \equiv\left[\mathbf{f}_{1}^{\mathrm{d}} ; \mathbf{f}_{3}^{\mathrm{d}} \cdots ; \mathbf{f}_{\mathrm{T}-1}^{\mathrm{d}}\right]$ is a $\mathrm{T} / 2 \times \mathrm{K}$ matrix when the IV period includes odd months, or $\mathbf{F}_{\mathrm{IV}}^{\mathrm{d}} \equiv\left[\mathbf{f}_{2}^{\mathrm{d}} ; \mathbf{f}_{4}^{\mathrm{d}} ; \cdots ; \mathbf{f}_{\mathrm{T}}^{\mathrm{d}}\right]$ is a $\mathrm{T} / 2 \times \mathrm{K}$ matrix when the IV period includes even months. $\boldsymbol{\Omega}_{\mathrm{IV}}^{\mathrm{d}}=\left[\boldsymbol{\varepsilon}_{1}^{\mathrm{d}} ; \boldsymbol{\varepsilon}_{3}^{\mathrm{d}} ; \cdots ; \boldsymbol{\varepsilon}_{\mathrm{T}-1}^{\mathrm{d}}\right]$ is a $\mathrm{T} / 2 \times \mathrm{N}$ matrix when the IV period includes odd months, or $\boldsymbol{\Omega}_{\mathrm{IV}}^{\mathrm{d}}=\left[\boldsymbol{\varepsilon}_{2}^{\mathrm{d}} ; \boldsymbol{\varepsilon}_{4}^{\mathrm{d}} ; \cdots ; \boldsymbol{\varepsilon}_{\mathrm{T}}^{\mathrm{d}}\right]$ is a $\mathrm{T} / 2 \times \mathrm{N}$ matrix when the IV period includes even months. The superscript $\mathrm{d}$ indicates a demeaned factor or demeaned residual, where average values of factors or residuals are taken over the corresponding IV period. For example, $\mathbf{f}_{1}^{\mathrm{d}} \equiv \mathbf{f}_{1}-\frac{2}{\mathrm{~T}}\left(\mathbf{f}_{1}+\mathbf{f}_{3}+\cdots+\mathbf{f}_{\mathrm{T}-1}\right)$ and $\mathbf{f}_{2}^{\mathrm{d}} \equiv \mathbf{f}_{2}-\frac{2}{\mathrm{~T}}\left(\mathbf{f}_{2}+\mathbf{f}_{4}+\cdots+\mathbf{f}_{\mathrm{T}}\right)$. From the above expression for $\hat{\boldsymbol{\beta}}_{\mathrm{IV}}-\boldsymbol{\beta}$, we obtain $\hat{\mathbf{B}}_{\mathrm{IV}}-\mathbf{B}=\left[\mathbf{0}_{\mathrm{I \times N}} ;\left(\mathbf{F}_{\mathrm{IV}}^{\mathrm{d}}{ }^{\prime} \mathbf{F}_{\mathrm{IV}}^{\mathrm{d}}\right)^{-1} \mathbf{F}_{\mathrm{IV}}^{\mathrm{d}} \mathbf{\Omega}_{\mathrm{IV}}^{\mathrm{d}}\right]$. Similarly, it can be easily shown that the estimation error for $\mathrm{EV}$ beta is $\hat{\boldsymbol{\beta}}_{\mathrm{EV}}-\boldsymbol{\beta}=\left(\mathbf{F}_{\mathrm{EV}}^{\mathrm{d}}{ }^{\prime} \mathbf{F}_{\mathrm{EV}}^{\mathrm{d}}\right)^{-1} \mathbf{F}_{\mathrm{EV}}^{\mathrm{d}} \mathbf{\Omega}_{\mathrm{EV}}^{\mathrm{d}} \equiv \mathbf{u}_{\mathrm{EV}}$, leading to $\hat{\mathbf{B}}_{\mathrm{EV}}-\mathbf{B}=\left[\mathbf{0}_{1 \times \mathrm{N}} ;\left(\mathbf{F}_{\mathrm{EV}}^{\mathrm{d}} \mathbf{F}_{\mathrm{EV}}^{\mathrm{d}}\right)^{-1} \mathbf{F}_{\mathrm{EV}}^{\mathrm{d}} \mathbf{\Omega}_{\mathrm{EV}}^{\mathrm{d}}\right]$, where $\mathbf{F}_{\mathrm{EV}}^{\mathrm{d}}$ and $\boldsymbol{\Omega}_{\mathrm{EV}}^{\mathrm{d}}$ are similarly defined as $\mathbf{F}_{\mathrm{IV}}^{\mathrm{d}}$ and $\boldsymbol{\Omega}_{\mathrm{IV}}^{\mathrm{d}}$, respectively.

The model for expected returns follows Eq. (1) in the main text. If riskless borrowing and lending are allowed, then the zero-beta asset earns the risk-free rate and its excess return is zero, i.e. in Eq. (1), $\gamma_{0}=0$. Thus, the cross-sectional regression model with $\gamma_{0}=0$ and ex-post risk 
premium (defined as $\mathbf{f}_{\mathrm{T}+1}+\boldsymbol{\gamma}$ ) can be written as $\mathbf{r}_{\mathrm{T}+1}=\left(\mathbf{f}_{\mathrm{T}+1}+\boldsymbol{\gamma}\right) \boldsymbol{\beta}+\boldsymbol{\varepsilon}_{\mathrm{T}+1}$, where gamma is a $1 \times \mathrm{K}$ vector of ex-ante risk premium. ${ }^{3}$ We rewrite it to

$$
\mathbf{r}_{\mathrm{T}+1}=\left(\mathbf{f}_{\mathrm{T}+1}+\boldsymbol{\gamma}\right) \hat{\boldsymbol{\beta}}_{\mathrm{EV}}+\left(\mathbf{f}_{\mathrm{T}+1}+\boldsymbol{\gamma}\right)\left(\boldsymbol{\beta}-\hat{\boldsymbol{\beta}}_{\mathrm{EV}}\right)+\boldsymbol{\varepsilon}_{\mathrm{T}+1} \text {. }
$$

Let $\xi_{\mathrm{T}+1}^{\mathrm{EV}}=\left(\mathbf{f}_{\mathrm{T}+1}+\boldsymbol{\gamma}\right)\left(\boldsymbol{\beta}-\hat{\boldsymbol{\beta}}_{\mathrm{EV}}\right)+\boldsymbol{\varepsilon}_{\mathrm{T}+1}=-\left(\mathbf{f}_{\mathrm{T}+1}+\boldsymbol{\gamma}\right) \mathbf{u}_{\mathrm{EV}}+\boldsymbol{\varepsilon}_{\mathrm{T}+1}$, and let $\boldsymbol{\Gamma}=\left(0, \boldsymbol{\gamma}+\mathbf{f}_{\mathrm{T}+1}\right)$, a $1 \times(\mathrm{K}+1)$ vector that contains the ex-post risk premiums. The assets' returns in time $\mathrm{T}+1$ can be written as

$$
\mathbf{r}_{\mathrm{T}+1}=\boldsymbol{\Gamma} \hat{\mathbf{B}}_{\mathrm{EV}}+\xi_{\mathrm{T}+1}^{\mathrm{EV}}
$$

We then propose the following IV estimator for ex-post risk premium in month $\mathrm{T}+1$ :

$$
\hat{\boldsymbol{\Gamma}}_{\mathrm{T}+1}{ }^{\prime}=\left(\hat{\mathbf{B}}_{\mathrm{IV}} \hat{\mathbf{B}}_{\mathrm{EV}}{ }^{\prime}\right)^{-1}\left(\hat{\mathbf{B}}_{\mathrm{IV}} \mathbf{r}_{\mathrm{T}+1}{ }^{\prime}\right) . \quad \text { (Eq. (4) in the main text) }
$$

In order to show the $\mathrm{N}$-consistency of the IV estimator (which is $\hat{\Gamma}_{\mathrm{T}+1}$ ), we need to make the following regularity assumptions:

(A1) The residual process $\left\{\boldsymbol{\varepsilon}_{\mathrm{t}}, \mathrm{t}=1, \cdots, \mathrm{T}\right\}$, where $\boldsymbol{\varepsilon}_{\mathrm{t}}=\left[\varepsilon_{\mathrm{t}}^{1}, \varepsilon_{\mathrm{t}}^{2}, \cdots, \varepsilon_{\mathrm{t}}^{\mathrm{N}}\right]$, is stationary with zero mean and finite fourth moments. In addition, $\varepsilon_{t}^{i}$ and $\varepsilon_{s}^{j}$ are uncorrelated as long as $s \neq t$. Moreover, for any $\mathrm{s} \neq \mathrm{t}, \frac{1}{\sqrt{\mathrm{N}}}\left(\varepsilon_{\mathrm{t}}^{1} \varepsilon_{\mathrm{s}}^{1}+\cdots+\varepsilon_{\mathrm{t}}^{\mathrm{N}} \varepsilon_{\mathrm{s}}^{\mathrm{N}}\right)$ have finite variances.

${ }^{3}$ Rewriting Eq. (1) (with $\gamma_{0}=0$ ) and Eq. (2) in the main text in matrix notations, we have $E\left(\mathbf{r}_{\mathrm{T}+1}\right)=\boldsymbol{\gamma} \boldsymbol{\beta}$ denoted as Eq. (1') and $\mathbf{r}_{\mathrm{T}+1}=\boldsymbol{\alpha}+\mathbf{f}_{\mathrm{T}+1} \boldsymbol{\beta}+\boldsymbol{\varepsilon}_{\mathrm{T}+1}$ denoted as Eq. (2') where $\boldsymbol{\gamma}=\left[\gamma_{1}, \cdots, \gamma_{\mathrm{K}}\right], \boldsymbol{\alpha}=\left[\alpha^{1}, \cdots, \alpha^{\mathrm{N}}\right]$, and $\boldsymbol{\varepsilon}_{\mathrm{T}+1}=\left[\varepsilon_{\mathrm{T}+1}^{1}, \cdots, \varepsilon_{\mathrm{T}+1}^{\mathrm{N}}\right]$. With the assumptions that $E\left(\mathbf{f}_{\mathrm{t}}\right)=0$ and $E\left(\boldsymbol{\varepsilon}_{\mathrm{t}}\right)=0$, taking the expectation of Eq. (2') produces $E\left(\mathbf{r}_{\mathrm{T}+1}\right)=\boldsymbol{\alpha} \quad$ denoted as Eq.(2'). Combining Eqs. (1'), (2'), and (2”) gives us $\mathbf{r}_{\mathrm{T}+1}=\left(\mathbf{f}_{\mathrm{T}+1}+\boldsymbol{\gamma}\right) \boldsymbol{\beta}+\boldsymbol{\varepsilon}_{\mathrm{T}+1}$. 
(A2) The factor process $\left\{\mathbf{f}_{t}, t=1, \cdots, T\right\}$ is stationary with finite fourth moments, and is independent of the residual process $\left\{\boldsymbol{\varepsilon}_{\mathrm{t}}, \mathrm{t}=1, \cdots, \mathrm{T}\right\}$.

(A3) For any $\mathrm{i}$ and $\mathrm{t}$, the elements in $\mathbf{b}^{\mathrm{i}}$ and $\varepsilon_{\mathrm{t}}^{\mathrm{i}}$ are uncorrelated. For any $\mathrm{t}$, the elements in $\frac{1}{\sqrt{\mathrm{N}}}\left(\mathbf{b}^{1} \varepsilon_{\mathrm{t}}^{1}+\cdots+\mathbf{b}^{\mathrm{N}} \varepsilon_{\mathrm{t}}^{\mathrm{N}}\right)$. Moreover, when $\mathrm{N} \rightarrow \infty, \mathbf{B B}^{\prime} / \mathrm{N}$ converges to an invertible matrix $\mathbf{b b}^{\prime}$ $\left(=E\left(\mathbf{b}^{\mathrm{i}}\left(\mathbf{b}^{\mathrm{i}}\right)^{\prime}\right)\right)$.

Note that the Assumptions (A1) and (A3) are satisfied if in each time t, the residuals in $\left[\varepsilon_{t}^{1}, \cdots, \varepsilon_{t}^{N}\right]$ are asymptotically weakly correlated (Shanken,1992), regression residuals have finite fourth moments, and the maximum values of betas across all stocks are finite.

With the Assumptions (A1) to (A3), N-consistency is presented in Theorem E.

Theorem E (Consistency, Proposition 1 in the main text) Assuming (A1) to (A3), the estimated risk premium $\hat{\boldsymbol{\Gamma}}_{\mathrm{T}+1}{ }^{\prime} \equiv\left(\frac{1}{\mathrm{~N}} \hat{\mathbf{B}}_{\mathrm{IV}} \hat{\mathbf{B}}_{\mathrm{EV}}\right)^{-1}\left(\frac{1}{\mathrm{~N}} \hat{\mathbf{B}}_{\mathrm{IV}} \mathbf{r}_{\mathrm{T}+1}{ }^{\prime}\right)$ converges to $\boldsymbol{\Gamma}^{\prime}$ when $\mathrm{N}$ approaches to infinity.

Proof of the consistency: Note that

$$
\hat{\boldsymbol{\Gamma}}_{\mathrm{T}+1}{ }^{\prime}-\boldsymbol{\Gamma}^{\prime}=\left(\frac{1}{\mathrm{~N}} \hat{\mathbf{B}}_{\mathrm{IV}} \hat{\mathbf{B}}_{\mathrm{EV}}\right)^{-1}\left(\frac{1}{\mathrm{~N}} \hat{\mathbf{B}}_{\mathrm{IV}} \xi_{\mathrm{T}+1}^{\mathrm{EV}}{ }^{\prime}\right) .
$$

To show the consistency as $\mathrm{N}$ goes to infinity, we need to prove the following two convergences:

$$
\begin{aligned}
& \frac{1}{\mathrm{~N}} \hat{\mathbf{B}}_{\mathrm{IV}} \xi_{\mathrm{T}+1}^{\mathrm{EV}}{ }^{\prime}=\frac{1}{\mathrm{~N}} \sum_{\mathrm{i}=1}^{\mathrm{N}}\left(\mathbf{b}^{\mathrm{i}}+\left[0 ;\left(\mathbf{F}_{\mathrm{IV}}^{\mathrm{d}}{ }^{\prime} \mathbf{F}_{\mathrm{IV}}^{\mathrm{d}}\right)^{-1} \mathbf{F}_{\mathrm{IV}}^{\mathrm{d}}{ }^{\prime}\left(\boldsymbol{\varepsilon}_{\mathrm{IV}}^{\mathrm{di}}\right)^{\prime}\right]\right) \xi_{\mathrm{T}+1}^{\mathrm{EV}, \mathrm{i}} \rightarrow \mathbf{0}_{(\mathrm{K}+1) \times 1} \text { and } \\
& \frac{1}{\mathrm{~N}} \hat{\mathbf{B}}_{\mathrm{IV}} \hat{\mathbf{B}}_{\mathrm{EV}}{ }^{\prime}=\frac{1}{\mathrm{~N}}\left(\mathbf{B}+\left[\mathbf{0}_{1 \times \mathrm{N}} ;\left(\mathbf{F}_{\mathrm{IV}}^{\mathrm{d}}{ }^{\prime} \mathbf{F}_{\mathrm{IV}}^{\mathrm{d}}\right)^{-1} \mathbf{F}_{\mathrm{IV}}^{\mathrm{d}} \mathbf{\Omega}_{\mathrm{IV}}^{\mathrm{d}}\right]\right)\left(\mathbf{B}+\left[\mathbf{0}_{1 \times \mathrm{N}} ;\left(\mathbf{F}_{\mathrm{EV}}^{\mathrm{d}} \cdot \mathbf{F}_{\mathrm{EV}}^{\mathrm{d}}\right)^{-1} \mathbf{F}_{\mathrm{EV}}^{\mathrm{d}} \boldsymbol{\Omega}_{\mathrm{EV}}^{\mathrm{d}}\right]\right)^{\prime} \\
& =\frac{1}{\mathrm{~N}} \sum_{i=1}^{\mathrm{N}}\left(\left(\mathbf{b}^{\mathrm{i}}+\left[0 ;\left(\mathbf{F}_{\mathrm{IV}}^{\mathrm{d}}{ }^{\prime} \mathbf{F}_{\mathrm{IV}}^{\mathrm{d}}\right)^{-1} \mathbf{F}_{\mathrm{IV}}^{\mathrm{d}}{ }^{\prime}\left(\boldsymbol{\varepsilon}_{\mathrm{IV}}^{\mathrm{di}}\right)^{\prime}\right]\right)\left(\mathbf{b}^{\mathrm{i}}+\left[0 ;\left(\mathbf{F}_{\mathrm{EV}}^{\mathrm{d}}{ }^{\prime} \mathbf{F}_{\mathrm{EV}}^{\mathrm{d}}\right)^{-1} \mathbf{F}_{\mathrm{EV}}^{\mathrm{d}}{ }^{\prime}\left(\boldsymbol{\varepsilon}_{\mathrm{EV}}^{\mathrm{d}, \mathrm{i}}\right)^{\prime}\right]\right)^{\prime}\right) \rightarrow \mathbf{b} \mathbf{b} \text {. }
\end{aligned}
$$

Here, $\boldsymbol{\varepsilon}_{\mathrm{IV}}^{\mathrm{d}, \mathrm{i}}$ is a $1 \times \mathrm{T} / 2$ vector that contains the demeaned residuals for asset $\mathrm{i}$ in the IV period, and $\boldsymbol{\varepsilon}_{\mathrm{EV}}^{\mathrm{d}, \mathrm{i}}$ is a $1 \times \mathrm{T} / 2$ vector that contains the demeaned residuals for asset $\mathrm{i}$ in the EV period. For example, if the IV period includes odd months, and the EV period includes even months, $\boldsymbol{\varepsilon}_{\mathrm{IV}}^{\mathrm{d}, \mathrm{i}}=\left[\varepsilon_{1}^{\mathrm{d}, \mathrm{i}}, \varepsilon_{3}^{\mathrm{d}, \mathrm{i}}, \cdots, \varepsilon_{\mathrm{T}-1}^{\mathrm{d}, \mathrm{i}}\right]$ and $\boldsymbol{\varepsilon}_{\mathrm{EV}}^{\mathrm{d}, \mathrm{i}}=\left[\varepsilon_{2}^{\mathrm{d,i}}, \varepsilon_{4}^{\mathrm{d}, \mathrm{i}}, \cdots, \varepsilon_{\mathrm{T}}^{\mathrm{d}, \mathrm{i}}\right]$ where $\varepsilon_{\mathrm{t}}^{\mathrm{d}, \mathrm{i}} \equiv \varepsilon_{\mathrm{t}}^{\mathrm{i}}-\frac{2}{\mathrm{~T}}\left(\varepsilon_{1}^{\mathrm{i}}+\varepsilon_{3}^{\mathrm{i}}+\cdots+\varepsilon_{\mathrm{T}-1}^{\mathrm{i}}\right)$ 
when $\mathrm{t}$ is odd, and $\varepsilon_{\mathrm{t}}^{\mathrm{d}, \mathrm{i}} \equiv \varepsilon_{\mathrm{t}}^{\mathrm{i}}-\frac{2}{\mathrm{~T}}\left(\varepsilon_{2}^{\mathrm{i}}+\varepsilon_{4}^{\mathrm{i}}+\cdots+\varepsilon_{\mathrm{T}}^{\mathrm{i}}\right)$ when $\mathrm{t}$ is even. Moreover, $\xi_{\mathrm{T}+1}^{\mathrm{EV}}$, a $1 \times \mathrm{N}$ vector, can be written as $\left[\xi_{\mathrm{T}+1}^{\mathrm{EV}, 1}, \cdots, \xi_{\mathrm{T}+1}^{\mathrm{EV}, \mathrm{N}}\right]$.

Under Assumptions (A1) to (A3), we now have the following observations:

I. For any i, $E\left(\mathbf{b}^{\mathrm{i}} \xi_{\mathrm{T}+1}^{\mathrm{EV}, \mathrm{i}}\right)=\mathbf{0}_{(\mathrm{K}+1) \times 1}, E\left(\mathbf{b}^{\mathrm{i}}\left[0 ;\left(\mathbf{F}_{\mathrm{IV}}^{\mathrm{d}} \mathbf{F}_{\mathrm{IV}}^{\mathrm{d}}\right)^{-1} \mathbf{F}_{\mathrm{IV}}^{\mathrm{d}}{ }^{\prime}\left(\boldsymbol{\varepsilon}_{\mathrm{IV}}^{\mathrm{d}, \mathrm{i}}\right)^{\prime}\right]^{\prime}\right)=\mathbf{0}_{(\mathrm{K}+1) \times(\mathrm{K}+1)}$,

$$
\begin{aligned}
& E\left(\mathbf{b}^{\mathrm{i}}\left(\left[0 ;\left(\mathbf{F}_{\mathrm{EV}}^{\mathrm{d}} \mathbf{F}_{\mathrm{EV}}^{\mathrm{d}}\right)^{-1} \mathbf{F}_{\mathrm{EV}}^{\mathrm{d}}{ }^{\prime}\left(\boldsymbol{\varepsilon}_{\mathrm{EV}}^{\mathrm{d}, \mathrm{i}}\right)^{\prime}\right]^{\prime}\right)=\mathbf{0}_{(\mathrm{K}+1) \times(\mathrm{K}+1)},\right. \\
& E\left(\left[0 ;\left(\mathbf{F}_{\mathrm{IV}}^{\mathrm{d},} \mathbf{F}_{\mathrm{IV}}^{\mathrm{d}}\right)^{-1} \mathbf{F}_{\mathrm{IV}}^{\mathrm{d}}{ }^{\prime}\left(\boldsymbol{\varepsilon}_{\mathrm{IV}}^{\mathrm{d}, \mathrm{i}}\right)^{\prime}\right]\left[0 ;\left(\mathbf{F}_{\mathrm{EV}}^{\mathrm{d}} \mathbf{F}_{\mathrm{EV}}^{\mathrm{d}}\right)^{-1} \mathbf{F}_{\mathrm{EV}}^{\mathrm{d}}{ }^{\prime}\left(\boldsymbol{\varepsilon}_{\mathrm{EV}}^{\mathrm{d}, \mathrm{i}}\right)^{\prime}\right]^{\prime}\right)=\mathbf{0}_{(\mathrm{K}+1) \times(\mathrm{K}+1)}, \text { and } \\
& E\left(\left[0 ;\left(\mathbf{F}_{\mathrm{IV}}^{\mathrm{d}} \mathbf{F}_{\mathrm{IV}}^{\mathrm{d}}\right)^{-1} \mathbf{F}_{\mathrm{IV}}^{\mathrm{d},}\left(\boldsymbol{\varepsilon}_{\mathrm{IV}}^{\mathrm{d}, \mathrm{i}}\right)^{\prime}\right] \xi_{\mathrm{T}+\mathbf{1}}^{\mathrm{EV}, \mathbf{i}}\right)=\mathbf{0}_{(\mathrm{K}+1) \times 1} .
\end{aligned}
$$

Since the elements in $\frac{1}{\sqrt{\mathrm{N}}}\left(\mathbf{b}^{1} \varepsilon_{t}^{1}+\cdots+\mathbf{b}^{\mathrm{N}} \varepsilon_{t}^{\mathrm{N}}\right)$ have finite variances for any time $\mathrm{t}$

(Assumption (A3)), it is clear that the elements in $\frac{1}{\sqrt{\mathrm{N}}}\left(\mathbf{b}^{1} \xi_{\mathrm{T}+1}^{\mathrm{EV}, 1}+\cdots+\mathbf{b}^{\mathrm{N}} \xi_{\mathrm{T}+1}^{\mathrm{EV}, \mathrm{N}}\right)$ have finite variances. For the same reason, the elements in

$\frac{1}{\sqrt{\mathrm{N}}}\left(\mathbf{b}^{1}\left[0 ;\left(\mathbf{F}_{\mathrm{IV}}^{\mathrm{d}} \mathbf{F}_{\mathrm{IV}}^{\mathrm{d}}\right)^{-1} \mathbf{F}_{\mathrm{IV}}^{\mathrm{d}}{ }^{\prime}\left(\boldsymbol{\varepsilon}_{\mathrm{IV}}^{\mathrm{d}, 1}\right)^{\prime}\right]^{\prime}+\cdots+\mathbf{b}^{\mathrm{N}}\left[0 ;\left(\mathbf{F}_{\mathrm{IV}}^{\mathrm{d}} \mathbf{F}_{\mathrm{IV}}^{\mathrm{d}}\right)^{-1} \mathbf{F}_{\mathrm{IV}}^{\mathrm{d}}{ }^{\prime}\left(\boldsymbol{\varepsilon}_{\mathrm{IV}}^{\mathrm{d}, \mathrm{N}}\right)^{\prime}\right]^{\prime}\right)$ have finite variances, and the elements in $\frac{1}{\sqrt{\mathrm{N}}}\left(\mathbf{b}^{1}\left[0 ;\left(\mathbf{F}_{\mathrm{EV}}^{\mathrm{d}} \mathbf{F}_{\mathrm{EV}}^{\mathrm{d}}\right)^{-1} \mathbf{F}_{\mathrm{EV}}^{\mathrm{d}}{ }^{\prime}\left(\boldsymbol{\varepsilon}_{\mathrm{EV}}^{\mathrm{d}, 1}\right)^{\prime}\right]^{\prime}+\cdots+\mathbf{b}^{\mathrm{N}}\left[0 ;\left(\mathbf{F}_{\mathrm{EV}}^{\mathrm{d}}{ }^{\prime} \mathbf{F}_{\mathrm{EV}}^{\mathrm{d}}\right)^{-1} \mathbf{F}_{\mathrm{EV}}^{\mathrm{d}}{ }^{\prime}\left(\boldsymbol{\varepsilon}_{\mathrm{EV}}^{\mathrm{d}, \mathrm{N}}\right)^{\prime}\right]^{\prime}\right)$ have finite variances.

II. If regression residuals have finite fouth moments (Assumption (A1)), and $\frac{1}{\sqrt{N}}\left(\varepsilon_{t}^{1} \varepsilon_{s}^{1}+\cdots+\varepsilon_{t}^{N} \varepsilon_{s}^{N}\right)$ have finite variances for any $s \neq t$ (Assumption (A1)), then for any $i$, the elements in $\frac{1}{\sqrt{\mathrm{N}}} \sum_{\mathrm{i}=1}^{\mathrm{N}}\left(\left[0 ;\left(\mathbf{F}_{\mathrm{IV}}^{\mathrm{d}}{ }^{\prime} \mathbf{F}_{\mathrm{IV}}^{\mathrm{d}}\right)^{-1} \mathbf{F}_{\mathrm{IV}}^{\mathrm{d}}{ }^{\prime}\left(\boldsymbol{\varepsilon}_{\mathrm{IV}}^{\mathrm{d}, \mathrm{i}}\right)^{\prime}\right] \xi_{\mathrm{T}+1}^{\mathrm{EV}, \mathrm{i}}\right)$ have finite variances, and the elements in $\frac{1}{\sqrt{\mathrm{N}}} \sum_{\mathrm{i}=1}^{\mathrm{N}}\left(\left[0 ;\left(\mathbf{F}_{\mathrm{IV}}^{\mathrm{d}} \mathbf{F}_{\mathrm{IV}}^{\mathrm{d}}\right)^{-1} \mathbf{F}_{\mathrm{IV}}^{\mathrm{d}}{ }^{\prime}\left(\boldsymbol{\varepsilon}_{\mathrm{IV}}^{\mathrm{d}, \mathrm{i}}\right)^{\prime}\right]\left[0 ;\left(\mathbf{F}_{\mathrm{EV}}^{\mathrm{d}}{ }^{\prime} \mathbf{F}_{\mathrm{EV}}^{\mathrm{d}}\right)^{-1} \mathbf{F}_{\mathrm{EV}}^{\mathrm{d}}{ }^{\prime}\left(\boldsymbol{\varepsilon}_{\mathrm{EV}}^{\mathrm{d}, \mathrm{i}}\right)^{\prime}\right]^{\prime}\right)$ also have finite variances.

With the observations I, II, and III, apply Markov's Law of Large Numbers, 


$$
\begin{aligned}
& \frac{1}{\mathrm{~N}} \sum_{\mathrm{i}=1}^{\mathrm{N}} \mathbf{b}^{\mathrm{i}} \xi_{\mathrm{T}+1}^{\mathrm{EV}, \mathrm{i}} \rightarrow \mathbf{0}_{(\mathrm{K}+1) \times 1} \\
& \frac{1}{\mathrm{~N}} \sum_{\mathrm{i}=1}^{\mathrm{N}}\left(\left[0 ;\left(\mathbf{F}_{\mathrm{IV}}^{\mathrm{d}} \mathbf{F}_{\mathrm{IV}}^{\mathrm{d}}\right)^{-1} \mathbf{F}_{\mathrm{IV}}^{\mathrm{d}}{ }^{\prime}\left(\boldsymbol{\varepsilon}_{\mathrm{IV}}^{\mathrm{d}, \mathrm{i}}\right)^{\prime}\right] \xi_{\mathrm{T}+1}^{\mathrm{EV}, \mathrm{i}}\right) \rightarrow \mathbf{0}_{(\mathrm{K}+1) \times 1} \\
& \frac{1}{\mathrm{~N}} \sum_{\mathrm{i}=1}^{\mathrm{N}}\left(\left[0 ;\left(\mathbf{F}_{\mathrm{IV}}^{\mathrm{d}}, \mathbf{F}_{\mathrm{IV}}^{\mathrm{d}}\right)^{-1} \mathbf{F}_{\mathrm{IV}}^{\mathrm{d}}{ }^{\prime}\left(\boldsymbol{\varepsilon}_{\mathrm{IV}}^{\mathrm{d}, \mathrm{i}}\right)^{\prime}\right]\left(\mathbf{b}^{\mathrm{i}}\right)^{\prime}\right) \rightarrow \mathbf{0}_{(\mathrm{K}+1) \times(\mathrm{K}+1)} \\
& \frac{1}{\mathrm{~N}} \sum_{\mathrm{i}=1}^{\mathrm{N}}\left(\mathbf{b}^{\mathrm{i}}\left[0 ;\left(\mathbf{F}_{\mathrm{EV}}^{\mathrm{d}}, \mathbf{F}_{\mathrm{EV}}^{\mathrm{d}}\right)^{-1} \mathbf{F}_{\mathrm{EV}}^{\mathrm{d}}{ }^{\prime}\left(\boldsymbol{\varepsilon}_{\mathrm{EV}}^{\mathrm{d}, \mathrm{i}}\right)^{\prime}\right]^{\prime}\right) \rightarrow \mathbf{0}_{(\mathrm{K}+1) \times(\mathrm{K}+1)} \\
& \frac{1}{\mathrm{~N}} \sum_{\mathrm{i}=1}^{\mathrm{N}}\left(\left[0 ;\left(\mathbf{F}_{\mathrm{IV}}^{\mathrm{d}}, \mathbf{F}_{\mathrm{IV}}^{\mathrm{d}}\right)^{-1} \mathbf{F}_{\mathrm{IV}}^{\mathrm{d}}{ }^{\prime}\left(\boldsymbol{\varepsilon}_{\mathrm{IV}}^{\mathrm{d}, \mathrm{i}}\right)^{\prime}\right]\left[0 ;\left(\mathbf{F}_{\mathrm{EV}}^{\mathrm{d}}, \mathbf{F}_{\mathrm{EV}}^{\mathrm{d}}\right)^{-1} \mathbf{F}_{\mathrm{EV}}^{\mathrm{d}}{ }^{\prime}\left(\boldsymbol{\varepsilon}_{\mathrm{EV}}^{\mathrm{d}, \mathrm{i}}\right)^{\prime}\right]^{\prime}\right) \rightarrow \mathbf{0}_{(\mathrm{K}+1) \times(\mathrm{K}+1)}
\end{aligned}
$$

From Assumption (A3), BB'/N converges to $\mathbf{b b}$ '. Together with the equations above, we have

$$
\begin{aligned}
& \frac{1}{\mathrm{~N}} \hat{\mathbf{B}}_{\mathrm{IV}} \xi_{\mathrm{T}+1}^{\mathrm{EV}{ }^{\prime}}=\frac{1}{\mathrm{~N}} \sum_{\mathrm{i}=1}^{\mathrm{N}}\left(\mathbf{b}^{\mathrm{i}}+\left[0 ;\left(\mathbf{F}_{\mathrm{IV}}^{\mathrm{d}}{ }^{\prime} \mathbf{F}_{\mathrm{IV}}^{\mathrm{d}}\right)^{-1} \mathbf{F}_{\mathrm{IV}}^{\mathrm{d}}{ }^{\prime}\left(\boldsymbol{\varepsilon}_{\mathrm{IV}}^{\mathrm{d}, \mathrm{i}}\right)^{\prime}\right]\right)\left(\xi_{\mathrm{T}+1}^{\mathrm{EV}, \mathrm{i}}\right) \rightarrow \mathbf{0}_{(\mathrm{K}+1) \times 1} \text {, and } \\
& \frac{1}{\mathrm{~N}} \hat{\mathbf{B}}_{\mathrm{IV}} \hat{\mathbf{B}}_{\mathrm{EV}}{ }^{\prime}=\frac{1}{\mathrm{~N}}\left(\mathbf{B}+\left[\mathbf{0}_{\mathrm{l} \times \mathrm{N}} ;\left(\mathbf{F}_{\mathrm{IV}}^{\mathrm{d}} \cdot \mathbf{F}_{\mathrm{IV}}^{\mathrm{d}}\right)^{-1} \mathbf{F}_{\mathrm{IV}}^{\mathrm{d}}{ }^{\prime} \boldsymbol{\Omega}_{\mathrm{IV}}^{\mathrm{d}}\right]\right)\left(\mathbf{B}+\left[\mathbf{0}_{\mathrm{I} \times \mathrm{N}} ;\left(\mathbf{F}_{\mathrm{EV}}^{\mathrm{d}} \mathbf{F}_{\mathrm{EV}}^{\mathrm{d}}\right)^{-1} \mathbf{F}_{\mathrm{EV}}^{\mathrm{d}}{ }^{\prime} \boldsymbol{\Omega}_{\mathrm{EV}}^{\mathrm{d}}\right]\right)^{\prime} \\
& =\frac{1}{\mathrm{~N}} \sum_{i=1}^{\mathrm{N}}\left(\left(\mathbf{b}^{\mathrm{i}}+\left[0 ;\left(\mathbf{F}_{\mathrm{IV}}^{\mathrm{d}}, \mathbf{F}_{\mathrm{IV}}^{\mathrm{d}}\right)^{-1} \mathbf{F}_{\mathrm{IV}}^{\mathrm{d}}{ }^{\prime}\left(\boldsymbol{\varepsilon}_{\mathrm{IV}}^{\mathrm{di}}\right)^{\prime}\right]\right)\left(\mathbf{b}^{\mathrm{i}}+\left[0 ;\left(\mathbf{F}_{\mathrm{EV}}^{\mathrm{d}} \mathbf{F}_{\mathrm{EV}}^{\mathrm{d}}\right)^{-1} \mathbf{F}_{\mathrm{EV}}^{\mathrm{d}}{ }^{\prime}\left(\boldsymbol{\varepsilon}_{\mathrm{EV}}^{\mathrm{d}, \mathrm{i}}\right)^{\prime}\right]\right)^{\prime}\right) \rightarrow \mathbf{b b} \text {. }
\end{aligned}
$$

We also derive the conditional and unconditional asymptotic distributions of the IV estimator as $\mathrm{N}$ goes to infinity. These theorems and proofs are available from the authors upon request.

\section{Appendix F. Consistency of IV estimator with time-varying betas}

Theorem $\mathrm{E}$ requires that betas and true risk premiums are constant. In this section, we relax this assumption (but still keep Assumptions (A1) and (A2) in Appendix E). With the assumption that riskless borrowing and lending are allowed, Eq. (1) in the main text with time-varying betas and risk premiums can be written as: 


$$
E\left(\mathrm{r}_{\mathrm{t}}^{\mathrm{i}} \mid \gamma_{\mathrm{t}, 1}, \cdots, \gamma_{\mathrm{t}, \mathrm{K}}, \beta_{\mathrm{t}, 1}^{\mathrm{i}} \cdots, \beta_{\mathrm{t}, \mathrm{K}}^{\mathrm{i}}\right)=\sum_{\mathrm{k}=1}^{\mathrm{K}} \beta_{\mathrm{t}, \mathrm{k}}^{\mathrm{i}} \times \gamma_{\mathrm{t}, \mathrm{k}} \cdot 4
$$

Here $\beta_{t, k}^{\mathrm{i}}$ is the beta of factor $\mathrm{k}$ for asset $\mathrm{i}$ in time $\mathrm{t}$, and $\gamma_{\mathrm{t}, \mathrm{k}}$ is the risk premium for factor $\mathrm{k}$ in time t. Similarly, the first-stage time-series regression can be written as: $r_{t}^{i}=\alpha^{i}+\sum_{k=1}^{K} \beta_{t, k}^{i} \times f_{k, t}+\varepsilon_{t}^{i}$. Let $\beta_{\mathrm{t}, \mathrm{k}}^{\mathrm{i}} \equiv \beta_{\mathrm{k}}^{\mathrm{i}}+\mathrm{u}_{\mathrm{t}, \mathrm{k}}^{\mathrm{i}}$ where $\beta_{\mathrm{k}}^{\mathrm{i}}$ is the unconditional mean of the beta of factor $\mathrm{k}$ for asset $\mathrm{i}$, and $\mathrm{u}_{\mathrm{t}, \mathrm{k}}^{\mathrm{i}}$ is the shock in beta in time $t$.

We can rewrite the above equations in vector and matrix notations. Assume that the true risk premium $\gamma_{t}$, a $1 \times K$ vector, is also time-varying and satisfies the following assumption:

Assumption (G): For all t, s and i, $\gamma_{\mathrm{t}}$ is independent of the regression residual $\varepsilon_{\mathrm{s}}^{\mathrm{i}}$.

Let $\boldsymbol{\beta}_{\mathrm{t}}^{\mathrm{i}}$, a $\mathrm{K} \times 1$ vector, be the betas of $\mathrm{K}$ factors for asset $\mathrm{i}$ in time $\mathrm{t}$, and $\boldsymbol{\beta}^{\mathrm{i}}$ be its unconditional mean. Let $\boldsymbol{\alpha}=\left[\alpha^{1}, \cdots, \alpha^{N}\right]$. In addition, Let $\boldsymbol{\beta}_{\mathrm{t}}^{\mathrm{i}} \equiv \boldsymbol{\beta}^{\mathrm{i}}+\mathbf{u}_{\mathrm{t}}^{\mathrm{i}}$, where the time t shock $\mathbf{u}_{\mathrm{t}}^{\mathrm{i}}$ is a $\mathrm{K} \times 1$ vector. Denote $\boldsymbol{\beta}=\left[\boldsymbol{\beta}^{1}, \cdots, \boldsymbol{\beta}^{\mathrm{N}}\right], \boldsymbol{\beta}_{\mathrm{t}}=\left[\boldsymbol{\beta}_{\mathrm{t}}^{1}, \cdots, \boldsymbol{\beta}_{\mathrm{t}}^{\mathrm{N}}\right]$ and $\mathbf{u}_{\mathrm{t}}=\left[\mathbf{u}_{\mathrm{t}}^{1}, \cdots, \mathbf{u}_{\mathrm{t}}^{\mathrm{N}}\right]$. The asset pricing model in Eq. (1) in the main text with time-varying betas and risk premium can be written as $E\left(\mathbf{r}_{\mathrm{T}+1} \mid \boldsymbol{\gamma}_{\mathrm{T}+1}, \boldsymbol{\beta}_{\mathrm{T}+1}\right)=\boldsymbol{\gamma}_{\mathrm{T}+1} \boldsymbol{\beta}_{\mathrm{T}+1}$ (with $\gamma_{0}=0$ ), and the first-stage time-series regression can be written as $\mathbf{r}_{\mathrm{t}}=\boldsymbol{\alpha}+\mathbf{f}_{\mathrm{t}} \boldsymbol{\beta}_{\mathrm{t}}+\boldsymbol{\varepsilon}_{\mathrm{t}}$. With the similar derivation in Appendix E, we can show that the cross-sectional regression model can be written as $\mathbf{r}_{\mathrm{T}+1}=\left(\mathbf{f}_{\mathrm{T}+1}+\boldsymbol{\gamma}_{\mathrm{T}+1}-E\left(\mathbf{f}_{\mathrm{T}+1} \mid \boldsymbol{\gamma}_{\mathrm{T}+1}, \boldsymbol{\beta}_{\mathrm{T}+1}\right)\right) \boldsymbol{\beta}+\mathbf{v}_{\mathrm{T}+1}$, where $\mathbf{v}_{\mathrm{T}+1}=\boldsymbol{\varepsilon}_{\mathrm{T}+1}+\left(\mathbf{f}_{\mathrm{T}+1}+\boldsymbol{\gamma}_{\mathrm{T}+1}-E\left(\mathbf{f}_{\mathrm{T}+1} \mid \boldsymbol{\gamma}_{\mathrm{T}+1}, \boldsymbol{\beta}_{\mathrm{T}+1}\right)\right) \mathbf{u}_{\mathrm{T}+1}$.

Define $\mathbf{B} \equiv\left[\mathbf{1}_{1 \times \mathrm{N}} ; \boldsymbol{\beta}\right], \hat{\mathbf{B}}_{\mathrm{IV}} \equiv\left[\mathbf{1}_{1 \times \mathrm{N}} ; \hat{\boldsymbol{\beta}}_{\mathrm{IV}}\right]$ and $\hat{\mathbf{B}}_{\mathrm{EV}} \equiv\left[\mathbf{1}_{1 \times \mathrm{N}} ; \hat{\boldsymbol{\beta}}_{\mathrm{EV}}\right]$ where $\hat{\boldsymbol{\beta}}_{\mathrm{IV}}$ and $\hat{\boldsymbol{\beta}}_{\mathrm{EV}}$ are the estimated betas in the IV and EV periods, respectively. The first-stage time-series regression can be written as $\mathbf{r}_{\mathrm{t}}=\boldsymbol{\alpha}+\mathbf{f}_{\mathrm{t}} \boldsymbol{\beta}+\mathbf{e}_{\mathrm{t}}$ where $\mathbf{e}_{\mathrm{t}} \equiv \boldsymbol{\varepsilon}_{\mathrm{t}}+\mathbf{f}_{\mathrm{t}} \mathbf{u}_{\mathrm{t}}$. The estimation errors for IV and EV betas are:

\footnotetext{
${ }^{4}$ Note that we use superscript $\mathrm{i}$ to indicate asset $\mathrm{i}$ in the Internet Appendix.
} 


$$
\begin{aligned}
& \hat{\boldsymbol{\beta}}_{\mathrm{IV}}-\boldsymbol{\beta}=\left(\mathbf{F}_{\mathrm{IV}}^{\mathrm{d}} \mathbf{F}_{\mathrm{IV}}^{\mathrm{d}}\right)^{-1} \mathbf{F}_{\mathrm{IV}}^{\mathrm{d}} \mathbf{E}_{\mathrm{IV}}^{\mathrm{d}}, \\
& \hat{\boldsymbol{\beta}}_{\mathrm{EV}}-\boldsymbol{\beta}=\left(\mathbf{F}_{\mathrm{EV}}^{\mathrm{d}} \cdot \mathbf{F}_{\mathrm{EV}}^{\mathrm{d}}\right)^{-1} \mathbf{F}_{\mathrm{EV}}^{\mathrm{d}} \cdot \mathbf{E}_{\mathrm{EV}}^{\mathrm{d}},
\end{aligned}
$$

respectively, where $\mathbf{E}_{\mathrm{IV}}^{\mathrm{d}}\left(\mathbf{E}_{\mathrm{EV}}^{\mathrm{d}}\right)$ is defined similarly to $\boldsymbol{\Omega}_{\mathrm{IV}}^{\mathrm{d}}\left(\boldsymbol{\Omega}_{\mathrm{EV}}^{\mathrm{d}}\right)$ in Appendix E, by replacing $\boldsymbol{\varepsilon}_{\mathrm{t}}$ with $\mathbf{e}_{\mathrm{t}}$.

Denote $\Gamma_{\mathrm{T}+1}$, a $1 \times(\mathrm{K}+1)$ vector, as the ex-post risk premiums in time $\mathrm{T}+1$ (defined as $\left.\boldsymbol{\Gamma}_{\mathrm{T}+1}=\left(0, \mathbf{f}_{\mathrm{T}+1}+\boldsymbol{\gamma}_{\mathrm{T}+1}-E\left(\mathbf{f}_{\mathrm{T}+1} \mid \boldsymbol{\gamma}_{\mathrm{T}+1}, \boldsymbol{\beta}_{\mathrm{T}+1}\right)\right)\right)$. Following the same derivation in Appendix E, the cross-sectional regression model can be written as

$$
\mathbf{r}_{\mathrm{T}+1}=\boldsymbol{\Gamma}_{\mathrm{T}+1} \hat{\mathbf{B}}_{\mathrm{EV}}+\xi_{\mathrm{T}+1}^{\mathrm{EV}}
$$

where $\xi_{\mathrm{T}+1}^{\mathrm{EV}}=\left(\mathbf{f}_{\mathrm{T}+1}+\boldsymbol{\gamma}_{\mathrm{T}+1}-E\left(\mathbf{f}_{\mathrm{T}+1} \mid \boldsymbol{\gamma}_{\mathrm{T}+1}, \boldsymbol{\beta}_{\mathrm{T}+1}\right)\right)\left(\boldsymbol{\beta}-\hat{\boldsymbol{\beta}}_{\mathrm{EV}}\right)+\mathbf{v}_{\mathrm{T}+1}$.

The IV estimator is $\hat{\boldsymbol{\Gamma}}_{\mathrm{T}+1}{ }^{\prime}=\left(\hat{\mathbf{B}}_{\mathrm{IV}} \hat{\mathbf{B}}_{\mathrm{EV}}{ }^{\prime}\right)^{-1}\left(\hat{\mathbf{B}}_{\mathrm{IV}} \mathbf{r}_{\mathrm{T}+1}{ }^{\prime}\right)$. We can show two types of consistency of this estimator, with different assumptions on the dynamcs of $\mathbf{u}_{\mathrm{t}}^{\mathrm{i}}$.

Assumption (U1): For all $\mathrm{t}, \mathrm{s}$ and $\mathrm{i}, \mathbf{u}_{\mathrm{t}}^{\mathrm{i}}$ is independent of $\mathbf{f}_{\mathrm{s}}$ (factor in time $\mathrm{s}$ ), $\varepsilon_{\mathrm{s}}^{\mathrm{i}}$ (regression residuals in time s), unconditional mean of beta $\boldsymbol{\beta}^{\mathrm{i}}$ and $\boldsymbol{\gamma}_{\mathrm{s}}$ (risk premium in time s). It also has zero mean and finite fourth moment. In addition, $\mathbf{u}_{\mathrm{t}}^{\mathrm{i}}$ and $\mathbf{u}_{\mathrm{s}}^{\mathrm{j}}$ are uncorrelated as long as $\mathrm{s} \neq \mathrm{t}$. Moreover, for each asset $\mathrm{i}$, the stochastic process $\left\{\mathbf{u}_{\mathrm{t}}^{\mathrm{i}}, \mathrm{t}=1, \cdots, \mathrm{T}\right\}$ is stationary. Moreover, for any $\mathrm{s} \neq \mathrm{t}$, elements in $\frac{1}{\sqrt{\mathrm{N}}}\left(\mathbf{u}_{\mathrm{t}}^{1}\left(\mathbf{u}_{\mathrm{s}}^{1}\right)^{\prime}+\cdots+\mathbf{u}_{\mathrm{t}}^{\mathrm{N}}\left(\mathbf{u}_{\mathrm{s}}^{\mathrm{N}}\right)^{\prime}\right)$ and $\frac{1}{\sqrt{\mathrm{N}}}\left(\mathbf{u}_{\mathrm{t}}^{1} \varepsilon_{\mathrm{s}}^{1}+\cdots+\mathbf{u}_{\mathrm{t}}^{\mathrm{N}} \varepsilon_{\mathrm{s}}^{\mathrm{N}}\right)$ have finite variances.

Assumption (U2): For all $\mathrm{t}, \mathrm{s}$ and $\mathrm{i}, \mathbf{u}_{\mathrm{t}}^{\mathrm{i}}$ is independent of $\mathbf{f}_{\mathrm{s}}$ (factor in time $\mathrm{s}$ ), $\varepsilon_{\mathrm{s}}^{\mathrm{i}}$ (regression residuals in time s), unconditional mean of beta $\boldsymbol{\beta}^{\mathrm{i}}$ and $\boldsymbol{\gamma}_{\mathrm{s}}$ (risk premium in time s). It also has zero mean and finite fourth moments. In addition, for each asset $i$, the stochastic process $\left\{\mathbf{u}_{\mathrm{t}}^{\mathrm{i}}, \mathrm{t}=1, \cdots, \mathrm{T}\right\}$ is stationary and ergodic. 
The key difference between those two assumptions is the autocorrelation of $\left\{\mathbf{u}_{\mathrm{t}}^{\mathrm{i}}, \mathrm{t}=1, \cdots, \mathrm{T}\right\}$ process. Assumption (U1) imposes no autocorrelation, while (U2) relaxes this assumption. In addition, since $\mathbf{u}_{\mathrm{t}}^{\mathrm{i}}$ is independent of $\mathbf{f}_{\mathrm{T}+1}$, we have $E\left(\mathbf{f}_{\mathrm{T}+1} \mid \boldsymbol{\gamma}_{\mathrm{T}+1}, \boldsymbol{\beta}_{\mathrm{T}+1}\right)=E\left(\mathbf{f}_{\mathrm{T}+1} \mid \boldsymbol{\gamma}_{\mathrm{T}+1}\right)$. Therefore, $\xi_{\mathrm{T}+1}^{\mathrm{EV}}=\left(\mathbf{f}_{\mathrm{T}+1}+\boldsymbol{\gamma}_{\mathrm{T}+1}-E\left(\mathbf{f}_{\mathrm{T}+1} \mid \boldsymbol{\gamma}_{\mathrm{T}+1}\right)\right)\left(\boldsymbol{\beta}-\hat{\boldsymbol{\beta}}_{\mathrm{EV}}\right)+\boldsymbol{\varepsilon}_{\mathrm{T}+1}+\left(\mathbf{f}_{\mathrm{T}+1}+\boldsymbol{\gamma}_{\mathrm{T}+1}-E\left(\mathbf{f}_{\mathrm{T}+1} \mid \boldsymbol{\gamma}_{\mathrm{T}+1}\right)\right) \mathbf{u}_{\mathrm{T}+1} \quad$ and $\boldsymbol{\Gamma}_{\mathrm{T}+1}=\left(0, \mathbf{f}_{\mathrm{T}+1}+\boldsymbol{\gamma}_{\mathrm{T}+1}-E\left(\mathbf{f}_{\mathrm{T}+1} \mid \boldsymbol{\gamma}_{\mathrm{T}+1}\right)\right)$. Since $\mathbf{f}_{\mathrm{T}+1}+\boldsymbol{\gamma}_{\mathrm{T}+1}-E\left(\mathbf{f}_{\mathrm{T}+1} \mid \boldsymbol{\gamma}_{\mathrm{T}+1}\right)$ is independent of $\mathbf{u}_{\mathrm{t}}^{\mathrm{i}}$ and $\varepsilon_{\mathrm{t}}^{\mathrm{i}}$ for any $\mathrm{t}$ and $\mathrm{i}$ (Assumptions (G) and (U1)), we can show that $\xi_{\mathrm{T}+1}^{\mathrm{EV}}$ has zero mean.

We also impose the following assumption on $\mathbf{u}_{\mathrm{t}}^{\mathrm{i}}$ process, $\varepsilon_{\mathrm{t}}^{\mathrm{i}}$ and matrix $\mathbf{B}$ (which can be written as $\left[\mathbf{b}^{1}, \cdots, \mathbf{b}^{\mathrm{N}}\right]$ as in Appendix E).

Assumption (B): The elements in $\frac{1}{\sqrt{\mathrm{N}}}\left(\mathbf{b}^{1}\left(\mathrm{u}_{\mathrm{t}}^{1}\right)^{\prime}+\cdots+\mathbf{b}^{\mathrm{N}}\left(\mathrm{u}_{\mathrm{t}}^{\mathrm{N}}\right)^{\prime}\right)$ and $\frac{1}{\sqrt{\mathrm{N}}}\left(\mathbf{b}^{1} \varepsilon_{\mathrm{t}}^{1}+\cdots+\mathbf{b}^{\mathrm{N}} \varepsilon_{\mathrm{t}}^{\mathrm{N}}\right)$ have finite variances for any $t$, and when $\mathrm{N} \rightarrow \infty, \mathbf{B B}^{\prime} / \mathrm{N}$ converges to an invertible matrix $\mathbf{b b}^{\prime}$ $\left(=E\left(\mathbf{b}^{\mathrm{i}}\left(\mathbf{b}^{\mathrm{i}}\right)^{\prime}\right)\right)$. In addition, for any $\mathrm{i}$ and $\mathrm{t}$, the elements in $\mathbf{b}^{\mathrm{i}}$ and $\varepsilon_{\mathrm{t}}^{\mathrm{i}}$ are uncorrelated.

We write $\xi_{\mathrm{T}+1}^{\mathrm{EV}}(1 \times \mathrm{N}$ vector $)$, as $\left[\xi_{\mathrm{T}+1}^{\mathrm{EV}, 1}, \cdots, \xi_{\mathrm{T}+1}^{\mathrm{EV}, \mathrm{N}}\right]$. Assumption (B) implies that the elements in $\frac{1}{\sqrt{\mathrm{N}}}\left(\mathbf{b}^{1} \xi_{\mathrm{T}+1}^{\mathrm{EV}, 1}+\cdots+\mathbf{b}^{\mathrm{N}} \xi_{\mathrm{T}+1}^{\mathrm{EV}, \mathrm{N}}\right)$ have finite variances, since $\xi_{\mathrm{T}+1}^{\mathrm{EV}, \mathrm{i}}$ is a linear combination of $\mathbf{u}_{\mathrm{t}}^{\mathrm{i}}$ 's and $\varepsilon_{\mathrm{t}}^{\mathrm{i}}$ 's. Assumptions (U1) and (B) imply that $\xi_{\mathrm{T}+1}^{\mathrm{EV}, \mathrm{i}}$ and $\mathbf{b}^{\mathrm{i}}$ are uncorrelated, i.e. $E\left(\mathbf{b}^{\mathrm{i}} \xi_{\mathrm{T}+1}^{\mathrm{EV}, \mathrm{i}}\right)=\mathbf{0}_{(\mathrm{K}+1) \times 1}$.

With the assumptions above, we state the following Theorem F:

Theorem F (1) (N-Consistency) Assuming (A1), (A2), (G), (U1) and (B), the estimated risk premium $\hat{\boldsymbol{\Gamma}}_{\mathrm{T}+1}{ }^{\prime} \equiv\left(\frac{1}{\mathrm{~N}} \hat{\mathbf{B}}_{\mathrm{IV}} \hat{\mathbf{B}}_{\mathrm{EV}}{ }^{\prime}\right)^{-1}\left(\frac{1}{\mathrm{~N}} \hat{\mathbf{B}}_{\mathrm{IV}} \mathbf{r}_{\mathrm{T}+1}{ }^{\prime}\right)$ converges to $\boldsymbol{\Gamma}_{\mathrm{T}+1}{ }^{\prime}$ when $\mathrm{N}$ approaches to infinity. 
(2) (Sequential consistency) Assuming (A1), (A2), (U2) and (B), the estimated risk premium $\hat{\boldsymbol{\Gamma}}_{\mathrm{T}+1}{ }^{\prime} \equiv\left(\frac{1}{\mathrm{~N}} \hat{\mathbf{B}}_{\mathrm{IV}} \hat{\mathbf{B}}_{\mathrm{EV}}{ }^{\prime}\right)^{-1}\left(\frac{1}{\mathrm{~N}} \hat{\mathbf{B}}_{\mathrm{IV}} \mathbf{r}_{\mathrm{T}+1}{ }^{\prime}\right)$ converges to $\boldsymbol{\Gamma}_{\mathrm{T}+1}{ }^{\prime}$ when we take a probability limit as $\mathrm{T}$ approaches to infinity first, and then take a probability limit as $\mathrm{N}$ approaches to infinity.

Proof of (1): With the assumptions above, the proof will be exactly the same as the proof for Theorem E, by replacing $\boldsymbol{\Omega}_{\mathrm{IV}}^{\mathrm{d}}\left(\boldsymbol{\Omega}_{\mathrm{EV}}^{\mathrm{d}}\right)$ with $\mathbf{E}_{\mathrm{IV}}^{\mathrm{d}}\left(\mathbf{E}_{\mathrm{EV}}^{\mathrm{d}}\right)$, and $\boldsymbol{\varepsilon}_{\mathrm{t}}$ with $\mathbf{e}_{\mathrm{t}}\left(=\boldsymbol{\varepsilon}_{\mathrm{t}}+\mathbf{f}_{\mathrm{t}} \mathbf{u}_{\mathrm{t}}\right)$.

Proof of (2): Similarly to the proof for Theorem E,

$$
\hat{\boldsymbol{\Gamma}}_{\mathrm{T}+1}{ }^{\prime}-\boldsymbol{\Gamma}_{\mathrm{T}+1}^{\prime}=\left(\frac{1}{\mathrm{~N}} \hat{\mathbf{B}}_{\mathrm{IV}} \hat{\mathbf{B}}_{\mathrm{EV}}{ }^{\prime}\right)^{-1}\left(\frac{1}{\mathrm{~N}} \hat{\mathbf{B}}_{\mathrm{IV}}^{\xi_{\mathrm{T}+1}^{\mathrm{EV}}{ }^{\prime}}\right) .
$$

We have shown that

$$
\begin{gathered}
\hat{\boldsymbol{\beta}}_{\mathrm{IV}}-\boldsymbol{\beta}=\left(\mathbf{F}_{\mathrm{IV}}^{\mathrm{d}}{ }^{\prime} \mathbf{F}_{\mathrm{IV}}^{\mathrm{d}}\right)^{-1} \mathbf{F}_{\mathrm{IV}}^{\mathrm{d}} \mathbf{E}_{\mathrm{IV}}^{\mathrm{d}}, \\
\hat{\boldsymbol{\beta}}_{\mathrm{EV}}-\boldsymbol{\beta}=\left(\mathbf{F}_{\mathrm{EV}}^{\mathrm{d}}{ }^{\prime} \mathbf{F}_{\mathrm{EV}}^{\mathrm{d}}\right)^{-1} \mathbf{F}_{\mathrm{EV}}^{\mathrm{d}}{ }^{\prime} \mathbf{E}_{\mathrm{EV}}^{\mathrm{d}} \cdot
\end{gathered}
$$

Let $\mathbf{e}_{\mathrm{t}}=\left[\mathrm{e}_{\mathrm{t}}^{1}, \cdots, \mathrm{e}_{\mathrm{t}}^{\mathrm{N}}\right]$. Since $\mathrm{e}_{\mathrm{t}}^{\mathrm{i}}$ is a linear combination of $\mathbf{u}_{\mathrm{t}}^{\mathrm{i}}$ and $\varepsilon_{\mathrm{t}}^{\mathrm{i}}$, from Assumptions (A1), (A2) and (U2), it is clear that the stochastic process $\left\{\mathrm{e}_{\mathrm{t}}^{\mathrm{i}}, \mathrm{t}=1, \cdots, \mathrm{T}\right\}$ is stationary and ergodic with zero mean and finite fourth moment, and for any $i, e_{t}^{i}$ is independent of factors. Taking a probability limit as T approaches to infinity, $\hat{\mathbf{B}}_{\mathrm{IV}} \rightarrow \mathbf{B}, \hat{\mathbf{B}}_{\mathrm{IV}} \rightarrow \mathbf{B}$ and $\xi_{\mathrm{T}+1}^{\mathrm{EV}} \rightarrow \mathbf{v}_{\mathrm{T}+1}$ following the Markov's law of large number. Hence,

$$
\left(\frac{1}{\mathrm{~N}} \hat{\mathbf{B}}_{\mathrm{IV}} \hat{\mathbf{B}}_{\mathrm{EV}}{ }^{\prime}\right)^{-1}\left(\frac{1}{\mathrm{~N}} \hat{\mathbf{B}}_{\mathrm{IV}} \xi_{\mathrm{T}+1}^{\mathrm{EV}}\right) \rightarrow\left(\frac{1}{\mathrm{~N}} \mathbf{B B}^{\prime}\right)^{-1}\left(\frac{1}{\mathrm{~N}} \mathbf{B v}_{\mathrm{T}+1}{ }^{\prime}\right)
$$

Next, since $\mathbf{v}_{\mathrm{T}+1}$ is a linear combination of $\mathbf{u}_{\mathrm{t}}$ and $\boldsymbol{\varepsilon}_{\mathrm{t}}$, from Assumptions (B) and (U2), $E\left(\mathbf{B} \mathbf{v}_{\mathrm{T}+1}{ }^{\prime}\right)=\mathbf{0}_{(\mathrm{k}+1) \times 1}$, and the elements in $\frac{1}{\sqrt{\mathrm{N}}}\left(\mathbf{b}^{1} \mathrm{v}_{\mathrm{T}+1}^{1}+\cdots+\mathbf{b}^{\mathrm{N}} \mathrm{v}_{\mathrm{T}+1}^{\mathrm{N}}\right)$ have finite variances when $\mathrm{N} \rightarrow \infty$. In addition, from Assumption $(\mathrm{B}),\left(\frac{1}{\mathrm{~N}} \mathbf{B B}^{\prime}\right) \rightarrow \mathbf{b b}^{\prime}$ as $\mathrm{N}$ appraoches to infinity. Apply 
Markov's law of large numbers, $\left(\frac{1}{\mathrm{~N}} \mathbf{B B}^{\prime}\right)^{-1}\left(\frac{1}{\mathrm{~N}} \mathbf{B v}_{\mathrm{T}+1}{ }^{\prime}\right) \rightarrow \mathbf{0}_{(\mathrm{k}+1) \times 1}$ when $\mathrm{N} \rightarrow \infty$. Therefore, $\left(\frac{1}{\mathrm{~N}} \hat{\mathbf{B}}_{\mathrm{IV}} \hat{\mathbf{B}}_{\mathrm{EV}}{ }^{\prime}\right)^{-1}\left(\frac{1}{\mathrm{~N}} \hat{\mathbf{B}}_{\mathrm{IV}} \xi_{\mathrm{T}+1}^{\mathrm{EV}}\right) \rightarrow \mathbf{0}_{(\mathrm{k}+1) \times 1}$ (i.e. $\hat{\boldsymbol{\Gamma}}_{\mathrm{T}+1}{ }^{\prime}$ converges to $\left.\boldsymbol{\Gamma}_{\mathrm{T}+1}{ }^{\prime}\right)$ when we take a probability limit as $\mathrm{T}$ approaches to infinity first, and then take a probability limit as $\mathrm{N}$ approaches to infinity.

\section{Appendix G. Time-varying characteristics}

In this section, we incorpate stock characteristics into the cross-sectional regression: i.e. in the second-stage regression, the independent variables are estimated betas as well as characteristics of stocks. We also assume that both estimated betas and characteristics are proxies for the true factor loading (true betas), and they are correlated cross-sectionally. Thus, characteristics are used both as instruments for beta estimates and as control variables. We propose a new IV estimator: the IV mean-estimator, and prove its convergence to the ex-post risk premium as the dimensions of cross-section and time-series grow indefinitely. The estimator in Proposition 2 in the main text is a special case of the IV mean-estimator proposed in this Appendix.

The dependent variable of the IV mean-estimator in the second-stage cross-sectional

regression is the average return $\overline{\mathbf{r}}_{\mathrm{DV}}=\frac{1}{\mathrm{~T}_{\mathrm{m}}} \sum_{\mathrm{t} \in \mathrm{DV}} \mathbf{r}_{\mathrm{t}}$ over the months not used to construct $\hat{\boldsymbol{\beta}}_{\mathrm{IV}}$ and $\hat{\boldsymbol{\beta}}_{\mathrm{EV}}$ (we call them the dependent variable period or the DV period, and assume that the DV period has $\mathrm{T}_{\mathrm{m}}$ months). Without loss of generality, we assume that IV and EV betas are constructed using observations from months 1 to $\mathrm{T}$, and the $\mathrm{DV}$ period has observations from months $\mathrm{T}+1$ to $\mathrm{T}+\mathrm{T}_{\mathrm{m}}$.

Following the similar derivations in Appendices $\mathrm{E}$ and $\mathrm{F}$, we can show that for any $\mathrm{t}$ in the DV period, the asset return with time-varying beta and true risk premium can be written as $\mathbf{r}_{\mathrm{t}}=\left(\mathbf{f}_{\mathrm{t}}+\boldsymbol{\gamma}_{\mathrm{t}}-E\left(\mathbf{f}_{\mathrm{t}} \mid \boldsymbol{\gamma}_{\mathrm{t}}, \boldsymbol{\beta}_{\mathrm{t}}\right)\right) \boldsymbol{\beta}_{\mathrm{t}}+\boldsymbol{\varepsilon}_{\mathrm{t}}$. From Assumption (U2), we have $E\left(\mathbf{f}_{\mathrm{t}} \mid \boldsymbol{\gamma}_{\mathrm{t}}, \boldsymbol{\beta}_{\mathrm{t}}\right)=E\left(\mathbf{f}_{\mathrm{t}} \mid \boldsymbol{\gamma}_{\mathrm{t}}\right)$, leading to $\mathbf{r}_{\mathrm{t}}=\left(\mathbf{f}_{\mathrm{t}}+\boldsymbol{\gamma}_{\mathrm{t}}-E\left(\mathbf{f}_{\mathrm{t}} \mid \boldsymbol{\gamma}_{\mathrm{t}}\right)\right) \boldsymbol{\beta}_{\mathrm{t}}+\boldsymbol{\varepsilon}_{\mathrm{t}}$ 
The cross-sectional regression model of regressing the average return over the DV period on the estimated beta over the EV period can be written as $\overline{\mathbf{r}}_{\mathrm{DV}}=\boldsymbol{\Gamma} \hat{\mathbf{B}}_{\mathrm{EV}}+\boldsymbol{\xi}_{\mathrm{DV}}$, where $\Gamma$ is defined as $\left(0, \frac{1}{\mathrm{~T}_{\mathrm{m}}} \sum_{\mathrm{t} \in \mathrm{DV}}\left(\mathbf{f}_{\mathrm{t}}+\boldsymbol{\gamma}_{\mathrm{t}}-E\left(\mathbf{f}_{\mathrm{t}} \mid \boldsymbol{\gamma}_{\mathrm{t}}\right)\right)\right)$, and the residual $\xi_{\mathrm{DV}}(1 \times \mathrm{N})$ takes the following form:

$$
\boldsymbol{\xi}_{\mathrm{DV}}=\left(\frac{1}{\mathrm{~T}_{\mathrm{m}}} \sum_{\mathrm{t} \in \mathrm{DV}}\left(\mathbf{f}_{\mathrm{t}}+\boldsymbol{\gamma}_{\mathrm{t}}-E\left(\mathbf{f}_{\mathrm{t}} \mid \boldsymbol{\gamma}_{\mathrm{t}}\right)\right)\right)\left(\overline{\boldsymbol{\beta}}_{\mathrm{DV}}-\hat{\boldsymbol{\beta}}_{\mathrm{EV}}\right)+\frac{1}{\mathrm{~T}_{\mathrm{m}}} \sum_{\mathrm{t} \in \mathrm{DV}}\left(\left(\mathbf{f}_{\mathrm{t}}+\boldsymbol{\gamma}_{\mathrm{t}}-E\left(\mathbf{f}_{\mathrm{t}} \mid \boldsymbol{\gamma}_{\mathrm{t}}\right)\right)\left(\boldsymbol{\beta}_{\mathrm{t}}-\overline{\boldsymbol{\beta}}_{\mathrm{DV}}\right)\right)+\overline{\boldsymbol{\varepsilon}}_{\mathrm{DV}}
$$

where $\overline{\boldsymbol{\beta}}_{\mathrm{DV}}=\frac{1}{\mathrm{~T}_{\mathrm{m}}} \sum_{\mathrm{t} \in \mathrm{DV}} \boldsymbol{\beta}_{\mathrm{t}}$ and $\overline{\boldsymbol{\varepsilon}}_{\mathrm{DV}}=\frac{1}{\mathrm{~T}_{\mathrm{m}}} \sum_{\mathrm{t} \in \mathrm{DV}} \boldsymbol{\varepsilon}_{\mathrm{t}}$.

Recall that $\boldsymbol{\beta}_{\mathrm{t}} \equiv \boldsymbol{\beta}+\mathbf{u}_{\mathrm{t}}$, where the shock in beta is $\mathbf{u}_{\mathrm{t}}=\left[\mathbf{u}_{\mathrm{t}}^{1}, \cdots, \mathbf{u}_{\mathrm{t}}^{\mathrm{N}}\right] .{ }^{5}$ Moreover, let $\mathbf{u}_{\mathrm{t}}^{\mathrm{d}, \mathrm{i}}=\mathbf{u}_{\mathrm{t}}^{\mathrm{i}}-\frac{1}{\mathrm{~T}_{\mathrm{m}}} \sum_{\mathrm{s} \in \mathrm{DV}} \mathbf{u}_{\mathrm{s}}^{\mathrm{i}}$, and $\mathbf{u}_{\mathrm{t}}^{\mathrm{d}}=\left[\mathbf{u}_{\mathrm{t}}^{\mathrm{d}, 1}, \cdots, \mathbf{u}_{\mathrm{t}}^{\mathrm{d}, \mathrm{N}}\right]$, which is demeaned residual in time $\mathrm{t}$, and a $\mathrm{K} \times \mathrm{N}$ matrix. Decomposing $\boldsymbol{\beta}_{\mathrm{t}}$ into its two components, i.e., $\boldsymbol{\beta}$ and $\mathbf{u}_{\mathrm{t}}$, the above regression residual $\xi_{\mathrm{DV}}$ can be re-written as

$$
\begin{aligned}
& \xi_{\mathrm{DV}}=\left(\frac{1}{\mathrm{~T}_{\mathrm{m}}} \sum_{\mathrm{t} \in \mathrm{DV}}\left(\mathbf{f}_{\mathrm{t}}+\boldsymbol{\gamma}_{\mathrm{t}}-E\left(\mathbf{f}_{\mathrm{t}} \mid \boldsymbol{\gamma}_{\mathrm{t}}\right)\right)\right)\left(\boldsymbol{\beta}-\hat{\boldsymbol{\beta}}_{\mathrm{EV}}\right)+\left(\frac{1}{\mathrm{~T}_{\mathrm{m}}} \sum_{\mathrm{t} \in \mathrm{DV}}\left(\mathbf{f}_{\mathrm{t}}+\boldsymbol{\gamma}_{\mathrm{t}}-E\left(\mathbf{f}_{\mathrm{t}} \mid \boldsymbol{\gamma}_{\mathrm{t}}\right)\right)\right)\left(\frac{1}{\mathrm{~T}_{\mathrm{m}}} \sum_{\mathrm{t} \in \mathrm{DV}} \mathbf{u}_{\mathrm{t}}\right), \\
& +\frac{1}{\mathrm{~T}_{\mathrm{m}}} \sum_{\mathrm{t} \in \mathrm{DV}}\left(\left(\mathbf{f}_{\mathrm{t}}+\boldsymbol{\gamma}_{\mathrm{t}}-E\left(\mathbf{f}_{\mathrm{t}} \mid \boldsymbol{\gamma}_{\mathrm{t}}\right)\right) \mathbf{u}_{\mathrm{t}}^{\mathrm{d}}\right)+\overline{\boldsymbol{\varepsilon}}_{\mathrm{DV}}
\end{aligned}
$$

Denote $\mathbf{c}_{\mathrm{t}}^{\mathrm{i}}$ as a vector of characteristics for asset $\mathrm{i}$ in time $\mathrm{t}$. Assume that there are $\mathrm{L}$ characteristics, so $\mathbf{c}_{\mathrm{t}}^{\mathrm{i}}$ is a $\mathrm{L} \times 1$ vector. Similarly to time-varying betas, we assume that the characteristics can be decomposed into the two parts: $\mathbf{c}_{\mathrm{t}}^{\mathrm{i}}=\mathbf{c}^{\mathrm{i}}+\mathbf{v}_{\mathrm{t}}^{\mathrm{i}}$, where $\mathbf{c}^{\mathrm{i}}$ is the unconditional expected value of characteristic for asset $\mathrm{i}$, and $\mathbf{v}_{\mathrm{t}}^{\mathrm{i}}$ is the shock in characteristic in time t. We make the following assumption on $\boldsymbol{v}_{\mathrm{t}}^{\mathrm{i}}$.

\footnotetext{
${ }^{5}$ Note that we use superscript $\mathrm{i}$ to indicate asset $\mathrm{i}$ in the Internet Appendix.
} 
Assumption $(\mathrm{C})$ : For each asset $\mathrm{i}$, the process $\left\{\boldsymbol{v}_{\mathrm{t}}^{\mathrm{i}}, \mathrm{t}=1, \cdots, \mathrm{T}\right\}$ is stationary and ergodic with zero mean and finite fourth moments.

In addition, denote $\mathbf{C}=\left[\mathbf{c}^{1}, \cdots, \mathbf{c}^{\mathrm{N}}\right]$, an $\mathrm{L} \times \mathrm{N}$ matrix, as the unconditional expected value of characteristic. Take the average of characteristic from $\mathrm{T}-\mathrm{T}_{\mathrm{c}}+1$ to $\mathrm{T}: \overline{\mathbf{C}} \equiv \frac{1}{\mathrm{~T}_{\mathrm{c}}} \sum_{\mathrm{t}=0}^{\mathrm{T}_{\mathrm{c}}-1} \mathbf{C}_{\mathrm{T}-\mathrm{t}}$, with $\mathbf{C}_{\mathrm{t}}=\left[\mathbf{c}_{\mathrm{t}}^{1}, \cdots, \mathbf{c}_{\mathrm{t}}^{\mathrm{N}}\right]$ an $\mathrm{L} \times \mathrm{N}$ matrix. ${ }^{6}$ With characteristics as control variables and additional instruments for beta estimates, we run the following cross-sectional regression: $\overline{\mathbf{r}}_{\mathrm{DV}}=\boldsymbol{\Gamma} \hat{\mathbf{B}}_{\mathrm{EV}}+\mathbf{\kappa} \overline{\mathbf{C}}+\xi_{\mathrm{DV}}^{\kappa}$, where the slope coefficient of characteristics, denoted by $\mathbf{\kappa}$, is an $1 \times \mathrm{L}$ vector. When characteristics play roles of proxies for the true factor loadings, i.e. they do not affect the cross-section of expected returns by themselves, the true value of $\mathbf{\kappa}$ is zero if the beta estimates are included in the regression. Under this null hypothesis, in above regression, $\xi_{\mathrm{DV}}^{\kappa}=\xi_{\mathrm{DV}}$, where $\xi_{\mathrm{DV}}$ is the error in the regression without characteristics. The estimated slope coefficents of our cross-sectional IV regression are given as

$$
[\hat{\boldsymbol{\Gamma}}, \hat{\mathbf{\kappa}}]^{\prime}=\left(\frac{1}{\mathrm{~N}}\left[\hat{\mathbf{B}}_{\mathrm{IV}} ; \overline{\mathbf{C}}\right]\left[\hat{\mathbf{B}}_{\mathrm{EV}} ; \overline{\mathbf{C}}\right]^{\prime}\right)^{-1}\left(\frac{1}{\mathrm{~N}}\left[\hat{\mathbf{B}}_{\mathrm{IV}} ; \overline{\mathbf{C}}\right] \frac{1}{\mathrm{~T}_{\mathrm{m}}} \sum_{\mathrm{t} \in \mathrm{DV}} \mathbf{r}_{\mathrm{t}}{ }^{\prime}\right)
$$

where $\left[\hat{\mathbf{B}}_{\text {IV }} ; \overline{\mathbf{C}}\right]$ (which is a $(\mathrm{K}+\mathrm{L}+1) \times \mathrm{N}$ matrix) stacks $\hat{\mathbf{B}}_{\mathrm{IV}}$ over $\overline{\mathbf{C}}$.

In order to show the convergences of the estimated slope coefficients above, we need to specify the regularity assumptions. To simplify the notations in the assumptions, we define the following two variables:

$$
\delta_{\mathrm{s}}^{\mathrm{i}}=-\left(\frac{1}{\mathrm{~T}_{\mathrm{m}}} \sum_{\mathrm{t} \in \mathrm{DV}}\left(\mathbf{f}_{\mathrm{t}}+\boldsymbol{\gamma}_{\mathrm{t}}-E\left(\mathbf{f}_{\mathrm{t}} \mid \boldsymbol{\gamma}_{\mathrm{t}}\right)\right)\right)\left(\left(\frac{2}{\mathrm{~T}} \mathbf{F}_{\mathrm{EV}}^{\mathrm{d}}{ }^{\prime} \mathbf{F}_{\mathrm{EV}}^{\mathrm{d}}\right)^{-1}\left(\mathbf{f}_{\mathrm{s}}^{\left.\mathrm{d}^{\mathrm{d}} \mathrm{e}_{\mathrm{s}}^{\mathrm{d}, \mathrm{i}}\right)}\right),{ }^{7}\right.
$$

\footnotetext{
${ }^{6}$ In proposition 2, we assume that $\mathrm{T}_{\mathrm{c}}=\mathrm{T}$, but here we relax this assumption.

${ }^{7}$ Assuming that $\mathrm{T}$ is even, $\mathbf{F}_{\mathrm{EV}}^{\mathrm{d}} \equiv\left[\mathbf{f}_{1}^{\mathrm{d}} ; \mathbf{f}_{3}^{\mathrm{d}} \cdots ; \mathbf{f}_{\mathrm{T}-1}^{\mathrm{d}}\right]$ is a $\mathrm{T} / 2 \times \mathrm{K}$ matrix when the EV period includes odd months, or $\mathbf{F}_{\mathrm{EV}}^{\mathrm{d}} \equiv\left[\mathbf{f}_{2}^{\mathrm{d}} ; \mathbf{f}_{4}^{\mathrm{d}} ; \cdots ; \mathbf{f}_{\mathrm{T}}^{\mathrm{d}}\right]$ is a $\mathrm{T} / 2 \times \mathrm{K}$ matrix when the EV period includes even months. The superscript $\mathrm{d}$
} 
for any $s$ in the EV period, where $\mathrm{e}_{\mathrm{s}}^{\mathrm{i}}=\varepsilon_{\mathrm{s}}^{\mathrm{i}}+\mathbf{f}_{\mathrm{s}} \mathbf{u}_{\mathrm{s}}^{\mathrm{i}}$, and $\mathrm{e}_{\mathrm{s}}^{\mathrm{d}, \mathrm{i}}=\mathrm{e}_{\mathrm{s}}^{\mathrm{i}}-\frac{2}{\mathrm{~T}} \sum_{\mathrm{t} \in \mathrm{EV}} \mathrm{e}_{\mathrm{t}}^{\mathrm{i}}$. Hence $\left[\frac{2}{\mathrm{~T}} \sum_{\mathrm{s} \in \mathrm{EV}} \delta_{\mathrm{s}}^{1}, \cdots, \frac{2}{\mathrm{~T}} \sum_{\mathrm{s} \in \mathrm{EV}} \delta_{\mathrm{s}}^{\mathrm{N}}\right]=\left(\frac{1}{\mathrm{~T}_{\mathrm{m}}} \sum_{\mathrm{t} \in \mathrm{DV}}\left(\mathbf{f}_{\mathrm{t}}+\boldsymbol{\gamma}_{\mathrm{t}}-E\left(\mathbf{f}_{\mathrm{t}} \mid \boldsymbol{\gamma}_{\mathrm{t}}\right)\right)\right)\left(\boldsymbol{\beta}-\hat{\boldsymbol{\beta}}_{\mathrm{EV}}\right)$.

$$
\pi_{\mathrm{s}}^{\mathrm{i}}=\left(\frac{1}{\mathrm{~T}_{\mathrm{m}}} \sum_{\mathrm{t} \in \mathrm{DV}}\left(\mathbf{f}_{\mathrm{t}}+\boldsymbol{\gamma}_{\mathrm{t}}-E\left(\mathbf{f}_{\mathrm{t}} \mid \boldsymbol{\gamma}_{\mathrm{t}}\right)\right)\right) \mathbf{u}_{\mathrm{s}}^{\mathrm{i}}+\left(\mathbf{f}_{\mathrm{s}}+\boldsymbol{\gamma}_{\mathrm{s}}-E\left(\mathbf{f}_{\mathrm{s}} \mid \boldsymbol{\gamma}_{\mathrm{s}}\right)\right) \mathbf{u}_{\mathrm{s}}^{\mathrm{d}, \mathrm{i}}+\varepsilon_{\mathrm{s}}^{\mathrm{i}}
$$

for any $s$ in the DV period, leading to

$$
\begin{aligned}
& {\left[\frac{1}{T_{m}} \sum_{s=T+1}^{\mathrm{T}+\mathrm{T}_{\mathrm{m}}} \pi_{\mathrm{s}}^{1}, \cdots, \frac{1}{\mathrm{~T}_{\mathrm{m}}} \sum_{\mathrm{s}=\mathrm{T}+1}^{\mathrm{T}+\mathrm{T}_{\mathrm{m}}} \pi_{\mathrm{s}}^{\mathrm{N}}\right]=} \\
& \left(\frac{1}{T_{m}} \sum_{t \in D V}\left(\mathbf{f}_{t}+\gamma_{t}-E\left(\mathbf{f}_{t} \mid \gamma_{t}\right)\right)\left(\frac{1}{T_{m}} \sum_{s \in D V} \mathbf{u}_{s}\right)+\frac{1}{T_{m}} \sum_{s \in D V}\left(\left(\mathbf{f}_{s}+\gamma_{s}-E\left(\mathbf{f}_{\mathrm{s}} \mid \boldsymbol{\gamma}_{\mathrm{s}}\right)\right) \mathbf{u}_{\mathrm{s}}^{\mathrm{d}}\right)+\overline{\boldsymbol{\varepsilon}}_{\mathrm{DV}}\right.
\end{aligned}
$$

Therefore, these two variables $\delta_{\mathrm{s}}^{\mathrm{i}}$ and $\pi_{\mathrm{s}}^{\mathrm{i}}$ can be used to decompose the regression residual $\xi_{\mathrm{DV}}^{\mathrm{k}}$ in the convergence proofs below. More specifically, define $\xi_{\mathrm{DV}}^{\kappa}=\left[\xi_{\mathrm{DV}}^{\kappa, 1}, \cdots, \xi_{\mathrm{DV}}^{\mathrm{K}, \mathrm{N}}\right]$, then $\xi_{\mathrm{DV}}^{\mathrm{k}, \mathrm{i}}=\frac{2}{\mathrm{~T}} \sum_{\mathrm{s} \in \mathrm{EV}} \delta_{\mathrm{s}}^{\mathrm{i}}+\frac{1}{\mathrm{~T}_{\mathrm{m}}} \sum_{\mathrm{s}=\mathrm{T}+1}^{\mathrm{T}+\mathrm{T}_{\mathrm{m}}} \pi_{\mathrm{s}}^{\mathrm{i}}$. From Assumptions (A1), (A2), and (U2), we have $E\left(\delta_{\mathrm{s}}^{\mathrm{i}}\right)=0$ for any $\mathrm{s}$ in the $\mathrm{EV}$ period, and $E\left(\pi_{\mathrm{s}}^{\mathrm{i}}\right)=0$ for any s in the DV period. Next we define

$$
\boldsymbol{\zeta}_{\mathrm{s}}^{\mathrm{i}}=\left[0 ;\left(\frac{2}{\mathrm{~T}} \mathbf{F}_{\mathrm{SP}}^{\mathrm{d}}{ }^{\prime} \mathbf{F}_{\mathrm{SP}}^{\mathrm{d}}\right)^{-1}\left(\mathbf{f}_{\mathrm{s}}^{\left.\mathrm{d}^{\prime} \mathrm{e}^{\mathrm{d}, \mathrm{i}}\right)}\right]\right.
$$

indicates a demeaned factor or demeaned residual, where average values of factors or residuals are taken over the corresponding EV period. For example, $\mathbf{f}_{1}^{\mathrm{d}} \equiv \mathbf{f}_{1}-\frac{2}{\mathrm{~T}}\left(\mathbf{f}_{1}+\mathbf{f}_{3}+\cdots+\mathbf{f}_{\mathrm{T}-1}\right), \mathbf{f}_{2}^{\mathrm{d}} \equiv \mathbf{f}_{2}-\frac{2}{\mathrm{~T}}\left(\mathbf{f}_{2}+\mathbf{f}_{4}+\cdots+\mathbf{f}_{\mathrm{T}}\right)$, and $\varepsilon_{\mathrm{t}}^{\mathrm{d}, \mathrm{i}} \equiv \varepsilon_{\mathrm{t}}^{\mathrm{i}}-\frac{2}{\mathrm{~T}}\left(\varepsilon_{1}^{\mathrm{i}}+\varepsilon_{3}^{\mathrm{i}}+\cdots+\varepsilon_{\mathrm{T}-1}^{\mathrm{i}}\right)$. 
a $(\mathrm{K}+1) \times 1$ vector, where the sample period $(\mathrm{SP})$ is either IV or EV period and s belongs to SP, and $\mathrm{e}_{\mathrm{s}}^{\mathrm{d}, \mathrm{i}}=\mathrm{e}_{\mathrm{s}}^{\mathrm{i}}-\frac{2}{\mathrm{~T}} \sum_{\mathrm{t} \in \mathrm{SP}} \mathrm{e}_{\mathrm{t}}^{\mathrm{i}}$. This variable is used to decompose the estimation errors in $\hat{\mathbf{B}}_{\mathrm{IV}}$ and $\hat{\mathbf{B}}_{\mathrm{EV}}$ in the convergence proofs. For example, $\hat{\mathbf{B}}_{\mathrm{IV}}-\mathbf{B}=\left[\frac{2}{\mathrm{~T}} \sum_{\mathrm{t} \in \mathrm{IV}} \boldsymbol{\varsigma}_{\mathrm{t}}^{1}, \cdots, \frac{2}{\mathrm{~T}} \sum_{\mathrm{t} \in \mathrm{IV}} \boldsymbol{s}_{\mathrm{t}}^{\mathrm{N}}\right]$, where $\mathbf{B}=\left[\mathbf{b}^{1}, \cdots, \mathbf{b}^{\mathrm{N}}\right]$ is a $(\mathrm{K}+1) \times \mathrm{N}$ matrix with a vector of ones and unconditional expected value of beta. Similarly, we have $\hat{\mathbf{B}}_{\mathrm{EV}}-\mathbf{B}=\left[\frac{2}{\mathrm{~T}} \sum_{\mathrm{t} \in \mathrm{EV}} \boldsymbol{s}_{\mathrm{t}}^{1}, \cdots, \frac{2}{\mathrm{~T}} \sum_{\mathrm{t} \in \mathrm{EV}} \boldsymbol{s}_{\mathrm{t}}^{\mathrm{N}}\right]$. From Assumptions (A1), (A2), and (U2), we have $E\left(\varsigma_{\mathrm{s}}^{\mathrm{i}}\right)=\mathbf{0}_{(\mathrm{K}+1) \times 1}$.

With these new variables, we describe regularity assumptions as follows:

(A4) For any $\mathrm{i}$ and $\mathrm{t}$, the elements in both $\mathbf{b}^{\mathrm{i}}$ and $\mathbf{c}^{\mathrm{i}}$ are uncorrelated with $\delta_{\mathrm{t}}^{\mathrm{i}}$. The elements in $\frac{1}{\sqrt{\mathrm{TN}}} \sum_{\mathrm{i}=1}^{\mathrm{N}} \sum_{\mathrm{t} \in \mathrm{EV}} \delta_{\mathrm{t}}^{\mathrm{i}}, \frac{1}{\sqrt{\mathrm{TN}}} \sum_{\mathrm{i}=1}^{\mathrm{N}} \sum_{\mathrm{t} \in \mathrm{EV}}\left(\mathbf{b}^{\mathrm{i}} \delta_{\mathrm{t}}^{\mathrm{i}}\right)$ and $\frac{1}{\sqrt{\mathrm{TN}}} \sum_{\mathrm{i}=1}^{\mathrm{N}} \sum_{\mathrm{t} \in \mathrm{EV}}\left(\mathbf{c}^{\mathrm{i}} \delta_{\mathrm{t}}^{\mathrm{i}}\right)$ have finite variances. Given that $E\left(\delta_{\mathrm{t}}^{\mathrm{i}}\right)=0$, apply Markov's Law of Large Numbers , $\frac{2}{\mathrm{TN}} \sum_{\mathrm{i}=1}^{\mathrm{N}} \sum_{\mathrm{t} \in \mathrm{EV}} \delta_{\mathrm{t}}^{\mathrm{i}} \rightarrow 0$, $\frac{2}{\mathrm{TN}} \sum_{\mathrm{i}=1}^{\mathrm{N}} \sum_{\mathrm{t} \in \mathrm{EV}}\left(\mathbf{b}^{\mathrm{i}} \delta_{\mathrm{t}}^{\mathrm{i}}\right) \rightarrow \mathbf{0}_{(\mathrm{K}+1) \times 1}$ and $\frac{2}{\mathrm{TN}} \sum_{\mathrm{i}=1}^{\mathrm{N}} \sum_{\mathrm{t} \in \mathrm{EV}}\left(\mathbf{c}^{\mathrm{i}} \delta_{\mathrm{t}}^{\mathrm{i}}\right) \rightarrow \mathbf{0}_{\mathrm{L} \times 1}$ when both $\mathrm{T}$ and $\mathrm{N}$ approach to infinity.

(A5) For any $i$ and $t$, the elements in both $\mathbf{b}^{\mathrm{i}}$ and $\mathbf{c}^{\mathrm{i}}$ are uncorrelated with $\boldsymbol{\zeta}_{\mathrm{t}}^{\mathrm{i}}$. The elements in $\frac{1}{\sqrt{\mathrm{TN}}} \sum_{\mathrm{i}=1}^{\mathrm{N}} \sum_{\mathrm{t} \in \mathrm{EV}} \boldsymbol{s}_{\mathrm{t}}^{\mathrm{i}} \quad, \quad \frac{1}{\sqrt{\mathrm{TN}}} \sum_{\mathrm{i}=1}^{\mathrm{N}} \sum_{\mathrm{t} \in \mathrm{IV}} \boldsymbol{s}_{\mathrm{t}}^{\mathrm{i}} \quad, \quad \frac{1}{\sqrt{\mathrm{TN}}} \sum_{\mathrm{i}=1}^{\mathrm{N}} \sum_{\mathrm{t} \in \mathrm{EV}}\left(\mathbf{b}^{\mathrm{i}}\left(\boldsymbol{\varsigma}_{\mathrm{t}}^{\mathrm{i}}\right)^{\prime}\right) \quad, \quad \frac{1}{\sqrt{\mathrm{TN}}} \sum_{\mathrm{i}=1}^{\mathrm{N}} \sum_{\mathrm{t} \in \mathrm{IV}}\left(\mathbf{b}^{\mathrm{i}}\left(\boldsymbol{\varsigma}_{\mathrm{t}}^{\mathrm{i}}\right)^{\prime}\right)$ $\frac{1}{\sqrt{\mathrm{TN}}} \sum_{\mathrm{i}=1}^{\mathrm{N}} \sum_{\mathrm{t} \in \mathrm{EV}}\left(\mathbf{c}^{\mathrm{i}}\left(\boldsymbol{\varsigma}_{\mathrm{t}}^{\mathrm{i}}\right)^{\prime}\right)$, and $\frac{1}{\sqrt{\mathrm{TN}}} \sum_{\mathrm{i}=1}^{\mathrm{N}} \sum_{\mathrm{t} \in \mathrm{IV}}\left(\mathbf{c}^{\mathrm{i}}\left(\boldsymbol{\varsigma}_{\mathrm{t}}^{\mathrm{i}}\right)^{\prime}\right)$ have finite variances. Given that $E\left(\varsigma_{\mathrm{t}}^{\mathrm{i}}\right)=\mathbf{0}_{(\mathrm{K}+1) \times 1}$, by Markov's Law of Large Numbers, $\frac{2}{\mathrm{TN}} \sum_{\mathrm{i}=1}^{\mathrm{N}} \sum_{\mathrm{t} \in \mathrm{EV}} \boldsymbol{\varsigma}_{\mathrm{t}}^{\mathrm{i}} \rightarrow \mathbf{0}_{(\mathrm{K}+1) \times 1}$, $\frac{2}{\mathrm{TN}} \sum_{\mathrm{i}=1}^{\mathrm{N}} \sum_{\mathrm{t} \in \mathrm{IV}} \boldsymbol{s}_{\mathrm{t}}^{\mathrm{i}} \rightarrow \mathbf{0}_{(\mathrm{K}+1) \times 1}, \frac{2}{\mathrm{TN}} \sum_{\mathrm{i}=1}^{\mathrm{N}} \sum_{\mathrm{t} \in \mathrm{EV}}\left(\mathbf{b}^{\mathrm{i}}\left(\boldsymbol{s}_{\mathrm{t}}^{\mathrm{i}}\right)^{\prime}\right) \rightarrow \mathbf{0}_{(\mathrm{K}+1) \times(\mathrm{K}+1)}, \frac{2}{\mathrm{TN}} \sum_{\mathrm{i}=1}^{\mathrm{N}} \sum_{\mathrm{t} \in \mathrm{IV}}\left(\mathbf{b}^{\mathrm{i}}\left(\boldsymbol{\varsigma}_{\mathrm{t}}^{\mathrm{i}}\right)^{\prime}\right) \rightarrow \mathbf{0}_{(\mathrm{K}+1) \times(\mathrm{K}+1)}$, 
$\frac{2}{\mathrm{TN}} \sum_{\mathrm{i}=1}^{\mathrm{N}} \sum_{\mathrm{t} \in \mathrm{EV}}\left(\mathbf{c}^{\mathrm{i}}\left(\boldsymbol{\epsilon}_{\mathrm{t}}^{\mathrm{i}}\right)^{\prime}\right) \rightarrow \mathbf{0}_{\mathrm{L} \times(\mathrm{K}+1)}$ and $\frac{2}{\mathrm{TN}} \sum_{\mathrm{i}=1}^{\mathrm{N}} \sum_{\mathrm{t} \in \mathrm{IV}}\left(\mathbf{c}^{\mathrm{i}}\left(\boldsymbol{\varsigma}_{\mathrm{t}}^{\mathrm{i}}\right)^{\prime}\right) \rightarrow \mathbf{0}_{\mathrm{L} \times(\mathrm{K}+1)}$ when both $\mathrm{T}$ and $\mathrm{N}$ approach to infinity.

(A6) For any $i$ and $t$, the elements in both $\mathbf{b}^{\mathrm{i}}$ and $\mathbf{c}^{\mathrm{i}}$ are uncorrelated with the elements in $\mathbf{v}_{\mathrm{t}}^{\mathrm{i}}$. The elements in $\frac{1}{\sqrt{\mathrm{T}_{\mathrm{c}} \mathrm{N}}} \sum_{\mathrm{i}=1}^{\mathrm{N}} \sum_{\mathrm{t}=\mathrm{T}-\mathrm{T}_{\mathrm{c}}+1}^{\mathrm{T}} \mathbf{v}_{\mathrm{t}}^{\mathrm{i}}, \frac{1}{\sqrt{\mathrm{T}_{\mathrm{c}} \mathrm{N}}} \sum_{\mathrm{i}=1}^{\mathrm{N}} \sum_{\mathrm{t}=\mathrm{T}-\mathrm{T}_{\mathrm{c}}+1}^{\mathrm{T}}\left(\mathbf{b}^{\mathrm{i}}\left(\mathbf{v}_{\mathrm{t}}^{\mathrm{i}}\right)^{\prime}\right)$, and $\frac{1}{\sqrt{\mathrm{T}_{\mathrm{c}} \mathrm{N}}} \sum_{\mathrm{i}=1}^{\mathrm{N}} \sum_{\mathrm{t}=\mathrm{T}-\mathrm{T}_{\mathrm{c}}+1}^{\mathrm{T}}\left(\mathbf{c}^{\mathrm{i}}\left(\mathbf{v}_{\mathrm{t}}^{\mathrm{i}}\right)^{\prime}\right)$ have finite variances. Given that $E\left(\mathbf{v}_{\mathrm{t}}^{\mathrm{i}}\right)=\mathbf{0}_{\mathrm{Lxl}}$ (Assumption (C)), by Markov's Law of Large Numbers, $\frac{1}{\mathrm{~T}_{\mathrm{c}} \mathrm{N}} \sum_{\mathrm{i}=1}^{\mathrm{N}} \sum_{\mathrm{t}=\mathrm{T}-\mathrm{T}_{\mathrm{c}}+1}^{\mathrm{T}} \boldsymbol{v}_{\mathrm{t}}^{\mathrm{i}} \rightarrow \mathbf{0}_{\mathrm{L} \times 1}, \frac{1}{\mathrm{~T}_{\mathrm{c}} \mathrm{N}} \sum_{\mathrm{i}=1}^{\mathrm{N}} \sum_{\mathrm{t}=\mathrm{T}-\mathrm{T}_{\mathrm{c}}+1}^{\mathrm{T}}\left(\mathbf{b}^{\mathrm{i}}\left(\mathbf{v}_{\mathrm{t}}^{\mathrm{i}}\right)^{\prime}\right) \rightarrow \mathbf{0}_{(\mathrm{K}+1) \times \mathrm{L}}$ and $\frac{1}{\mathrm{~T}_{\mathrm{c}} \mathrm{N}} \sum_{\mathrm{i}=1}^{\mathrm{N}} \sum_{\mathrm{t}=\mathrm{T}-\mathrm{T}_{\mathrm{c}}+1}^{\mathrm{T}}\left(\mathbf{c}^{\mathrm{i}}\left(\mathbf{v}_{\mathrm{t}}^{\mathrm{i}}\right)^{\prime}\right) \rightarrow \mathbf{0}_{\mathrm{L} \times \mathrm{L}}$ when both $\mathrm{T}_{\mathrm{c}}$ and $\mathrm{N}$ approach to infinity.

(A7) For any $\mathrm{i}$ and $\mathrm{t}$, the elements in both $\mathbf{b}^{\mathrm{i}}$ and $\mathbf{c}^{\mathrm{i}}$ are uncorrelated with $\pi_{\mathrm{t}}^{\mathrm{i}}$. The elements in $\frac{1}{\sqrt{\mathrm{NT}_{\mathrm{m}}}} \sum_{\mathrm{i}=1}^{\mathrm{N}} \sum_{\mathrm{t}=\mathrm{T}+1}^{\mathrm{T}+\mathrm{T}_{\mathrm{m}}} \pi_{\mathrm{t}}^{\mathrm{i}}, \frac{1}{\sqrt{\mathrm{NT}_{\mathrm{m}}}} \sum_{\mathrm{i}=1}^{\mathrm{N}} \sum_{\mathrm{t}=\mathrm{T}+1}^{\mathrm{T}+\mathrm{T}_{\mathrm{m}}}\left(\mathbf{b}^{\mathrm{i}} \pi_{\mathrm{t}}^{\mathrm{i}}\right)$ and $\frac{1}{\sqrt{\mathrm{NT}_{\mathrm{m}}}} \sum_{\mathrm{i}=1}^{\mathrm{N}} \sum_{\mathrm{t}=\mathrm{T}+1}^{\mathrm{T}+\mathrm{T}_{\mathrm{m}}}\left(\mathbf{c}^{\mathrm{i}} \pi_{\mathrm{t}}^{\mathrm{i}}\right)$ have finite variances. Given that $E\left(\pi_{\mathrm{t}}^{\mathrm{i}}\right)=0 \quad$, by Markov's Law of Large Numbers, $\frac{1}{\mathrm{NT}_{\mathrm{m}}} \sum_{\mathrm{i}=1}^{\mathrm{N}} \sum_{\mathrm{t}=\mathrm{T}+1}^{\mathrm{T}+\mathrm{T}_{\mathrm{m}}} \pi_{\mathrm{t}}^{\mathrm{i}} \rightarrow 0$, $\frac{1}{N T_{m}} \sum_{i=1}^{N} \sum_{t=T+1}^{T+T_{m}}\left(\mathbf{b}^{i} \pi_{t}^{i}\right) \rightarrow \mathbf{0}_{(K+1) \times 1}$, and $\frac{1}{N_{m}} \sum_{i=1}^{N} \sum_{t=T+1}^{T+T_{m}}\left(c^{i} \pi_{t}^{i}\right) \rightarrow \mathbf{0}_{L \times 1}$ when both $T_{m}$ and $N$ approach to infinity.

(A8) When $\mathrm{N} \rightarrow \infty, \frac{1}{\mathrm{~N}}[\mathbf{B} ; \mathbf{C}][\mathbf{B} ; \mathbf{C}]^{\prime}$ converges to an invertible matrix, denoted by $\left[\begin{array}{ll}\mathbf{b} \mathbf{b}^{\prime} & \mathbf{b c} \\ \mathbf{c b} & \mathbf{c c}\end{array}\right]$, which is $E\left[\left[\begin{array}{ll}\mathbf{b}^{\mathrm{i}}\left(\mathbf{b}^{\mathrm{i}}\right)^{\prime} & \mathbf{b}^{\mathrm{i}}\left(\mathbf{c}^{\mathrm{i}}\right)^{\prime} \\ \mathbf{c}^{\mathrm{i}}\left(\mathbf{b}^{\mathrm{i}}\right)^{\prime} & \mathbf{c}^{\mathrm{i}}\left(\mathbf{c}^{\mathrm{i}}\right)^{\prime}\end{array}\right]\right]$.

With these assumptions, the convergence of the IV mean-estimator is established in the following Theorem. 
Theorem G Suppose that Assumptions (A1), (A2), (A4)-(A8), (U2) and (C) in Appendices E, F, and $\mathrm{G}$ hold, Then $[\hat{\boldsymbol{\Gamma}}, \hat{\mathbf{k}}]^{\prime}$ converges to $\left(\boldsymbol{\Gamma}, \mathbf{0}_{1 \times \mathrm{L}}\right)^{\prime}$ when $\mathrm{N}, \mathrm{T}_{\mathrm{m}}, \mathrm{T}_{\mathrm{c}}$, and $\mathrm{T}$ approach to infinity

Proof: Note that

$[\hat{\boldsymbol{\Gamma}}, \hat{\mathbf{\kappa}}]^{\prime}-\left(\boldsymbol{\Gamma}, \mathbf{0}_{1 \times \mathrm{L}}\right)^{\prime}=\left(\frac{1}{\mathrm{~N}}\left[\hat{\mathbf{B}}_{\mathrm{IV}} ; \overline{\mathbf{C}}\right]\left[\hat{\mathbf{B}}_{\mathrm{EV}} ; \overline{\mathbf{C}}\right]^{\prime}\right)^{-1}\left(\frac{1}{\mathrm{~N}}\left[\hat{\mathbf{B}}_{\mathrm{IV}} ; \overline{\mathbf{C}}\right]\left(\xi_{\mathrm{DV}}^{\kappa}\right)^{\prime}\right)$

where $\xi_{\mathrm{DV}}^{\mathrm{k}}=\left[\xi_{\mathrm{DV}}^{\mathrm{k}, 1}, \cdots, \xi_{\mathrm{DV}}^{\mathrm{k}, \mathrm{N}}\right]$ and $\xi_{\mathrm{DV}}^{\mathrm{k}, \mathrm{i}}=\frac{2}{\mathrm{~T}} \sum_{\mathrm{s} \in \mathrm{EV}} \delta_{\mathrm{s}}^{\mathrm{i}}+\frac{1}{\mathrm{~T}_{\mathrm{m}}} \sum_{\mathrm{s}=\mathrm{T}+1}^{\mathrm{T}+\mathrm{T}_{\mathrm{m}}} \pi_{\mathrm{s}}^{\mathrm{i}}$.

We want to show that the above equation converges to $\mathbf{0}_{(\mathrm{K}+\mathrm{L}+1) \times 1}$, which requires to show the following three convergences:

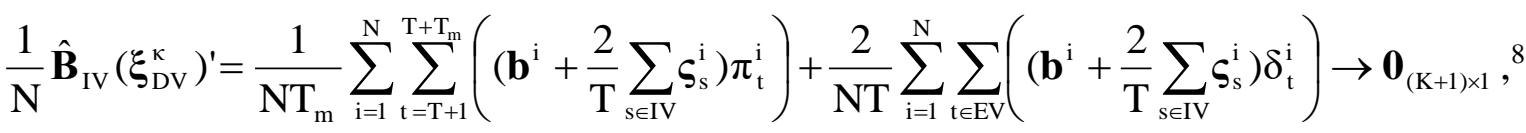

$$
\begin{aligned}
& \frac{1}{N} \overline{\mathbf{C}}\left(\xi_{\mathrm{DV}}^{\mathrm{K}}\right)^{\prime}=\frac{1}{\mathrm{NT} \mathrm{T}_{\mathrm{m}}} \sum_{\mathrm{i}=1}^{\mathrm{N}} \sum_{\mathrm{t}=\mathrm{T}+1}^{\mathrm{T}+\mathrm{T}_{\mathrm{m}}}\left(\left(\mathbf{c}^{\mathrm{i}}+\frac{1}{\mathrm{~T}_{\mathrm{c}}} \sum_{\mathrm{s}=\mathrm{T}-\mathrm{T}_{\mathrm{c}}+1}^{\mathrm{T}} \mathbf{v}_{\mathrm{s}}^{\mathrm{i}}\right) \pi_{\mathrm{t}}^{\mathrm{i}}\right)+\frac{2}{\mathrm{NT}} \sum_{\mathrm{i}=1}^{\mathrm{N}} \sum_{\mathrm{t} \in \mathrm{EV}}\left(\left(\mathbf{c}^{\mathrm{i}}+\frac{1}{\mathrm{~T}_{\mathrm{c}}} \sum_{\mathrm{s}=\mathrm{T}-\mathrm{T}_{\mathrm{c}}+1}^{\mathrm{T}} \mathbf{v}_{\mathrm{s}}^{\mathrm{i}}\right) \delta_{\mathrm{t}}^{\mathrm{i}}\right) \rightarrow \mathbf{0}_{\mathrm{L} \times 1},
\end{aligned}
$$

and $\left(\frac{1}{\mathrm{~N}}\left[\hat{\mathbf{B}}_{\mathrm{IV}} ; \overline{\mathbf{C}}\right]\left[\hat{\mathbf{B}}_{\mathrm{EV}} ; \overline{\mathbf{C}}\right]^{\prime}\right)^{-1}$ converges to $\left[\begin{array}{ll}\mathbf{b b} & \mathbf{b c}^{\prime} \\ \mathbf{c b} & \mathbf{c c}^{\prime}\end{array}\right]^{-1}$.

Those three convergences can be shown as follows: From Assumption (A4), $\frac{2}{\mathrm{TN}} \sum_{\mathrm{i}=1}^{\mathrm{N}} \sum_{\mathrm{t} \in \mathrm{EV}}\left(\mathbf{b}^{\mathrm{i}} \delta_{\mathrm{t}}^{\mathrm{i}}\right) \rightarrow \mathbf{0}_{(\mathrm{K}+1) \times 1}$ and $\frac{2}{\mathrm{TN}} \sum_{\mathrm{i}=1}^{\mathrm{N}} \sum_{\mathrm{t} \in \mathrm{EV}} \delta_{\mathrm{t}}^{\mathrm{i}} \rightarrow 0$, when $\mathrm{N}$ and $\mathrm{T}$ approach to infinity. From Assumptions (A1) and (A2) in Appendix E, and Assumption (U2) in Appendix F, $\frac{2}{\mathrm{~T}} \sum_{\mathrm{s} \in \mathrm{IV}} \boldsymbol{\zeta}_{\mathrm{s}}^{\mathrm{i}} \rightarrow \mathbf{0}_{(\mathrm{K}+1) \times 1}$ for any asset $\mathrm{i}$, as $\mathrm{T}$ approaches to infinity. Together with $\frac{2}{\mathrm{TN}} \sum_{\mathrm{i}=1}^{\mathrm{N}} \sum_{\mathrm{t} \in \mathrm{EV}} \delta_{\mathrm{t}}^{\mathrm{i}} \rightarrow 0$,

${ }^{8}$ Recall that $\hat{\mathbf{B}}_{\mathrm{IV}}-\mathbf{B}=\left[\frac{2}{\mathrm{~T}} \sum_{\mathrm{t} \in \mathrm{IV}} \boldsymbol{\zeta}_{\mathrm{t}}^{1}, \cdots, \frac{2}{\mathrm{~T}} \sum_{\mathrm{t} \in \mathrm{IV}} \boldsymbol{\zeta}_{\mathrm{t}}^{\mathrm{N}}\right]$, and $\mathbf{B}=\left[\mathbf{b}^{1}, \cdots, \mathbf{b}^{\mathrm{N}}\right]$. 
this implies that when $\mathrm{N}$ and $\mathrm{T}$ approach to infinity at the same time, $\frac{2}{\mathrm{NT}} \sum_{\mathrm{i}=1}^{\mathrm{N}} \sum_{\mathrm{t} \in \mathrm{EV}}\left(\left(\frac{2}{\mathrm{~T}} \sum_{\mathrm{s} \in \mathrm{IV}} \varsigma_{\mathrm{s}}^{\mathrm{i}}\right) \delta_{\mathrm{t}}^{\mathrm{i}}\right) \rightarrow \mathbf{0}_{(\mathrm{K}+1) \times 1}$. Therefore, when $\mathrm{T}$ and $\mathrm{N}$ approach to infinity,

$$
\frac{2}{\mathrm{NT}} \sum_{\mathrm{i}=1}^{\mathrm{N}} \sum_{\mathrm{t} \in \mathrm{EV}}\left(\left(\mathbf{b}^{\mathrm{i}}+\frac{2}{\mathrm{~T}} \sum_{\mathrm{s} \in \mathrm{IV}} \boldsymbol{\varsigma}_{\mathrm{s}}^{\mathrm{i}}\right) \delta_{\mathrm{t}}^{\mathrm{i}}\right)=\frac{2}{\mathrm{NT}} \sum_{\mathrm{i}=1}^{\mathrm{N}} \sum_{\mathrm{t} \in \mathrm{EV}}\left(\mathbf{b}^{\mathrm{i}} \delta_{\mathrm{t}}^{\mathrm{i}}\right)+\frac{2}{\mathrm{NT}} \sum_{\mathrm{i}=1}^{\mathrm{N}} \sum_{\mathrm{t} \in \mathrm{EV}}\left(\left(\frac{2}{\mathrm{~T}} \sum_{\mathrm{s} \in \mathrm{IV}} \boldsymbol{\varsigma}_{\mathrm{s}}^{\mathrm{i}}\right) \delta_{\mathrm{t}}^{\mathrm{i}}\right) \rightarrow \mathbf{0}_{(\mathrm{K}+1) \times 1} .
$$

Similarly, from Assumption (A7), $\frac{1}{N T_{m}} \sum_{i=1}^{N} \sum_{t=T+1}^{T+T_{m}}\left(\mathbf{b}^{i} \pi_{t}^{i}\right) \rightarrow \mathbf{0}_{(K+1) \times 1}$ and $\frac{1}{N T_{m}} \sum_{i=1}^{N} \sum_{t=T+1}^{T+T_{m}} \pi_{t}^{i} \rightarrow 0$ when both $\mathrm{T}_{\mathrm{m}}$ and $\mathrm{N}$ approach to infinity, and $\frac{2}{\mathrm{~T}} \sum_{\mathrm{s} \in \mathrm{IV}} \varsigma_{\mathrm{s}}^{\mathrm{i}} \rightarrow \mathbf{0}_{(\mathrm{K}+1) \times 1}$ for any asset $\mathrm{i}$, as $\mathrm{T}$ approaches to infinity. Together with $\frac{1}{\mathrm{NT}_{\mathrm{m}}} \sum_{\mathrm{i}=1}^{\mathrm{N}} \sum_{\mathrm{t}=\mathrm{T}+1}^{\mathrm{T}+\mathrm{T}_{\mathrm{m}}} \pi_{\mathrm{t}}^{\mathrm{i}} \rightarrow 0$, this implies that when $\mathrm{N}, \mathrm{T}_{\mathrm{m}}$, and $\mathrm{T}$ approach to infinity at the same time, $\frac{1}{\mathrm{NT}_{\mathrm{m}}} \sum_{\mathrm{i}=1}^{\mathrm{N}} \sum_{\mathrm{t}=\mathrm{T}+1}^{\mathrm{T}+\mathrm{T}_{\mathrm{m}}}\left(\left(\frac{2}{\mathrm{~T}} \sum_{\mathrm{s} \in \mathrm{IV}} \varsigma_{\mathrm{s}}^{\mathrm{i}}\right) \pi_{\mathrm{t}}^{\mathrm{i}}\right) \rightarrow \mathbf{0}_{(\mathrm{K}+1) \times 1}$. Thus, when $\mathrm{T}, \mathrm{T}_{\mathrm{m}}$ and $\mathrm{N}$ approach to infinity,

$\frac{1}{\mathrm{NT}_{\mathrm{m}}} \sum_{\mathrm{i}=1}^{\mathrm{N}} \sum_{\mathrm{t}=\mathrm{T}+1}^{\mathrm{T}+\mathrm{T}_{\mathrm{m}}}\left(\left(\mathbf{b}^{\mathrm{i}}+\frac{2}{\mathrm{~T}} \sum_{\mathrm{s} \in \mathrm{IV}} \varsigma_{\mathrm{s}}^{\mathrm{i}}\right) \pi_{\mathrm{t}}^{\mathrm{i}}\right)=\frac{1}{\mathrm{NT}} \sum_{\mathrm{m}=1}^{\mathrm{N}} \sum_{\mathrm{t}=\mathrm{T}+1}^{\mathrm{T}+\mathrm{T}_{\mathrm{m}}}\left(\mathbf{b}^{\mathrm{i}} \pi_{\mathrm{t}}^{\mathrm{i}}\right)+\frac{1}{\mathrm{NT}} \sum_{\mathrm{i}=1}^{\mathrm{N}} \sum_{\mathrm{t}=\mathrm{T}+1}^{\mathrm{T}+\mathrm{T}_{\mathrm{m}}}\left(\left(\frac{2}{\mathrm{~T}} \sum_{\mathrm{s} \in \mathrm{IV}} \boldsymbol{\varsigma}_{\mathrm{s}}^{\mathrm{i}}\right) \pi_{\mathrm{t}}^{\mathrm{i}}\right) \rightarrow \mathbf{0}_{(\mathrm{K}+1) \times 1}$.

Hence, $\frac{1}{\mathrm{~N}} \hat{\mathbf{B}}_{\mathrm{IV}}\left(\xi_{\mathrm{DV}}^{\kappa}\right)^{\prime} \rightarrow \mathbf{0}_{(\mathrm{K}+1) \times 1}$

Similarly, we can show that $\frac{1}{\mathrm{~N}} \overline{\mathbf{C}}\left(\boldsymbol{\xi}_{\mathrm{DV}}^{\kappa}\right)^{\prime} \rightarrow \mathbf{0}_{\mathrm{L} \times 1}$ with Assumptions (A4), (A7), (C), as well as $E\left(\pi_{\mathrm{t}}^{\mathrm{i}}\right)=0$ and $E\left(\delta_{\mathrm{t}}^{\mathrm{i}}\right)=0$.

Moreover,

$\frac{1}{\mathrm{~N}} \hat{\mathbf{B}}_{\mathrm{IV}} \hat{\mathbf{B}}_{\mathrm{EV}}{ }^{\prime}=\frac{1}{\mathrm{~N}} \mathbf{B B}^{\prime}+\frac{2}{\mathrm{TN}} \sum_{\mathrm{i}=1}^{\mathrm{N}} \sum_{\mathrm{t} \in \mathrm{EV}}\left(\mathbf{b}^{\mathrm{i}}\left(\boldsymbol{\varsigma}_{\mathrm{t}}^{\mathrm{i}}\right)^{\prime}\right)+\frac{2}{\mathrm{TN}} \sum_{\mathrm{i}=1}^{\mathrm{N}} \sum_{\mathrm{t} \in \mathrm{IV}}\left(\mathbf{b}^{\mathrm{i}}\left(\boldsymbol{\varsigma}_{\mathrm{t}}^{\mathrm{i}}\right)^{\prime}\right)^{\prime}+\frac{1}{\mathrm{~N}} \sum_{\mathrm{i}=1}^{\mathrm{N}}\left(\frac{2}{\mathrm{~T}} \sum_{\mathrm{t} \in \mathrm{IV}}\left(\boldsymbol{\varsigma}_{\mathrm{t}}^{\mathrm{i}}\right) \frac{2}{\mathrm{~T}} \sum_{\mathrm{s} \in \mathrm{EV}}\left(\boldsymbol{\varsigma}_{\mathrm{s}}^{\mathrm{i}}\right)^{\prime}\right)$. 
From Assumption (A5), $\frac{2}{\mathrm{TN}} \sum_{\mathrm{i}=1}^{\mathrm{N}} \sum_{\mathrm{t} \in \mathrm{EV}}\left(\mathbf{b}^{\mathrm{i}}\left(\boldsymbol{\varsigma}_{\mathrm{t}}^{\mathrm{i}}\right)^{\prime}\right) \rightarrow \mathbf{0}_{(\mathrm{K}+1) \times(\mathrm{K}+1)}$ and $\frac{2}{\mathrm{TN}} \sum_{\mathrm{i}=1}^{\mathrm{N}} \sum_{\mathrm{t} \in \mathrm{IV}}\left(\mathbf{b}^{\mathrm{i}}\left(\boldsymbol{\varsigma}_{\mathrm{t}}^{\mathrm{i}}\right)^{\prime}\right) \rightarrow \mathbf{0}_{(\mathrm{K}+1) \times(\mathrm{K}+1)}$ when both $\mathrm{T}$ and $\mathrm{N}$ approach to infinity. From Assumptions (A1), (A2) and (U2), $\frac{2}{\mathrm{~T}} \sum_{\mathrm{t} \in \mathrm{IV}} \boldsymbol{\zeta}_{\mathrm{t}}^{\mathrm{i}} \rightarrow \mathbf{0}_{(\mathrm{K}+1) \times 1}$ for any asset $\mathrm{i}$, when $\mathrm{T}$ approaches to infinity. Also from Assumption (A5), $\frac{2}{\mathrm{TN}} \sum_{\mathrm{i}=1}^{\mathrm{N}} \sum_{\mathrm{s} \in \mathrm{EV}}\left(\boldsymbol{\varsigma}_{\mathrm{s}}^{\mathrm{i}}\right)^{\prime} \rightarrow \mathbf{0}_{1 \times(\mathrm{K}+1)}$ when both $\mathrm{T}$ and $\mathrm{N}$ approach to infinity. The above two convergences imply that when both $\mathrm{T}$ and $\mathrm{N}$ approach to infinity, $\frac{1}{\mathrm{~N}} \sum_{\mathrm{i}=1}^{\mathrm{N}}\left(\frac{2}{\mathrm{~T}} \sum_{\mathrm{t} \in \mathrm{V}}\left(\boldsymbol{\varsigma}_{\mathrm{t}}^{\mathrm{i}}\right) \frac{2}{\mathrm{~T}} \sum_{\mathrm{s} \in \mathrm{EV}}\left(\boldsymbol{\varsigma}_{\mathrm{s}}^{\mathrm{i}}\right)^{\prime}\right) \rightarrow \mathbf{0}_{(\mathrm{K}+1) \times(\mathrm{K}+1)}$. Therefore, with Assumption (A8), it is clear that $\frac{1}{\mathrm{~N}} \hat{\mathbf{B}}_{\mathrm{IV}} \hat{\mathbf{B}}_{\mathrm{EV}}{ }^{\prime} \rightarrow \mathbf{b b}$ ' when both $\mathrm{T}$ and $\mathrm{N}$ approach to infinity.

Similarly, $\frac{1}{\mathrm{~N}} \hat{\mathbf{B}}_{\mathrm{IV}} \overline{\mathbf{C}}^{\prime} \rightarrow \mathbf{b c}^{\prime}, \frac{1}{\mathrm{~N}} \overline{\mathbf{C}}_{\mathrm{EV}} \hat{\mathrm{E}}^{\prime} \rightarrow \mathbf{c b ^ { \prime }}$, and $\frac{1}{\mathrm{~N}} \overline{\mathbf{C}} \overline{\mathbf{C}}^{\prime} \rightarrow \mathbf{c c}^{\prime}$ when both $\mathrm{T}$ and $\mathrm{N}$ approach to infinity, with Assumptions (A5), (A6), (A8), (U2) and (C); hence, $\left(\frac{1}{\mathrm{~N}}\left[\hat{\mathbf{B}}_{\mathrm{IV}} ; \overline{\mathbf{C}}\right]\left[\hat{\mathbf{B}}_{\mathrm{EV}} ; \overline{\mathbf{C}}\right]^{\prime}\right)^{-1}$ converges to $\left[\begin{array}{ll}\mathbf{b b} & \mathbf{b c}^{\prime} \\ \mathbf{c b}^{\prime} & \mathbf{c c}^{\prime}\end{array}\right]^{-1}$. Together with $\frac{1}{\mathrm{~N}} \hat{\mathbf{B}}_{\mathrm{IV}}\left(\xi_{\mathrm{DV}}^{\mathrm{K}}\right)^{\prime} \rightarrow \mathbf{0}_{(\mathrm{K}+1) \times 1}$ and $\frac{1}{\mathrm{~N}} \overline{\mathbf{C}}\left(\xi_{\mathrm{DV}}^{\mathrm{K}}\right)^{\prime} \rightarrow \mathbf{0}_{\mathrm{L} \times 1}$, we establish $[\hat{\boldsymbol{\Gamma}}, \hat{\mathbf{\kappa}}]^{\prime}-\left(\boldsymbol{\Gamma}, \mathbf{0}_{1 \times L}\right)^{\prime} \rightarrow \mathbf{0}_{(\mathrm{K}+\mathrm{L}+1) \times 1}$ (i.e. $[\hat{\boldsymbol{\Gamma}}, \hat{\mathbf{\kappa}}]^{\prime}$ converges to $\left.\left(\boldsymbol{\Gamma}, \mathbf{0}_{1 \times \mathrm{L}}\right)^{\prime}\right)$ when $\mathrm{N}, \mathrm{T}_{\mathrm{m}}, \mathrm{T}_{\mathrm{c}}$, and $\mathrm{T}$ approach to infinity.

In Theorem G, we assume that betas and characteristics can be any stationary and ergodic processes; hence, Proposition 2 in the main text is a special case under AR(1) processes. The regularity Assumptions (A4)-(A8) are satisfied when (a) Processes $\left\{\varepsilon_{\mathrm{t}}^{\mathrm{i}}, \mathrm{t}=1, \cdots, \mathrm{T}\right\},\left\{\boldsymbol{v}_{\mathrm{t}}^{\mathrm{i}}, \mathrm{t}=1, \cdots, \mathrm{T}\right\}$ and $\left\{\mathbf{u}_{\mathrm{t}}^{\mathrm{i}}, \mathrm{t}=1, \cdots, \mathrm{T}\right\}$ for each asset $\mathrm{i}$ are stationary and ergodic, (b) For all t, s and $\mathrm{i}, \varepsilon_{\mathrm{t}}^{\mathrm{i}}, \mathbf{v}_{\mathrm{t}}^{\mathrm{i}}$ and $\mathbf{u}_{\mathrm{t}}^{\mathrm{i}}$ are independent of $\mathbf{f}_{\mathrm{s}}$ (factor in time $\mathrm{s}$ ), $\varepsilon_{\mathrm{s}}^{\mathrm{i}}$ (regression residuals in time s), unconditional means of beta $\boldsymbol{\beta}^{\mathrm{i}}$ and characteristic $\mathrm{c}^{\mathrm{i}}$, and $\boldsymbol{\gamma}_{\mathrm{s}}$ (risk premium in time s), and the maximum values for unconditional mean of beta and characteristic of all assets are finite. (c) In each time t, residuals in 
$\left[\varepsilon_{\mathrm{t}}^{1}, \cdots, \varepsilon_{\mathrm{t}}^{\mathrm{N}}\right],\left[\mathbf{v}_{\mathrm{t}}^{1}, \cdots, \mathbf{v}_{\mathrm{t}}^{\mathrm{N}}\right]$ and $\left[\mathbf{u}_{\mathrm{t}}^{1}, \cdots, \mathbf{u}_{\mathrm{t}}^{\mathrm{N}}\right]$ are asymptotically weakly correlated cross-sectionally (Shanken,1992). 